\title{
WestVirginiaUniversity
}

THE RESEARCH REPOSITORY @ WVU

Graduate Theses, Dissertations, and Problem Reports

2004

\section{Augmentation of the differentiation response to antitumor quinolines}

\author{
Rayhana Rahim-Bata \\ West Virginia University
}

Follow this and additional works at: https://researchrepository.wvu.edu/etd

\section{Recommended Citation}

Rahim-Bata, Rayhana, "Augmentation of the differentiation response to antitumor quinolines" (2004). Graduate Theses, Dissertations, and Problem Reports. 2145.

https://researchrepository.wvu.edu/etd/2145

This Dissertation is protected by copyright and/or related rights. It has been brought to you by the The Research Repository @ WVU with permission from the rights-holder(s). You are free to use this Dissertation in any way that is permitted by the copyright and related rights legislation that applies to your use. For other uses you must obtain permission from the rights-holder(s) directly, unless additional rights are indicated by a Creative Commons license in the record and/ or on the work itself. This Dissertation has been accepted for inclusion in WVU Graduate Theses, Dissertations, and Problem Reports collection by an authorized administrator of The Research Repository @ WVU.

For more information, please contact researchrepository@mail.wvu.edu. 


\title{
Augmentation of the Differentiation Response to Antitumor Quinolines
}

\author{
Rayhana Rahim-Bata
}

Dissertation submitted to the

School of Medicine

at West Virginia University

in partial fulfillment of the requirements

for the degree of

Doctor of Philosophy

in

Pharmacology and Toxicology

Jeannine S. Strobl, Ph.D., Chair

Stephen G. Graber, Ph.D.

Andrew K. Shiemke, Ph.D.

Knox Van Dyke, Ph.D.

David B. Yelton, Ph.D.

Department of Pharmacology and Toxicology

Morgantown, West Virginia

2004

Key Words: Chloroquine, Hydroxychloroquine, Retinoic Acid, Differentiation, Breast Cancer 


\title{
ABSTRACT \\ Augmentation of the Differentiation Response to Antitumor Quinolines
}

\author{
Rayhana Rahim-Bata
}

An impeding challenge to breast cancer drug therapies is the availability of more effective and less toxic chemotherapeutic agents that do not relay harm to neighboring normal breast cells and tissues. Preliminary studies showed that the quinoline antimalarials, chloroquine (CQ) and hydroxychloroquine (HCQ), inhibit proliferation and induce differentiation in breast cancer cell lines without toxicity to normal MCF-10A breast cells. Hence, the goal of these studies was to explore: (1) whether a drug combination modulating epigenetic events would sensitize breast cancer cells to the antitumor activity of CQ or HCQ, (2) and if so, which would be the most promising combination of agents for the generation of safer and less toxic chemotherapeutic agents for the prevention and treatment of advanced breast cancer. We hypothesized that the use of a drug combination modulating epigenetic events would lower the concentration of CQ or HCQ needed to produce the differentiation response. Hence, the quinoline agents were used in combination with the demethylating agent, 5-Aza-2'-deoxycytidine (5-Aza-dC or Aza), or with the differentiating agent, alltrans-Retinoic acid (ATRA) in order to lower the threshold for chemotherapy-induced cell death in breast cancer cells. Cell survival, cellular differentiation, and histone $\mathrm{H} 3 / \mathrm{H} 4$ acetylation status were measured to show that combination of 5-Aza-dC or ATRA with the quinolines sensitized breast cancer cells to enhanced growth inhibition, differentiation, and histone hyperacetylation compared to cells treated with either CQ or HCQ alone. Furthermore, ATRA was identified as a direct HDAC inhibitor and upon combination treatment with HCQ had the most significant inhibitory effect on tumor cell clonogenic survival in both estrogen receptor (ER+) and (ER-) breast cancers. Thus, ATRA combined with HCQ served as the most promising combination of chemotherapeutic agents and were subsequently assessed using a new and highly sensitive assay for histone acetylation by mass spectrometry to generate a profile on lysine modification (acetylation/deacetylation). The combination of ATRA with HCQ increased acetylation of N-terminal lysine residues on histones $\mathrm{H} 3 / \mathrm{H} 4$ as well as caused direct HAT activation. The overall data suggest that HCQ might contribute to breast cancer cell differentiation by modulating HAT activity; whereas, ATRA sensitizes breast cancer cells to the antitumor activity of HCQ via regulation of both HAT and HDAC enzymatic activities. 


\section{DEDICATION}

I would like to dedicate this work to my "mothers":

my mom, Gulmakai Rahim and my aunt, Judy Khair.

Words cannot express how indebted I am to these two special women for their everlasting love, support, encouragement, guidance, and sacrifice. I truly feel that I have been blessed with two mothers who are both the epitome of perfection. With open arms and warm smiles, they have not only sacrificed endless hours to help raise my two sons, but they have also given me a lifetime of joy and happiness. With my deepest love and appreciation... Thank You!

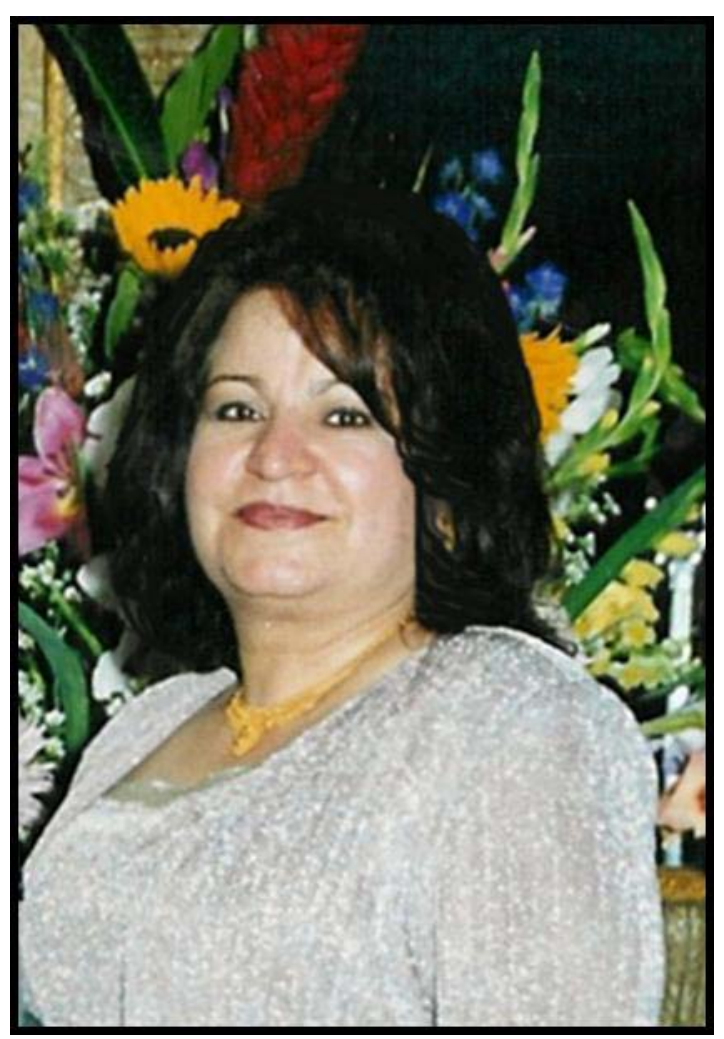

Gulmakai Khair Rahim

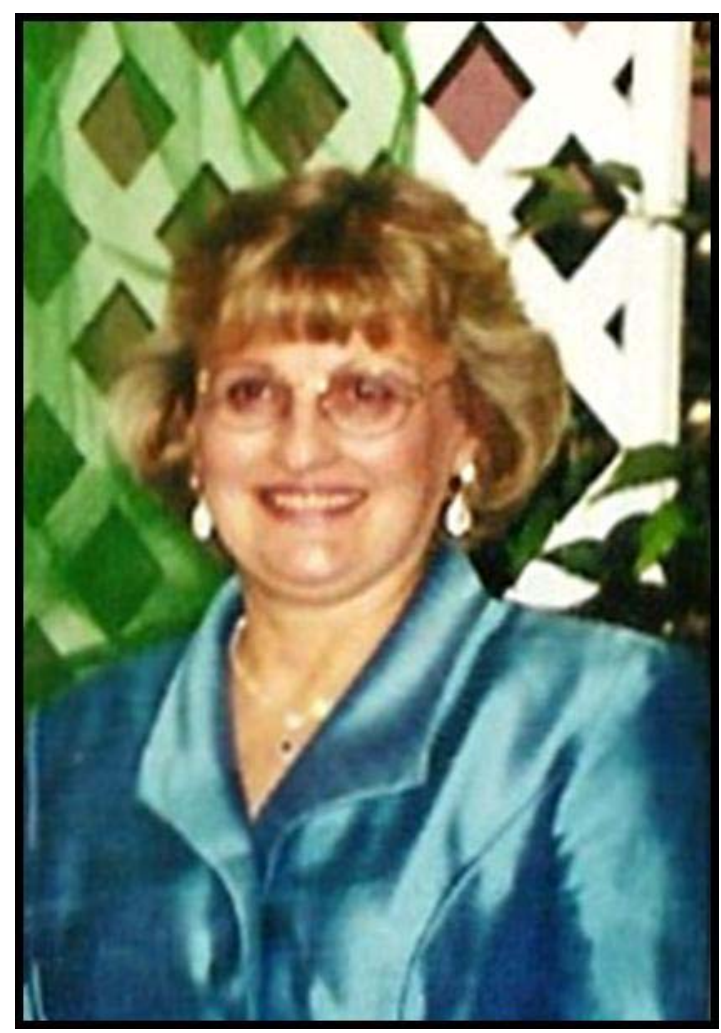

Judith Borsay Khair 


\section{MEMORIAM}

In loving memory of Suhaila Barakzoy.

Although your time with us was short, you have remained a pivotal source of inspiration and admiration. In your remembrance, I hope that this work and future endeavors can offer an impetus for the fight against breast cancer.

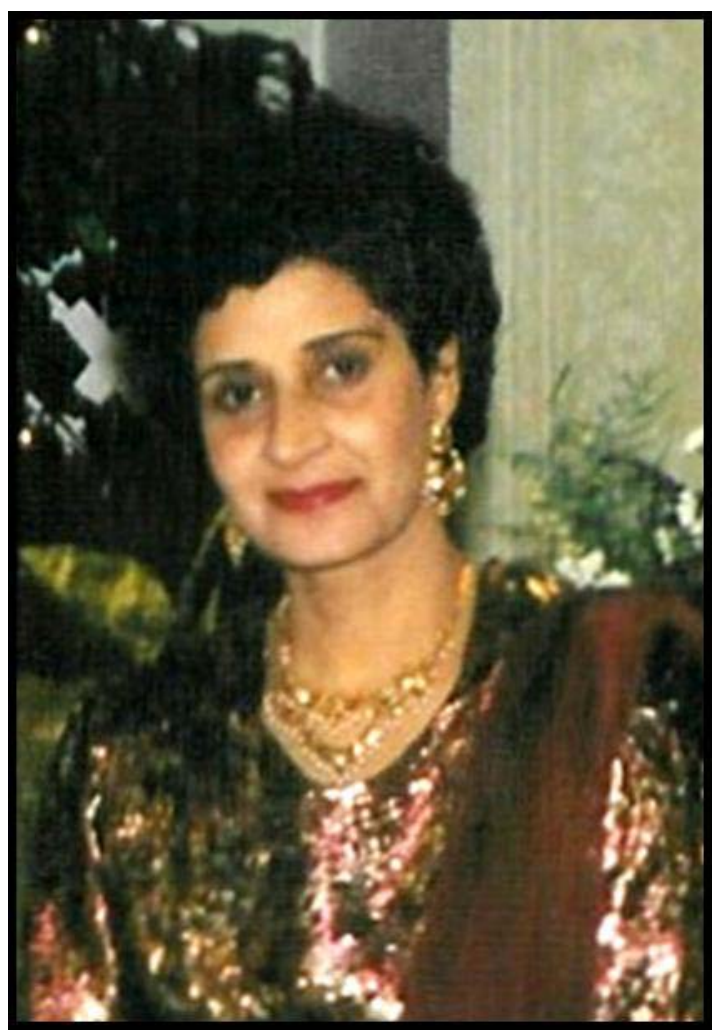

Suhaila Barakzoy

September 15, 1958-March 25, 1998

"Ina Lilahee wa Illayhee Raj'oon" 


\section{ACKNOWLEDGEMENTS}

First and foremost, I must thank Allah (SWT) for His infinite Grace, Mercy, and Wisdom in all facets of my life.

I would like to acknowledge many people who have made the completion of this dissertation possible. I would like to thank my research advisor, Dr. Jeannine Strobl, for her relentless encouragement, enthusiasm, and dedication. Her insight, both personally and professionally, has shaped and molded my persona only for the better. She has instilled in me a thirst for knowledge not only in science, but in all of life's explorations. I would also like to extend my gratitude towards my graduate committee: Drs. Steve Graber, Drew Shiemke, Knox Van Dyke, and David Yelton for their critical, yet constructive remarks. Their advice and direction is truly appreciated. Special thanks to Dr. Van Dyke for his support, invaluable discussions, and thought-provoking theories. I am also very grateful for

Dr. Robert E. Stitzel for his continuous encouragement and optimism throughout my graduate career. I would like to recognize and thank my colleagues: Zara Melkoumian, Meredith McCracken, Qun Zhou, Anna Martirosyan, and Stacey Brower for their help and friendship throughout all these years. Thanks to the many people in the department who have made my graduate experience pleasant and memorable.

Finally, I would like to express my love and appreciation for my family, without whom none of this would have been possible. I am grateful to my parents, Shamsullah and Gulmakai Rahim; to my godparents, Dr. Abdul Wahab and Judy Khair; as well as to my inlaws, Drs. Reda Bata and Laila El-Gazzar for their unconditional love and support throughout these years. I am extremely thankful to my siblings: Sosan (peace be upon her) 
for watching over me as well as to Ilyas, Sultana, and Idris for their heartfelt guidance, direction, and support. Special thanks to the Barakzoy family: Dr. Ahmad Shah, Bebejon, Fatihma, Nahied, Zohra, Merwis, Iman, and Kareem for teaching me about the value of life. I would also like to extend my gratitude to the Bata family: Drs. Rania, Ahmed, and Mandy for their generosity and thoughtfulness. Most importantly, I would like to thank my husband and soul-mate, Hazem, for his love, patience, understanding, and encouragement as we have journeyed through life together. Last, but not least, this work would not be complete without thanking those responsible for bringing me the greatest joy and happiness, my two little blessings in disguise, my sons, Imran and Ibrahim! 


\section{TABLE OF CONTENTS}

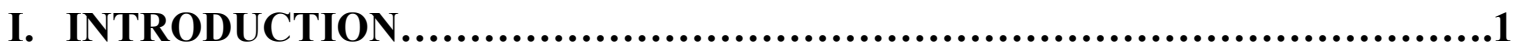

1. Breast Cancer...........................................................

1.1. Oncogenes and Tumor Suppressors...................................... 2

1.2. Cell Cycle...........................................................4

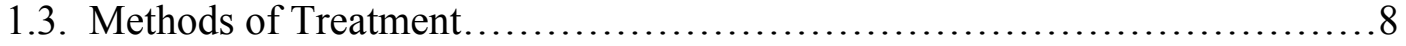

1.3.1. Local Treatment..................................................... 8

1.3.2. Systemic Treatment.............................................. 9

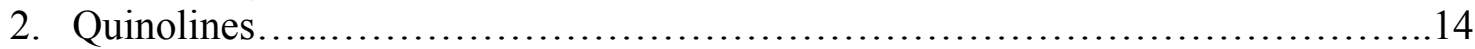

2.1. Chloroquine (CQ) ............................................... 14

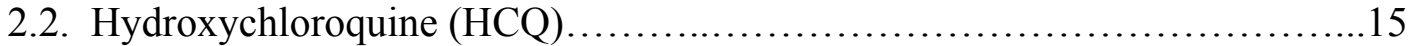

3. Histone Acetylation Status and Breast Cancer................................... 18

3.1. Chromatin Regulation................................................. 18

3.2. Pharmacological HDAC Inhibitors...................................... 21

4. Retinoids and Breast Cancer................................................ 22

4.1. Retinoid Metabolism...............................................22

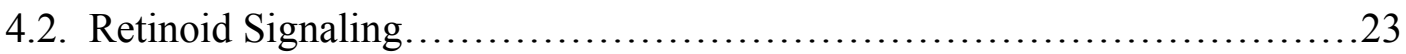

4.3. Retinoid Agents....................................................26

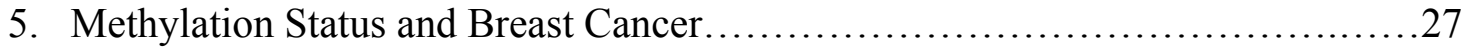

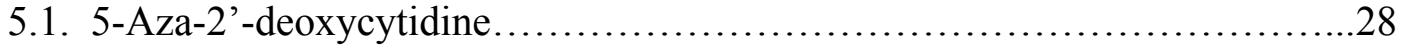

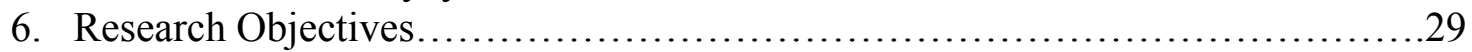

II. MATERIALS AND METHODS..............................................34

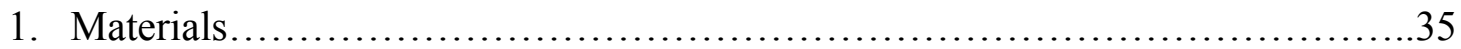

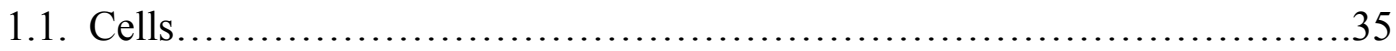

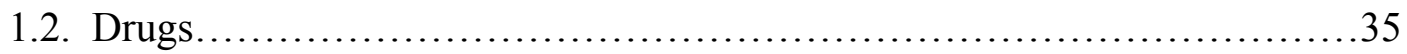

1.3. Antibodies.......................................................... 35

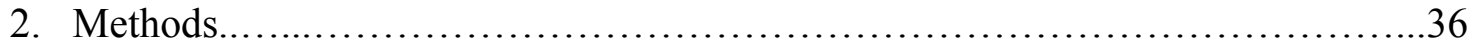

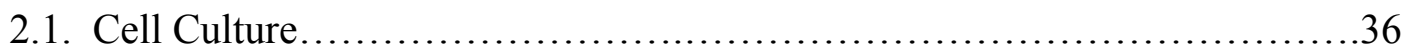

2.2. Oil Red-O assay ..................................................... 36

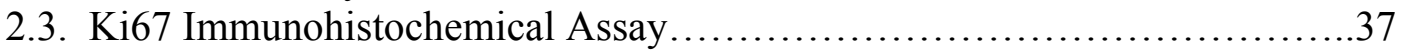

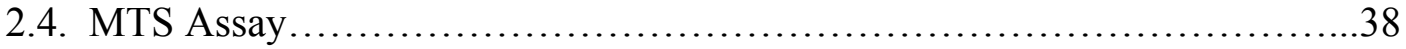

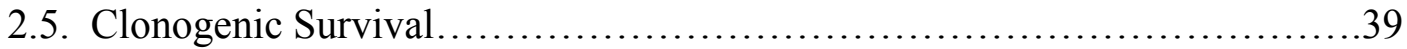

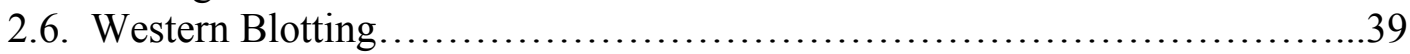

2.7. HDAC Activity Assay................................................. 41

2.8. HAT Assay .......................................................... 41

2.9. Histone Extraction .................................................. 42

2.10.Mass Spectrometry.................................................. 43

2.11.Statistical Analysis............................................ 44 
1. Augmentation of the Differentiation Response using all-trans-Retinoic Acid in Combination with Chloroquine or Hydroxychloroquine...............46

1.1. Selective toxicity of chloroquine and hydroxychloroquine................46

1.1. Chloroquine and hydroxychloroquine caused accumulation of cytoplasmic lipid droplets in MCF-7 and MDA-MB-231 breast cancer cells but not in MCF-10A normal mammary epithelial cells...........48

1.3. Chloroquine increased the G0 cell population indicated by loss of Ki67 antigen in MCF-7 breast cancer ells.

1.4. MCF-7 and MDA-MB-231 cell survival in response to chloroquine and ATRA.

1.5. Combination of chloroquine or hydroxychloroquine with ATRA inhibited growth of human breast cancer cell lines

1.6. Combination of chloroquine or hydroxychloroquine with ATRA reduced tumor cell clonogenic survival.

1.7. Combination of chloroquine or hydroxychloroquine with ATRA caused enhanced accumulation of cytoplasmic lipid droplets in MCF-7 and MDA-MB-231 breast cancer cells.

1.8. Combination of chloroquine or hydroxychloroquine with ATRA elevated the Ki67 index.

1.9. Downregulation of E2F-1 protein in MCF-7 breast cancer cells in response to chloroquine and ATRA.............................70

1.10.Downregulation of c-myc protein in MCF-7 breast cancer cells in response to chloroquine and ATRA....

2. Augmentation of the Differentiation Response using 5-Aza-2'deoxycytidine in Combination with Chloroquine or Hydroxychloroquine....................76

2.1. Combination of chloroquine or hydroxychloroquine with 5-Aza-dC inhibited growth of human breast cancer cell lines.

2.2. Combination of chloroquine or hydroxychloroquine with 5-Aza-dC reduced tumor cell clonogenic survival.

2.3. Combination of chloroquine or hydroxychloroquine with 5-Aza-dC caused enhanced accumulation of cytoplasmic lipid droplets in MCF-7 and MDA-MB-231 breast cancer cells.

2.4. Combination of chloroquine or hydroxychloroquine with 5-Aza-dC elevated the Ki67 index.

3. Histone H3/H4 Hyperacetylation Status in Response to Combination Treatment with Antitumor Quinolines.

3.1. Effect of combination treatment of chloroquine or hydroxychloroquine with 5-Aza-dC on acetylated histone H4, HDAC, and RAR $\beta 2$ protein levels in MDA-MB-231 breast cancer cells. 
3.2. Effect of combination treatment of chloroquine or hydroxychloroquine with 5-Aza-dC on acetylated histone $\mathrm{H} 3 / \mathrm{H} 4$, HDAC, and RAR $\beta 2$ protein levels in MCF-7 breast cancer cells.

3.3. Histone Deacetylase (HDAC) activity of chloroquine or hydroxychloroquine \pm ATRA

3.4. Identification of acetylated histone $\mathrm{H} 3$ by mass spectrometry...............106

3.5. Identification of acetylated histone $\mathrm{H} 4$ by mass spectrometry..............114

3.6. Histone Acetylase (HAT) activity of hydroxychloroquine and ATRA.......122

4. Additional Studies. .124

4.1. Identification of differentiation-inducing quinolines as experimental breast cancer agents in the MCF-7 human breast cancer cell model.

4.1.1. Antiproliferative quinolines act as cell differentiation agents......126

4.1.2. E2F-1 as a differentiation response marker.

4.2. Design, synthesis, and bioactivities of steroid-linked taxol analogues as potential targeted drugs for prostate and breast cancer.

IV. DISCUSSION

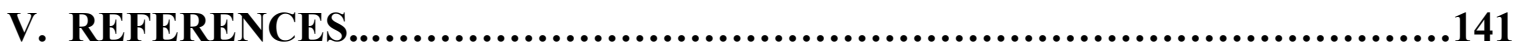

VI. CURRICULUM VITAE. 


\section{LIST OF FIGURES}

Figure 1. Interactions of cell cycle regulatory proteins during $\mathrm{G} 1$ and $\mathrm{S}$ phase..........7

Figure 2. Chemical structure of chloroquine and hydroxychloroquine................17

Figure 3. Schematic representation of nucleosome core histones...................20

Figure 4. Schematic representation of retinoid signaling upon ligand activation........25

Figure 5. Chloroquine and Hydroxychloroquine cause accumulation of cytoplasmic lipid droplets in MCF-7 and MDA-MB-231 breast cancer cells but not in MCF-10A normal mammary epithelial cells..........................49

Figure 6. Ki67 immunohistochemical staining of MCF-7 cells....................52

Figure 7. Inhibition of MCF-7 and MDA-MB-231 cell survival.....................54

Figure 8. Inhibition of growth in MCF-7 and MDA-MB-231 breast cancer cells compared to MCF-10A normal mammary epithelial cells...................56

Figure 9. MCF-7 cell clonogenic survival...................................60

Figure 10. Oil Red-O Histochemistry: enhanced accumulation of cytoplasmic lipid droplets in MCF-7 and MDA-MB-231 breast cancer cells using Chloroquine or Hydroxychloroquine in combination with ATRA...........64

Figure 11. KI67 Histochemistry: Increase in G0 cell population in both MCF-7 and MDA-MB-231 breast cancer cells treated with Chloroquine or Hydroxychloroquine in combination with ATRA .68

Figure 12. E2F-1 protein expression in MCF-7 cells following treatment with

Chloroquine \pm ATRA.

Figure 13. c-myc protein expression in $\mathrm{MCF}-7$ cells following treatment with Chloroquine \pm ATRA. .74

Figure 14. Inhibition of growth in MCF-7 and MDA-MB-231 breast cancer cells compared to MCF-10A normal mammary epithelial cells .78

Figure 15. Oil-Red-O Histochemistry: enhanced accumulation of cytoplasmic lipid droplets in MCF-7 and MDA-MB-231 breast cancer cells using Chloroquine or Hydroxychloroquine in combination with 5-Aza-dC. .85 
Figure 16. KI67 Histochemistry: Increased G0 cell population in both MCF-7 and MDA-MB-231 breast cancer cells treated with Chloroquine or Hydroxychloroquine in combination with 5-Aza-dC.

Figure 17. HDAC, acetylated histone $H 4$, and RAR $\beta_{2}$ protein levels in MDA-MB-231 cells following treatment with Chloroquine or Hydroxychloroquine \pm Aza...93

Figure 18. HDAC, acetylated histone $\mathrm{H} 3 / \mathrm{H} 4$, and $\mathrm{RAR} \beta_{2}$ protein levels in MCF-7 cells following treatment with Chloroquine or Hydroxychloroquine \pm ATRA.....99

Figure 19. Histone Deacetylase (HDAC) Fluorescent Activity of Chloroquine or Hydroxychloroquine \pm ATRA

Figure 20. Histone H3 acetylation status in MCF-7 cells.............................108

Figure 21. Histone $\mathrm{H} 4$ acetylation status in MCF-7 cells 116

Figure 22. Histone Acetyltransferase (HAT) Activity of Hydroxychloroquine \pm ATRA

Figure 23. Chemical structures of quinoline-ring containing NSC compounds

Figure 24. Inhibition of MCF-7 cell growth by quinoline compounds 128

Figure 25. E2F-1 protein expression in MCF-7 cells following treatment with quinoline compounds

Figure 26. Downregulation of E2F-1 protein in MCF-7 cells treated with quinoline compounds.

Figure 27. Downregulation of c-myc protein in MCF-7 cells treated with quinoline compounds 


\section{LIST OF TABLES}

Table 1. Growth inhibitory concentrations for Chloroquine and Hydroxychloroquine...47

Table 2. Tumor cell clonogenic survival using ATRA.............................61

Table 3. Tumor cell clonogenic survival using 5-Aza-dC ..........................82

Table 4. Antiproliferative activity of breast tumor differentiating NSC quinoline compounds in MCF-7 and MDA-MB-231 cells...........................127

Table 5. Summary of differentiation activity by NSC compounds in MCF-7

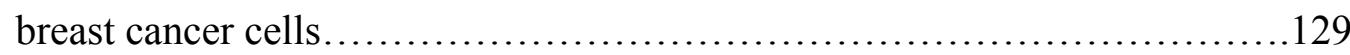

Table 6. Cytotoxicity of steroid-linked taxol derivatives.........................135 


\section{LIST OF ABBREVIATIONS}

5-Aza-dC 5-Aza-2'-Deoxycytidine

ATRA All-trans-Retinoic Acid

BSA Bovine Serum Albumin

CQ Chloroquine

CRABP Cellular Retinoic Acid Binding Protein

CRBP Cellular Retinol Binding Protein

DMEM Dulbecco's Modified Eagle's Medium

DMSO Dimethyl Sulfoxide

DNMT DNA Methyl Transferase

DTT Dithiothreitol

ER Estrogen Receptor

FBS Fetal Bovine Serum

HAT Histone Acetyl Transferase

HBSS Hank's Balanced Salt Solution

HDAC Histone Deacetylase

HMEC Human Mammary Epithelial Cells

HPLC High Performance Liquid Chromatography

HCQ Hydroxychloroquine

MeCP2 Methyl-cytosine Binding Protein 2

MS Mass Spectrometry

MTS 3-(4,5-dimethylthiazol-2-yl)-5-(3-carboxymethoxyphenyl)-2-(4-sulfophenyl)-

2H-tetrazolium

ORO Oil Red-O

PBS Phosphate Buffered Saline

RA Retinoic Acid

RAR Retinoic Acid Receptor

RARE Retinoic Acid Response Element

RXR Retinoid X Receptor

TSA Trichostatin A 


\section{INTRODUCTION}




\section{Breast Cancer}

Breast cancer affects many individuals around the world. For this year, 2004, it is estimated that 215,990 new cases of invasive breast cancer will be diagnosed among women in the United States alone. Breast cancer affects men as well and is estimated that 1,450 new cases of breast cancer will arise among men. Breast cancer is the most frequently diagnosed cancer among women and the second leading cause of cancer related deaths, after lung cancer. An estimated 40,580 deaths are anticipated in 2004 (American Cancer Society, 2004). Breast cancer is a cellular disease, which is the outcome of aberrant cell growth starting in the breast tissue. From the breast tissue, malignant tumors are able to metastasize to other organs of the body, making breast cancer so deadly. There have been insights into the causes of breast cancer and a myriad of epidemiological studies that provide a correlation between environmental, racial, and cultural influences and the occurrence of cancerous cells; however, both the absolute cause of breast cancer and the means for its cure still remain unknown (Polyak, 2001).

\subsection{Oncogenes and Tumor Suppressors}

Two gene classes play a pertinent role in the development of cancer: protooncogenes and tumor suppressor genes. Proto-oncogenes encourage growth and code for proteins that stimulate cell division. On the other hand, tumor suppressor genes, which are known as the "guardians of the genome" code for proteins that inhibit cell division (Weinberg, 1996). Since collaboration between cells ensures that the size as well as the structure of the breast tissue is maintained, normal cells reproduce only when instructed to do so by other cells in their vicinity. To the contrary, cancer cells violate this scheme and 
overexpress stimulatory proteins that regulate the cell cycle. When a proto-oncogene becomes mutated, it is called an oncogene, and can cause overexpression of these stimulatory proteins. Some genes that function as oncogenes in breast cancer include c-myc, erb-B2 (HER-2 or neu), Bcl-2, Bcl-1, and Mdm2. Mutations in tumor suppressor genes can cause the proteins that inhibit cell division to be inactivated; therefore, depriving cells of essential restraints on proliferation. Some genes that function as tumor suppressor genes in the breast include Rb, p53, BRCA1, and BRCA2 (Kopnin, 2000).

The human epidermal growth factor receptor 2 gene encodes HER-2/neu, which is an epithelial cell surface receptor that expresses tyrosine kinase activity. In normal cells, HER$2 /$ neu acts as a receptor for cellular growth factors, thereby, regulating cell growth and division. However, in cancer cells HER-2/neu acts as an oncogene and loses its normal response to regulatory proteins, thus resulting in unregulated progression of cell growth. About $25-30 \%$ of patients with invasive breast cancer overexpress HER-2/neu, which has been shown to play an important role in the malignant transformation and aggressiveness of breast cancer. It is also associated with early recurrence, shorter disease-free interval, and overall poorer outcome in breast cancer (de Bono et al., 2003).

There is a significant correlation between breast cancer and the inherited form of the disease. Breast cancer susceptibility genes, BRCA1 and BRCA2 account for $83 \%$ of breast cancers occurring by age 70 . However, only about $20 \%$ of women with familial history of breast cancer carry these inherited genes, indicating that the majority of breast cancers do not develop solely because of heredity (Prichard et al., 2003). Mutations in the DNA of a normal cell account for the development of the majority of breast cancer, thus making the offspring more susceptible to cancer. BRCA1 and BRCA2 instruct large proteins involved 
in the transition from S to G2 phase of the cell cycle. They play a pertinent role in the maintenance of chromatin structure by aiding in DNA strand break repair. When cells enter G2 arrest, they are held there and repaired by either BRCA1 or BRCA2; therefore, mutations in these genes result in the lack of or incorrect repair of DNA (Kopnin, 2000).

The failure of DNA damage to be corrected in cellular reproduction is one of the main reasons for cancer. The tumor suppressor gene, p53, can correct DNA damage, and subsequently prevent aberrant cell growth. Sequences at the N-terminus of the p53 protein function as transcriptional activators, which activate the transcription of genes involved in the suppression of cell growth (Hanahan and Weinberg, 2000).

\subsection{Cell Cycle}

The cell cycle consists of four stages: G1, S, G2, and M phase. During the longest phase, G1 (gap 1), the cell increases in size and prepares to replicate its DNA. The replication occurs in the next phase, $\mathrm{S}$ (for synthesis), but before the cell proceeds to the next phase it must make a transition that occurs at the restriction point (R) in G1, which commits the cell to the proliferative cycle. If the conditions that signal this transition are not present, the cell exits the cell cycle and enters G0, a nonproliferative phase during which growth, differentiation and apoptosis occur. Once the cell has passed the restriction point, it is ready to enter the S phase, which allows for the duplication of the precise complement of chromosomes. A second gap phase, G2, follows after replication and allows for the cell to prepare for the final phase, $\mathrm{M}$ (mitosis). During $\mathrm{M}$ phase, the parent cell divides in half to generate two daughter cells, each of which is endowed with a complete set of chromosomes. 
The new daughter cells may then enter G1 and proceed through the full cycle again, or they may stop cycling temporarily or permanently in the G0 resting phase (Weinberg, 1996).

Passage through the four phases of the cell cycle is regulated by a family of cyclins that act as regulatory subunits for cyclin-dependent kinases (cdks). The activity of the various cyclin/cdk complexes that regulate the progression through G1, S, and G2 phases of the cell cycle is controlled by the synthesis of the appropriate cyclins during a specific phase of the cell cycle. Each cyclin binds to the corresponding cdk and activates its catalytic subunit with sequential phosphorylation and dephosphorylation of key residues. In early G1, a cyclin cdk complex is formed with either cdk4 or cdk6 bound to a cyclin D isoform. Several proteins can inhibit the cell cycle in the G1 phase (Figure 1). If DNA damage has occurred, p53 accumulates in the cell and induces the p21-mediated inhibition of cyclin D/cdk4/6. Mdm2, which is responsible for the inactivation and nuclear export of p53, becomes part of an inhibitory feedback loop that inactivates p21-mediated G1 arrest. Similarly, activation of TGF- $\beta$ receptors induces the inhibition of cyclin D/cdk by 15 , while cyclic AMP inhibits the cyclin $\mathrm{D} / \mathrm{cdk}$ complex via $\mathrm{p} 27$. If the cyclin $\mathrm{D} / \mathrm{cdk}$ complex is inhibited, retinoblastoma protein $(\mathrm{Rb})$ is in a state of low phosphorylation and is tightly bound to the transcription factor E2F, inhibiting its activity and therefore, inhibiting cell cycle progression.

Passage through the restriction point and transition to $\mathrm{S}$ phase is triggered by the activation of the cyclin $\mathrm{D} / \mathrm{cdk} 4 / 6$ complex, which phosphorylates $\mathrm{Rb}$. Phosphorylated $\mathrm{Rb}$ dissociates from E2F, which is then free to initiate DNA replication. Cyclin E/cdk2 accumulates during late $\mathrm{G}$ phase and triggers the passage into $\mathrm{S}$ phase. The synthesis and accumulation of cyclin $\mathrm{B} / \mathrm{cdk} 2$ also begins during $\mathrm{S}$ phase, but the complex is phosphorylated at $\mathrm{Thr}^{14}-\mathrm{Tyr}^{15}$ and remains inactive. Cyclin A/cdk2 accumulates during $\mathrm{S}$ 
phase and its activation triggers the transition to $\mathrm{G} 2$, a phase characterized by the accumulation of cyclin B/cdk2, DNA replication, cell growth and new protein synthesis (Weinberg, 1996; Hanahan and Weinberg, 2000).

Mutations and abnormalities in the regulatory cell cycle proteins are frequent in most cancer types. Normal cells reproduce only when instructed to do so and are subject to strict control of cell cycle regulation. On the other hand, cancer cells have their own internal agenda and exert a degree of independence from the normal regulation of the cell cycle. 


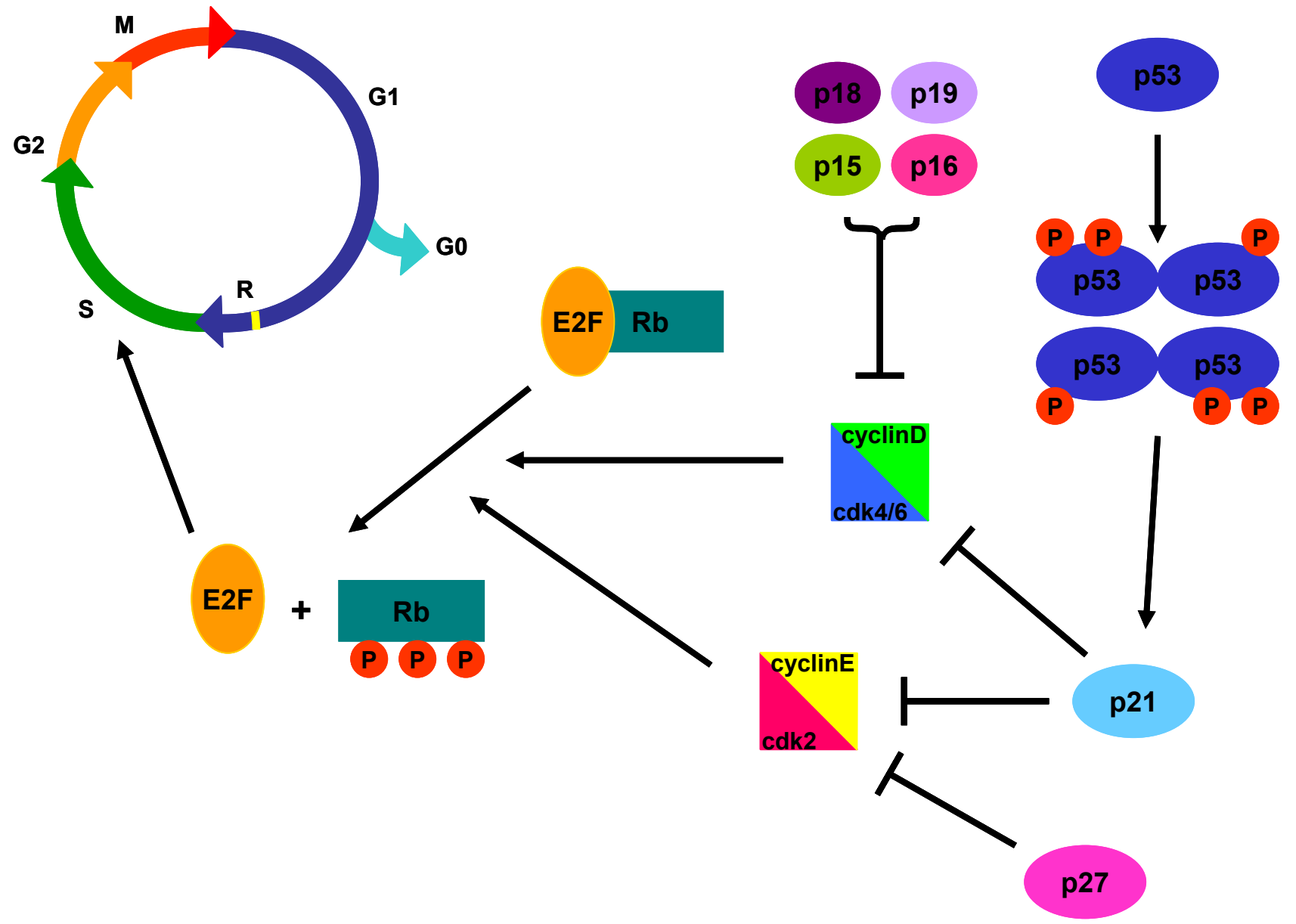

Figure 1. Interactions of cell cycle regulatory proteins during $G 1$ and $S$ phase. 


\subsection{Methods of Treatment}

Current methods of treatment include local and systemic treatment. Local treatment includes lumpectomy, mastectomy, or radiation therapy. Systemic treatment involves hormone therapy or chemotherapy, depending on whether the breast cancer is estrogen receptor $(\mathrm{ER}+)$ and progesterone receptor $(\mathrm{PR}+)$.

\subsubsection{Local Treatment}

Breast-conserving surgery involves lumpectomy, or the surgical removal of a tumor and the surrounding clean margin of normal tissue, followed by radiation therapy. The goal of this treatment is to excise the tumor, while maintaining a cosmetically acceptable breast. It has proven to be effective for early-stage breast cancers that have not metastasized or spread to other organs in the body.

Mastectomy, or the surgical removal of the breast, can be accomplished in several different ways depending on the size of the tumor and the extent of the disease. Either the entire breast and lymph nodes are removed or just the breast is removed, leaving the lymph nodes intact (Sakorafas, 2000). Because mastectomy requires more extensive surgery than does a lumpectomy, greater discomfort occurs.

Radiation therapy, which includes the use of high-energy waves (x-rays or gamma rays) or streams of particles (electrons, protons, neutrons, alpha particles, and beta particles), works by damaging DNA. It is estimated that $50-60 \%$ of all patients with cancer will receive radiation at some time during their cancer treatment. Radiation therapy is more successful on cells that are actively reproducing and on those that divide more rapidly (Sullivan, 1980). It is less effective on cells that are in the resting phase or that divide 
slowly. Although radiation therapy attacks reproducing cells, it does not display selectivity and therefore, does not distinguish between cancer cells and cells of normal tissues. The damage to normal cells can result in side effects. A balance between eradicating the cancer cells and sparing the normal cells, in order to minimize undesirable side effects is involved each time radiation therapy is given. For this reason, radiation treatment is given in small doses or fractions over several weeks to allow the optimal dose to kill the cancer with less damage to normal tissues.

Radiation therapy is used as an adjuvant treatment in addition to the primary treatment, which is usually surgery. It is used before surgery to shrink a large tumor so that the tumor can be surgically removed and to relieve symptoms such as pain and bleeding when the cancer has spread. It is given about one month after a lumpectomy or mastectomy to destroy malignant cells that may remain undetected in the breast region, which includes the breast, chest wall, or armpit.

\subsubsection{Systemic Treatment}

Hormone therapy, which is also known as endocrine therapy, is used for hormone dependent breast cancer. Estrogen and progesterone hormones circulate in the bloodstream and can attach to breast cancer cells, and thereby, support the growth of the cancer. Estrogen is the major promoter of cell growth in hormone dependent breast cancer. The goal of hormone therapy is to deprive the cancer tissue of estrogen, resulting in the blocking or slowing of cancer cell growth. Unlike chemotherapy, hormone therapy does not kill the cancer cell. Hormone therapy acts by either blocking estrogen from reaching cancer cells, receptor blocker, or inhibiting the synthesis of estrogen. The specific hormone treatment 
chosen depends on many factors including whether the tumor is estrogen and/or progesterone receptor positive or negative. Hormone therapy is effective only in hormone receptor-positive or unknown status breast cancers. Hormone therapy is not used with ER/PR negative breast cancers, as they are unlikely to respond to hormone therapy. Hormone treatments include estrogen receptor modulators, aromatase inhibitors, or progestins. (Osborne et al., 2000)

Estrogen receptor modulators block estrogen's action at the tumor. The oldest and most commonly used antiestrogen drug is tamoxifen, which is an effective treatment for both early and advanced stage breast cancer. Tamoxifen, which is used as a first-line hormone therapy, does not stop estrogen from being made in the body, but it prevents breast cancer cells from growing by blocking the estrogen receptors in the cancer cells and thereby, preventing the estrogen hormone from reaching the receptor (Osborne et al., 2000). Although there are some serious side effects to tamoxifen treatment, in most cases they are outweighed by the benefits of the drug on breast cancer. Randomized trials have failed to demonstrate an advantage for taking tamoxifen for more than five years, so the current practice is to take the drug for five years only. However, tamoxifen is the most frequently prescribed cancer drug worldwide, and the only antiestrogen approved to lower the risk of breast cancer in high-risk women. Another antiestrogen, osteoporosis-preventing drug, raloxifene, is currently being studied in a large number of healthy, high-risk women throughout the country to determine how its cancer-prevention benefits compare with tamoxifen (Prichard et al., 2003).

Aromatase inhibitors, such as anastrozole, letrozole, and exemestane are used as secondline hormone therapy. These drugs work by blocking a specific enzyme necessary for 
estrogen production in the fat tissues, including the breast, of postmenopausal women. These estrogen reducing drugs are used in advanced or metastatic breast cancer as first-line therapy or second-line therapy after tamoxifen. (Osborne et al., 2000)

Progestins, which are progesterone like drugs such as megestrol acetate, reduce the effect of estrogen on breast cancer cells. They are traditionally used in postmenopausal women as a third-line therapy after tamoxifen and the aromatase inhibitors.

Chemotherapy is the systemic use of natural or synthetic chemical agents utilized in order to reverse or suppress the progression to an invasive carcinoma (Prichard et al., 2003). It is considered a systemic therapy since it enters the bloodstream and is distributed throughout the body, except for the brain, so that it can damage or destroy cancer cells. Studies have shown that the combinations of chemotherapy drugs are the most efficacious, by offering distinct ways of destroying the cancer cells; thereby, reducing the chance of the cancer becoming resistant to one drug. Some of the drugs used in combination are cyclophosphamide, methotrexate, and 5-fluorouracil, with or without prednisone, or vincristine, as well as doxorubicin with paclitaxel. The drug combinations are usually either DNA alkylating agents, mitotic spindle inhibitors, antimetabolites, or DNA intercalators.

Chemotherapy destroys proliferating cells and does not distinguish between cancer cells and normal, healthy cells. When normal cells are killed, side effects from the drugs occur. Because cells of the skin, nails, and hair divide quickly, chemotherapy causes hair thinning or loss of hair over the entire body, dry skin, and weak nails. Chemotherapy drugs are immunosuppressive and interfere with blood cell production. Chemotherapy drugs may also induce early or premature menopause, particularly in older women. Some drugs, such as doxorubicin or epirubilin can cause permanent damage to the heart; therefore, measures 
have to be taken to limit the amount of drug that is used and to monitor heart function periodically during therapy. More rarely, certain drugs may cause another cancer to develop as a result of the chemotherapy itself, such as leukemia.

Another method of systemic treatment includes immunotherapy, which enhances the body's own defense system, enabling it to destroy cancer cells. While different immunotherapy approaches, such as anti-tumor vaccines, are under investigation for breast cancer, thus far none have been shown to work for breast cancer. Trastuzumab (Herceptin) is a monoclonal antibody that binds with HER-2/neu receptors on the surface of some breast cancers (Prichard et al., 2003). The proto-oncogene, HER-2/neu (or erbB2), is a gene that occurs normally in our bodies. However, during the evolution from normal to cancer cells, this gene often mutates and becomes an oncogene. When it does so, it generates excessive amounts of growth promoting proteins called growth factors. When the HER-2/neu protein binds to the receptor on the tumor cell surface, the MAPK (mitogen-activated protein kinase) signaling pathway is activated causing the cell to divide. Herceptin binds to the HER-2/neu receptor, making it impossible for the growth promoting protein to bind and therefore, inhibits the tumor from growing (de Bono et al., 2003). When used in combination with other chemotherapy drugs such as paclitaxel, doxorubicin, and cyclophosphamide, it increases the potential of these drugs so that they are more effective in tumors than the drugs alone. Herceptin alone is for patients whose tumors have progressed in spite of standard chemotherapy regimens. A serious side effect for this drug is heart toxicity, which is more common among those who take Herceptin in combination with anthracyclines, such as doxorubicin and epirubicin. 
As can be seen from the above chemoprevention agents, a pertinent challenge to breast cancer drug therapies is the availability of more promising antitumor agents that have the ability to eradicate breast tumor cells without displaying toxicity to neighboring normal breast cells and tissues. Despite improvements in therapeutic treatments for breast cancer within the last thirty years, there is still a lack of effective chemoprevention agents that are active against breast cancer and that do not display harmful toxicity at higher doses. Novel strategies must be devised to administer potent therapy against cancer cells without the side effects of high-dose chemotherapy in breast cancer treatment. 


\section{Quinolines}

Chloroquine and hydroxychloroquine belong to the quinolone family and possess diverse pharmacological properties including antimalarial and anti-inflammatory activity, which are exploited clinically. They are related drugs with different therapeutic and clinical indications for use. Initially, both chloroquine and hydroxychloroquine were given for malaria prophylaxis and treatment, and, later, they were used by rheumatologists for treating rheumatoid arthritis, systemic/discoid lupus erythematosus, and other connective tissue disorders (Scheibal and Van Dyke, 1997). Currently, chloroquine is used as an antimalarial and hydroxychloroquine is used to treat rheumatoid arthritis.

\subsection{Chloroquine (CQ)}

Chloroquine (Aralen) is a 4-aminoquinoline compound (figure 2) that displays antimalarial activity. Chloroquine is an effective antimalarial drug, especially against the asexual intraerythrocytic forms of human plasmodia, because it is concentrated in the erythrocyte of the malarial parasite (Parris, 2003). The quinoline drug has been proposed to selectively target the parasite by inhibition of parasite feeding of hemoglobin. Chloroquine is an effective inhibitor of catalase activity of heme. The catalase activity converts hydrogen peroxide to water and oxygen; thereby, detoxifying the reactive oxygen species. Inhibition of this process by chloroquine, therefore, makes the heme toxic to the parasite (Foley and Tilley, 1998). Chloroquine can also exert its actions by intercalating into DNA and binding to ferriprotoporphyrin IX in the phagocytic vesicles of the parasite (Misra et al., 1997).

Chloroquine is also an effective anti-inflammatory agent that has been shown to reduce proinflammatory cytokine release in both in vitro and in vivo studies. Chloroquine blocks 
interleukin-mediated induction of $\mathrm{NF}-\kappa \mathrm{B}$, a nuclear transcription factor primarily responsible for induction of key inflammatory proteins involved in inflammation (Bonizzi et al.,1997). Chloroquiine also inhibits the production of TNF, a potent immunoregulatory cytokine which is associated with inflammatory diseases such as rheumatoid arthritis, multiple sclerosis, and cerebral malaria (Jeong et al., 1997; Hong et al., 2004).

Interestingly, chloroquine also displays antitumor activity. In cultured mouse myeloid leukemia cells, chloroquine induced differentiation and inhibited DNA and RNA polymerases (Morrow et al., 1989). Preliminary results also showed that chloroquine caused cell differentiation in a panel of beast cancer cells while having no effect on normal mammary epithelial cells. Chloroquine may be a promising candidate for breast cancer treatment. The advantage of using this quinoline for breast cancer treatment is that is in wide use and its human pharmacology is well known (Scheibal and Van Dyke, 1997). Although, at an extremely high dose ( $>100 \mathrm{~g} / \mathrm{ml})$, chloroquine can generate ocular toxicity, it displays very low and predictable toxicities in humans (Foley and Tilley, 1998). Combination therapy of other differentiating agents with chloroquine may be a promising option for breast cancer treatment by permitting lower doses of chloroquine for maximum therapeutic effects.

\subsection{Hydroxychloroquine (HCQ)}

Hydroxychloroquine (Plaquenil) is a 4-aminoquinoline compound (figure 2) that also displays antimalarial activity. Most notably, hydroxychloroquine is already widely used by many pre- and post-menopausal women to treat rheumatoid arthritis because of its efficacy and low toxicity profile (Suarez-Almazor et al., 2000). Hydroxychloroquine also inhibits 
induction of TNF and NF-אB production necessary for inflammation (Jeong et al., 1997). Long term use of the quinoline, hydroxychloroquine has shown that it is relatively safe and affords other benefits. It may be used in pregnancy, has steroid sparing effects, and alleviates the risk of thrombosis associated with antiphospholipid antibodies. When used for the treatment of mild to moderate lupus, hydroxychloroquine lowered serum levels of cholesterol, triglycerides, and LDL in patients (Cruz, 2001). In lupus patients, treatment with hydroxychloroquine also decreased mean blood glucose levels (Petri, 1996).

Preliminary results also showed that hydroxychloroquine caused cell differentiation in MCF-7 and MDA-MB-231 beast cancer cells while having no effect on normal mammary epithelial cells. Hydroxychloroquine may be a promising candidate for breast cancer treatment, especially because of its many advantages and its low toxicity profile. Another advantage of using this quinoline for breast cancer treatment is that is already widely used and its human pharmacology is well known (Scheibal and Van Dyke, 1997). Combination therapy of other differentiating agents with hydroxychloroquine may be a promising option for breast cancer treatment by possibly enhancing its therapeutic effects. 

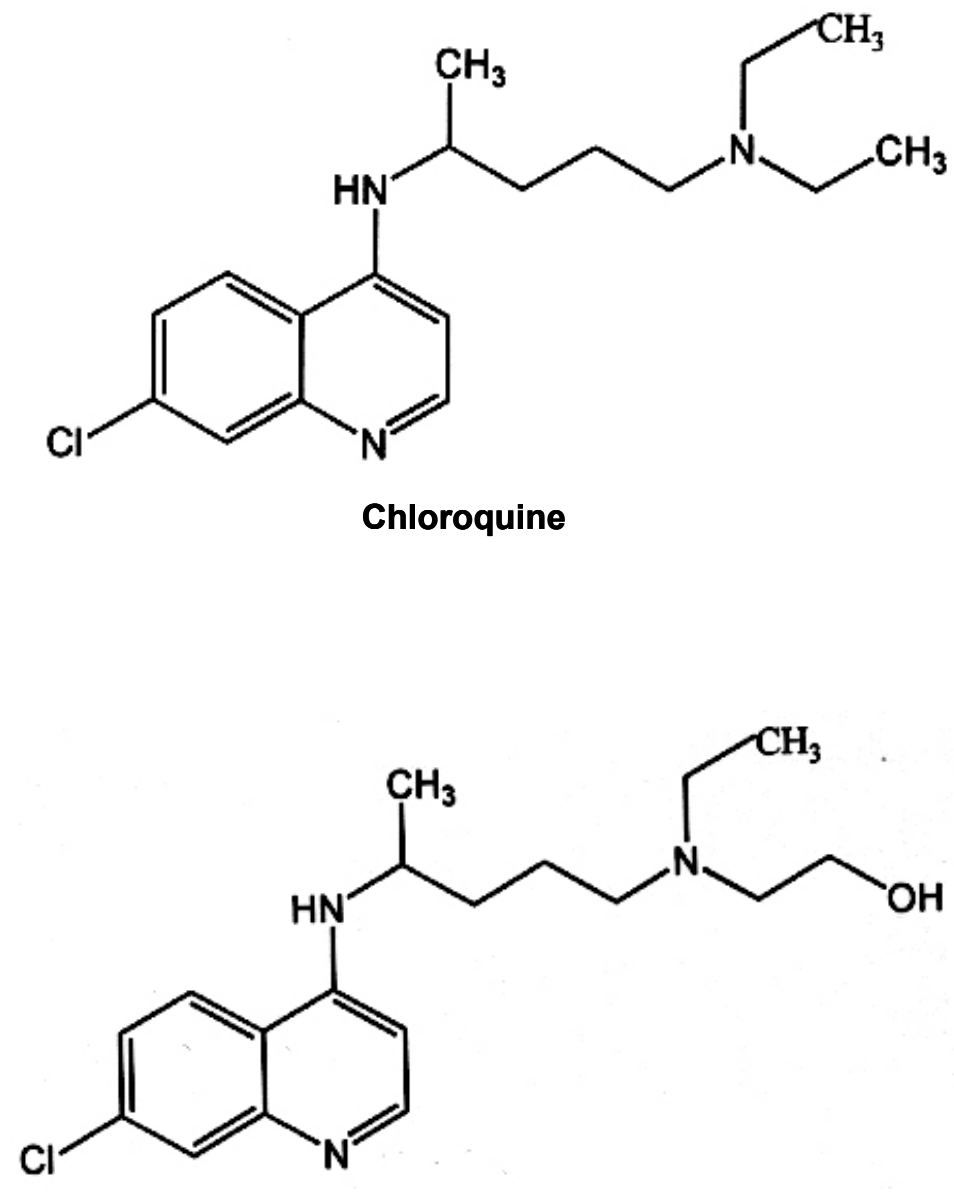

Hydroxychloroquine

Figure 2. Chemical structure of chloroquine and hydroxychloroquine 


\section{Histone Acetylation Status and Breast Cancer}

Organization of chromatin structure is a fundamental component of transcriptional regulation (Hanahan et al., 2000). Modifications of histones, the building blocks of chromatin, serve as significant determinants in the eventual fate of all eukaryotic cells. Post-tanslational modifications of histones include methylation, phosphorylation, and acetylation; however, acetylation is the best understood of these modifications (Khorasanizadeh, 2004). Much evidence suggests that changes in acetylation or deacetylation of nucleosome core histones play a role in the uncontrolled growth and development of cancer (Yoshida et al., 1999; Zhou et al., 2000; Walia et al., 1998). The acetylation status of histones is critical in the modulation of chromatin structure and the regulation of gene transcription. Alteration of chromatin structure via histone acetylation, has long been associated with transcriptional activation (Hebbes et al., 1988), whereas deacetylation of histones has been associated with gene silencing and transcriptional repression (Vigushin et al., 2002).

\subsection{Chromatin Regulation}

The activities of two families of enzymes, the histone acetyl transferases (HATs) and histone deacetylases (HDACs), control the acetylation status of histones. Whereas HAT acetylates the nucleosome core histones, HDAC is responsible for the removal of acetyl groups from lysine residues in these histones (Walia et al., 1998). The principal targets for this acetylation or deacetylation are at the N-terminal tail domains of lysine residues on histone $\mathrm{H} 3$ or histone $\mathrm{H} 4$ (Figure 3). When HDAC deacetylates histone $\mathrm{H} 3$ or histone $\mathrm{H} 4$ at their respective lysine sites, the positively charged lysine residues on the hypoacetylated 
histone bind tightly to the negatively charged phosphate backbone of DNA; thereby, maintaining chromatin in a transcriptionally silent state by preventing access of transcription factors, transcriptional regulatory complexes, and RNA polymerases to DNA (Yoshida et al., 1999). The active site in the catalytic domain of HDAC consists of a curved tubular pocket. A charge-relay system is used in order to remove an acetyl group. An essential component of this charge-relay system is the presence of a zinc ion, which is bound to the zinc binding site on the bottom of the pocket (de Ruijter et al., 2003). Since HDAC condenses chromatin into a tightly supercoiled conformation characteristic of transcriptionally inactive or repressed genes, it is thought to be a critical player in triggering cell growth and ultimately tumor progression (Vigushin et al., 2002); therefore, inhibition of HDAC serves as a pertinent chemotherapeutic target for cancer treatment. 


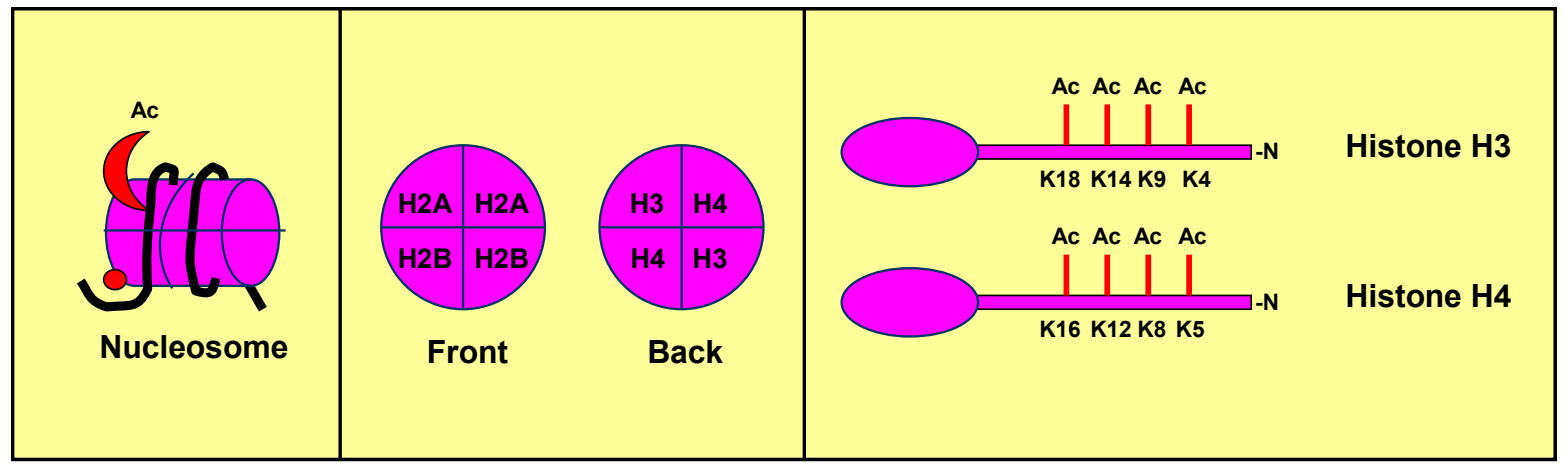

Figure 3. Schematic representation of nucleosome core histones. Pink color represents histones in the core octamer. The N-terminal histone tail of histones $\mathrm{H} 3 / \mathrm{H} 4$ can be acetylated by the histone acetyltransferase (HAT) enzyme. A red circle depicts an Nterminal tail that has been deacetylated. DNA is shown in black wrapped around the nucleosome. A histone tail with an acetyl group relieves the tight packaging of the DNA. 


\subsection{Pharmacological HDAC Inhibitors}

There are many histone deacetylase (HDAC) inhibitors known, but the most potent discovered so far is trichostatin A (TSA). TSA inhibits HDAC by displacing the zinc ion in HDAC's active site and therefore, rendering the charge-relay system dysfunctional. Originally, TSA was used as an antifungal agent; however, later it was discovered to have significant antiproliferative activity in cancerous cells. It belongs to the hydroxamic acid family of compounds and is effective at nanomolar concentrations in vivo. Due to the extremely high cost, inefficient production, and toxicity of TSA, the search for alternative HDAC inhibitors has been ongoing and of great importance (de Ruijter et al., 2003).

Another renowned group of HDAC inhibitors include short-chain fatty acids, such as sodium butyrate, phenylbutyrate, and valproic acid; however, these compounds are less efficient in their HDAC inhibitory activity than TSA.

Cyclic tetrapeptide antibiotics are the third group of HDAC inhibitors and include: trapoxin, depsipeptide, apicidine, depudesin, chlamydocin, and HC-toxin. Most of these compounds are products of bacteria or fungi. Apicidine and depsipeptide are composed of a combination of hydroxamic acids and cyclic tetrapeptides.

All of these HDAC inhibitors work by inhibiting HDAC in a reversible fashion. Trapoxin and depudesin are exceptions and instead they irreversibly inhibit HDAC via covalent bonding to the epoxyketone group (Furumai et al., 2001; de Ruijter et al., 2003). 


\section{Retinoids and Breast Cancer}

Vitamin A plays a critical role in epithelial cell differentiation. Since undifferentiated cells are more susceptible to insults and neoplastic changes, vitamin A has been studied as a chemoprevention agent and a treatment modality for breast cancer. Vitamin A must be obtained from the diet as either preformed vitamin A (mainly as retinol or retinyl ester) or as provitamin A carotenoids that are converted to vitamin A within the body (Paik et al., 2003). Chemically synthesized compounds that mimic biological actions of vitamin A are collectively known as retinoids. These vitamin A derivatives, which include retinol, retinal, and retinoic acid are vital for normal growth, vision, tissue maintenance, reproduction, and overall survival (Chambon, 1994). At the molecular level, retinoids play a myriad of potential roles in the prevention or repression of breast cancer cells, including growth inhibition, cell differentiation, and induction of apoptosis. Clinically, retinoids are able to reverse premalignant lesions and inhibit the generation of second primary tumors in some patients (Yang et al., 2002).

\subsection{Retinoid Metabolism}

Intestinal absorption of vitamin A is necessary for survival. Two sources of vitamin A are available: carotenoids from fruits and vegetables as well as retinyl esters from animal tissues (Demmer et al., 1987). $\beta$-Carotene, or provitamin A, which is one of the more prevalent biologically active carotenoids, undergoes cleavage by a soluble dioxygenase located in the small intestinal mucosa resulting in two molecules of retinal. These molecules are subsequently reduced to retinol by retinaldehyde reductase. Within the gut lumen, dietary retinyl esters are converted to retinol and subsequently taken up by the small 
intestinal lining cell or enterocyte, where retinol gets esterified to retinyl palmitate. The resulting retinyl esters are then incorporated into the core of chylomicron particles before they are exported from the small intestine and delivered to the blood. Finally, the principal site of storage of vitamin A is the liver, where the retinol formed is stored as retinyl esters.

At least four important intracellular binding proteins are thought to participate in the uptake and intracellular metabolism of vitamin A: cellular retinol binding proteins (CRBPs) I and II (Demmer et al., 1987; Yang et al., 2002) and cellular retinoic acid binding proteins (CRABPs) I and II (Napoli, 1999). All vertebrates express each of these high-affinity, highly conserved cytoplasmic proteins. CRBPs I and II selectively bind retinal and retinol and discriminate against retinoic acid, whereas CRABPs I and II selectively bind retinoic acid and discriminate against retinal and retinol; thus, these intracellular binding proteins regulate the level of retinoic acid available for interaction with nuclear receptors. Increasing data suggest that these proteins play a very pertinent role in the intestinal absorption and regulation of retinoid metabolism. Defective expression of the cytoplasmic CRBPs can alter retinoic acid availability and lead to aberrant retinoid signaling, which has been reported in human breast cancer cell lines (Jing et al., 1996) and tumors (Kuppumbatti et al., 2000).

\subsection{Retinoid Signaling}

Two types of nuclear retinoid receptor transduce the retinoid signals: retinoic acid receptors (RARs) and retinoid $\mathrm{X}$ receptors (RXRs), which are members of the steroid/thyroid hormone receptor superfamily. Both types of receptor are comprised of three distinct genes designated $\alpha, \beta$, and $\gamma$. In turn, each gene occurs as multiple isoforms (denoted by numerals) that may be generated through the utilization of alternative 
transcription promoters, mRNA splicing, and the usage of more than one translation initiation codon (Lefebvre, 2001; Paik et al., 2003). Interestingly, RXRs are heterodimeric partners not only for RARs, but also for other nuclear receptors such as thyroid hormone receptors, vitamin D receptor, peroxisome proliferator activated receptors, and a number of orphan nuclear receptors (Lefebvre, 2001). The RXR-RAR heterodimers, as well as RXRRXR homodimers, function as ligand dependent transcription factors that regulate transcription by binding to specific retinoic acid response elements (RAREs) located in the 5'-upstream region of target genes (Paik et al., 2003). The naturally occurring retinoids known to transactivate RARs and RXRs are all-trans-retinoic acid (ATRA) and 9-cisretinoic acid, respectively (Figure 4). These retinoic acid isomers are available at low levels in tissues; however, most tissues express oxidative enzymes that are able to activate vitamin A (retinol) to retinoic acid (Decensi et al., 2003). 


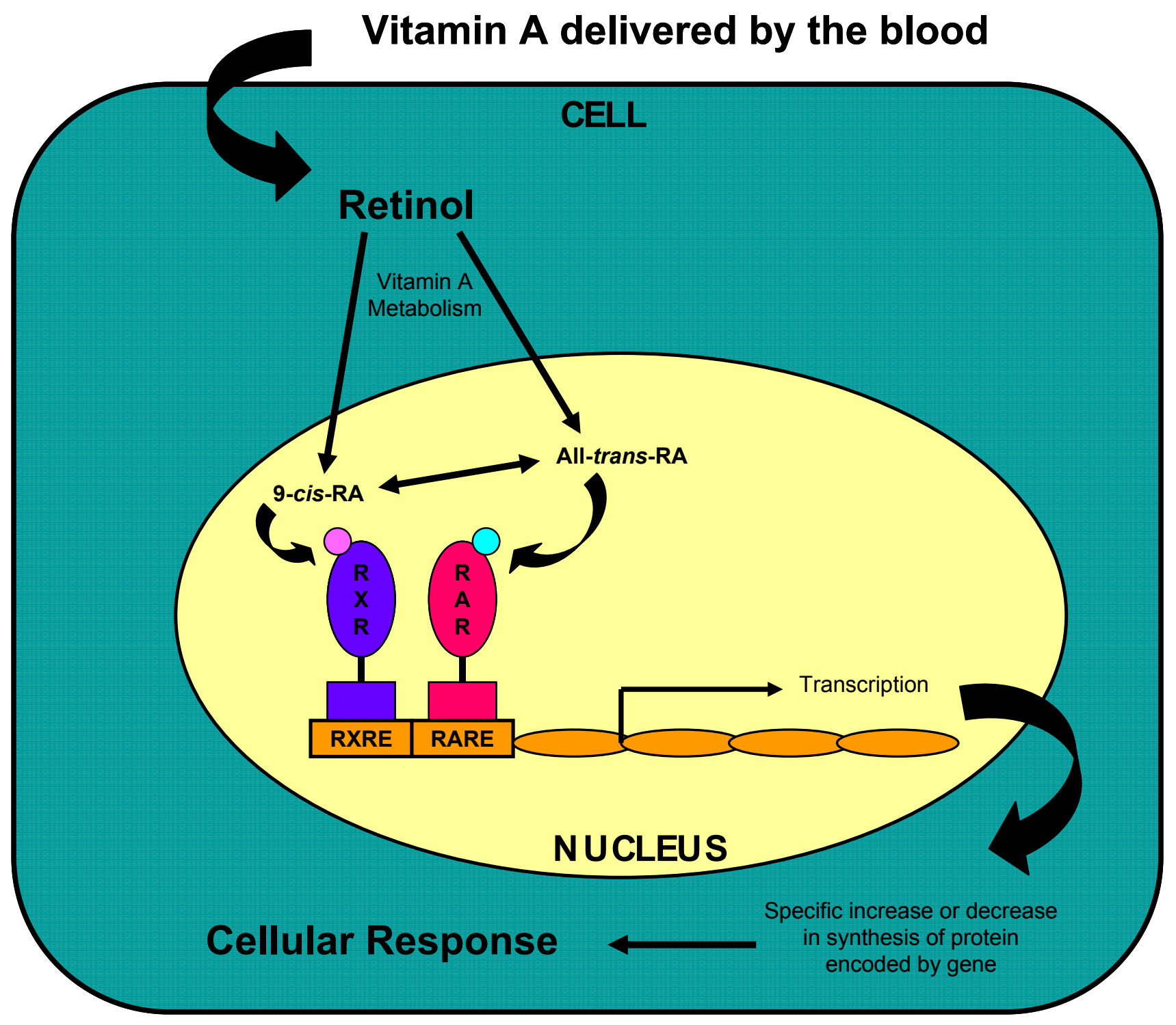

Figure 4. Schematic representation of retinoid signaling upon ligand activation. 


\subsection{Retinoid Agents}

All-trans-retinoic acid has been studied extensively in clinical trials. The biological activity of all-trans-retinoic acid (ATRA) was assessed when used in combination with tamoxifen. ATRA alone caused a 33\% induction of RAR $\beta$ in patients. Combination therapy with tamoxifen potentiated the ATRA-induced biological changes (Toma et al., 2000).

The most widely studied retinoid in chemoprevention clinical trials is fenretinide (N-(4hydroxyphenyl)retinamide), which is a synthetic derivative of ATRA. Experiments assessing the biological activity of fenretinide showed that the drug displayed preferential accumulation in the breast instead of the liver (Sporn et al., 1976). Fenretinide has shown low toxicity and antiproliferative activity in mammary carcinomas (Mehta et al., 1991). Although, the parent compound, ATRA, is well known for its differentiating activity, fenretinide instead inhibits cell growth through the induction of apoptosis. Although the mechanism is not well understood, it is thought to work by upregulating RAR $\beta$, TGF $\beta$, or apoptotic genes (Decensi, et al., 2003). 


\section{Methylation Status and Breast Cancer}

Not only is the degree of core histone acetylation important in modulating transcriptional regulation, but DNA methylation status serves as a critical determinant of chromatin structure and function as well (Fabian and Kimler, 2001; Wang et al, 2001). In general, DNA methylation induces hypoacetylation of histones on heterochromatin, and thus leads to transcriptional repression (El-Osta et al., 2002; Hu et al., 2000). For this reason, DNA methylation is often associated with the pathological silencing of tumor suppressor genes in human cancers (Ferguson et al., 1997; Yang et al., 2001). The mechanisms linking DNA methylation and histone deacetylation in the control of gene expression have been established. Recent studies have demonstrated that inhibitory transcription factors recruit DNA methyltransferase-1 (DNMT1) to chromatin, which subsequently methylates the CG dinucleotide in the promoter region of target genes. The transcriptional repressor methylcytosine binding protein $2(\mathrm{MeCP} 2)$ then binds to the methylated $\mathrm{CG}$ dinucleotides and interacts in a complex with HDAC and the corepressor mSin3 to alter chromatin architecture and gene regulation (Hu et al., 2000). It has been shown that DNMT also interacts directly with HDAC to generate a transcriptionally inactive chromatin structure (Spencer and Davie, 2000; Yang et al., 2001). The formation of MeCP2/mSin3/HDAC and DNMT1/HDAC transcriptional repression complexes are emerging as an important mechanism in silencing a variety of genes in breast cancer. Compounds used to reverse the methylation of chromatin are showing promise as chemoprevention agents for treatment in breast cancer. 


\subsection{5-Aza-2'-deoxycytidine}

The cytosine analog 5-Aza-2'-deoxycytidine (5-Aza-dC) is a potent inhibitor of DNMT. 5-Aza-dC has showed clinical utility and success in the treatment of human blood diseases and tumor progression, which in large part is attributed to its ability to induce cellular differentiation as a result of hypomethylation (Ferguson et al., 1997). Other studies have showed that 5-Aza-dC treatment on estrogen receptor (ER)-negative human breast cancer cells, which have a hypermethylated ER gene promoter, led to reexpression of the ER gene and apoptosis of the cancer cells (Ferguson et al., 1997; Yang et al., 2001; Worm et al., 2001). When 5-Aza-dC treatment was combined with the HDAC inhibitor, trichostatin A (TSA), there was a 10-fold greater elevation in ER mRNA levels, suggesting that the combination of a DNMT1 inhibitor with HDAC inhibitors may play a pertinent therapeutic role in the management of (ER)-negative breast cancers (Yang et al., 2001). Other reports have also demonstrated that the antitumor activity of HDAC inhibitors with 5-Aza-dC is synergistic in a panel of human cancer cell lines, suggesting a correlative link between the antiproliferative and pro-apoptotic activities of the DNMT1 inhibitor, 5-Aza-dC, and HDAC inhibitors (Zhu et al., 2001; Singh et al., 2000). 


\section{Research Objectives}

Preliminary studies showed that two of the quinoline antimalarials, chloroquine (CQ) and hydroxychloroquine (HCQ), displayed selective toxicity only to breast cancer cells. Hence the goal of these studies was to explore: (1) whether a drug combination modulating epigenetic events would sensitize breast cancer cells to the antitumor activity of CQ or HCQ, (2) and if so, which would be the most promising combination of agents for the generation of safer and less toxic chemotherapeutic agents for the prevention and treatment of advanced breast cancer.

\section{Hypothesis 1: Combination of epigenetic agents will augment the antiproliferative} effects of CQ and/or HCQ (Model 1). MCF-7, estrogen receptor (ER+), and MDA-MB231 (ER-) transformed human breast cancer cell lines were used in comparison with MCF10A non-transformed immortalized human epithelial cell line. All-trans-retinoic acid (ATRA) or 5-Aza-2'-deoxycytidine (5-Aza-dC; Aza) was combined with either CQ or HCQ. Cell survival was measured using three endpoints:

(1) MTS metabolism assay

(2) cell growth curve

(3) clonogenic survival

\section{Hypothesis 2: Combination of epigenetic agents will augment the differentiation} response to CQ and/or HCQ (Model 1). MCF-7, estrogen receptor (ER+), and MDA-MB231 (ER-) transformed human breast cancer cell lines were used. ATRA or 5-Aza-dC (Aza) was combined with either CQ or HCQ. Three differentiation endpoints were measured: 

(1) lipid droplet accumulation
(2) loss of Ki67 protein
(3) expression of E2F-1 and c-myc cell cycle regulatory proteins

\section{Hypothesis 3: Combination of ATRA or 5-Aza-dC with CQ or HCQ will increase}

histone $\mathrm{H3}$ and/or histone $\mathrm{H} 4$ acetylation status via inhibition of HDAC protein and therefore, increase $\mathbf{R A R} \beta_{2}$ tumor suppressor protein levels (Models 2 and 3). MCF-7 or MDA-MB-231 transformed human breast cancer cell lines were used. ATRA or 5-Aza-dC (Aza) was combined with either CQ or HCQ. Three endpoints were measured:

(1) acetylated histone $\mathrm{H} 3$ and/or histone $\mathrm{H} 4$ protein levels

(2) HDAC protein and activity levels

(3) $\mathrm{RAR} \beta_{2}$ protein levels

Finally, the most promising combination of agents were assessed by mass spectrometry to measure their effect on histone $\mathrm{H} 3$ and histone $\mathrm{H} 4$ acetylation sites. 
Model 1

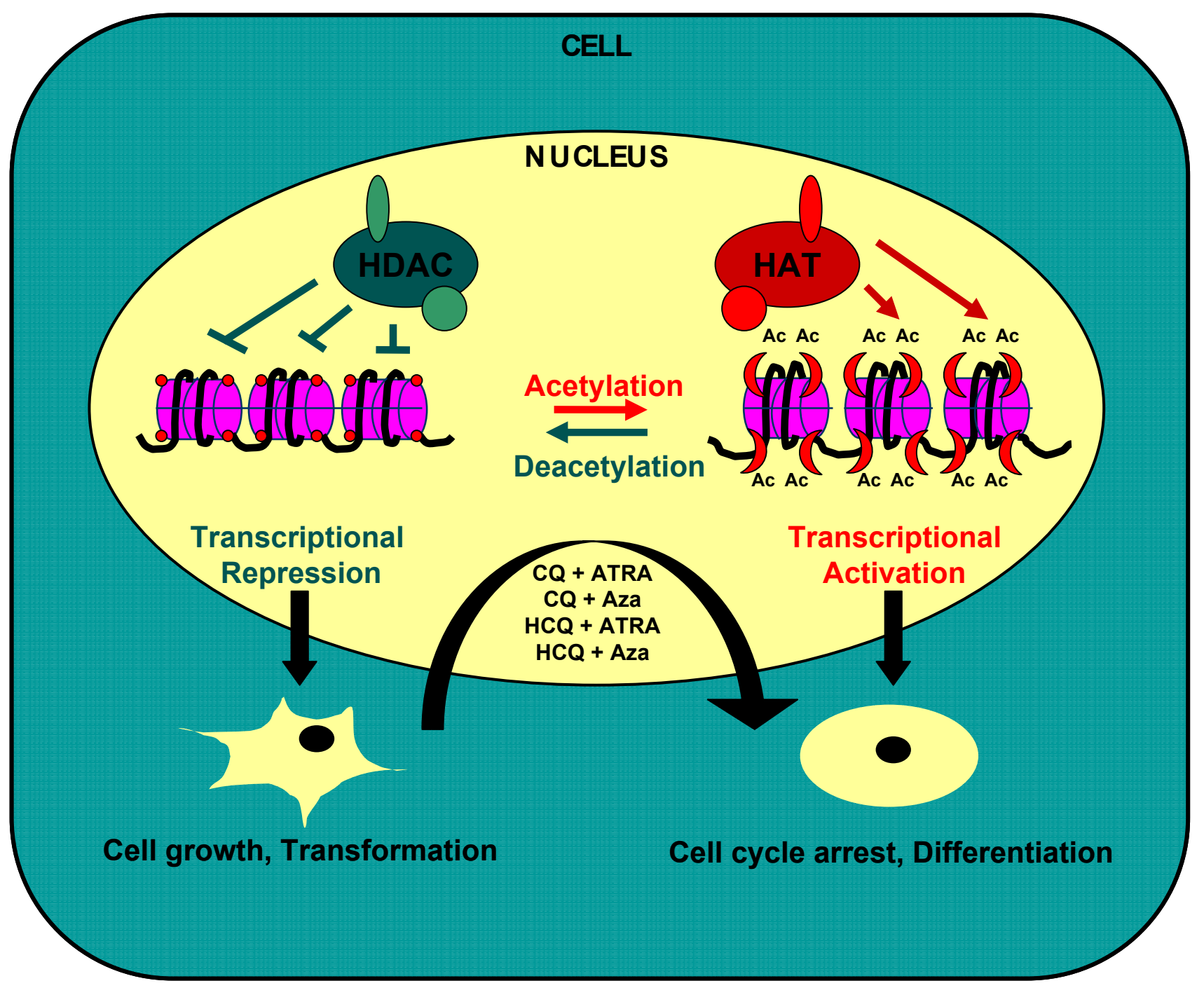

A model for the antiproliferative and differentiating activities in breast cancer cells upon combination treatment with ATRA/5-Aza-dC (Aza) and CQ/HCQ. Histone deacetylase (HDAC) modulates chromatin structure via the removal of acetyl groups from lysine residues on the $\mathrm{N}$-terminal tail of histone proteins. The $(+)$ charged lysine residues are then allowed to bind very tightly to the (-) charged phosphate backbone of DNA; thereby, generating a more condensed chromatin structure characteristic of transcriptionally inactive genes involved in tumorigenesis. On the other hand, histone acetyltransferase (HAT) modulates chromatin structure via the addition of acetyl groups, which neutralizes the $(+)$ charged lysine residues and therefore, generates a more relaxed chromatin structure that allows transcription factors and RNA polymerase to access DNA and activate transcription of tumor suppressor genes. The hypothesis is that upon combination therapy, the effects of HDAC will be reversed and therefore, ATRA or Aza will enhance the antiproliferative and differentiation responses to $\mathrm{CQ} / \mathrm{HCQ}$ in breast cancer cells. 


\section{Model 2}

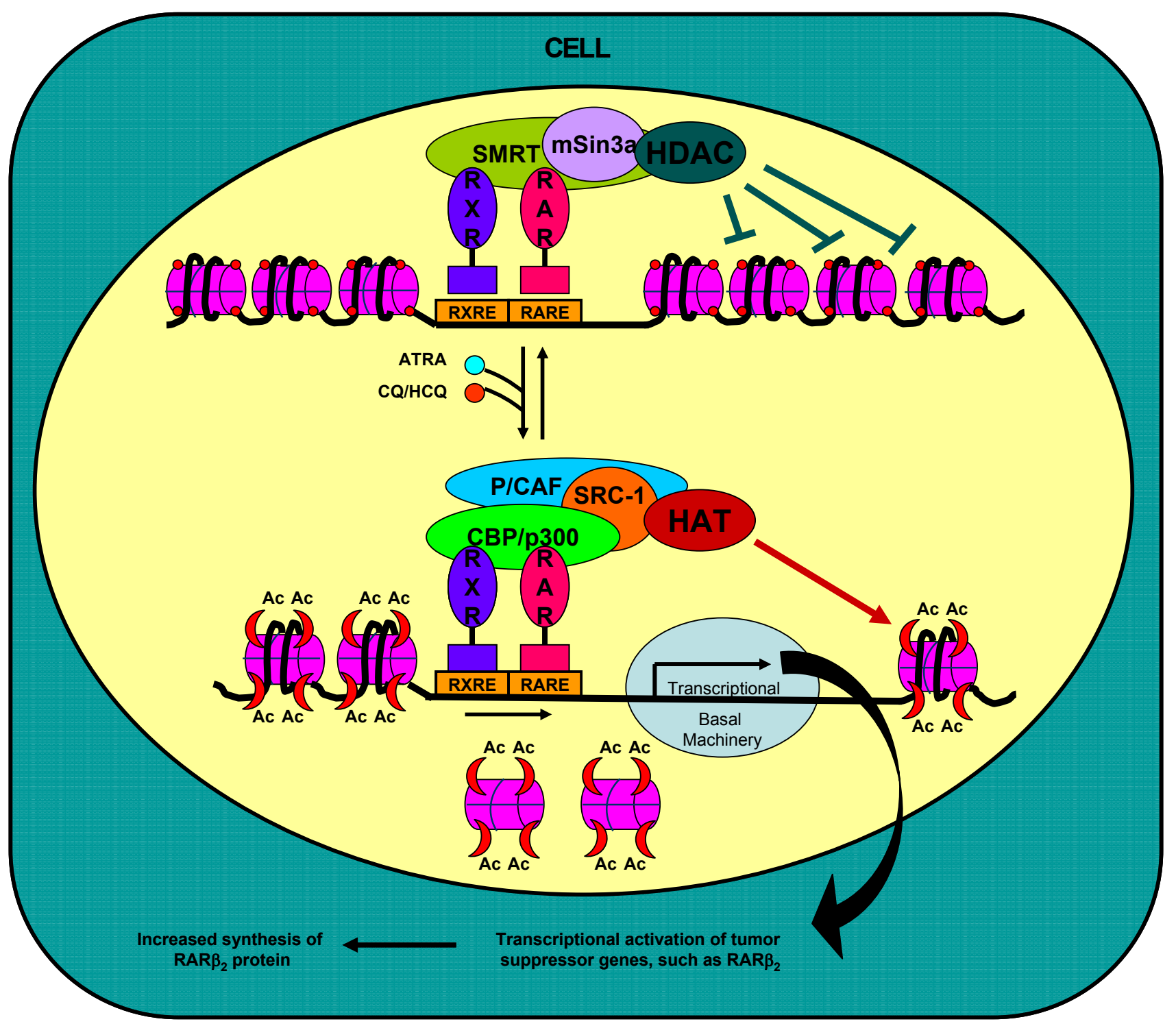

A model for gene activation by ATRA and CQ/HCQ. In the absence of ligand, the RXRRAR heterodimeric complex associates with the corepressor complex: silencing mediator of retinoid and thyroid hormone receptor (SMRT)-mSin3a-histone deacetylase (HDAC). HDAC maintains the tight association between deacetylated histones and chromatin, thereby, resulting in repressed gene transcription. The hypothesis is that ATRA, the ligand for the RXR-RAR heterodimeric complex, and CQ/HCQ treatment will reverse these effects via direct or indirect inhibition of HDAC. The corepressor complex will dissociate from the receptor complex with simultaneous recruitment of a coactivator complex: CREB-binding protein $(\mathrm{CBP}), \mathrm{CBP}$-associated factor $(\mathrm{p} / \mathrm{CAF})$, and steroid receptor coactivator-1 (SRC-1), all of which will activate histone acetyltransferase (HAT). Acetylated histones will generate a relaxed chromatin structure, allowing the transcriptional preinitiation complex to bind DNA and the ligand activated RXR-RAR heterodimeric complex to bind to its response elements (RXRE, RARE) in the promoter region of the target gene, such as RAR $\beta_{2}$, to activate transcription. 


\section{Model 3}

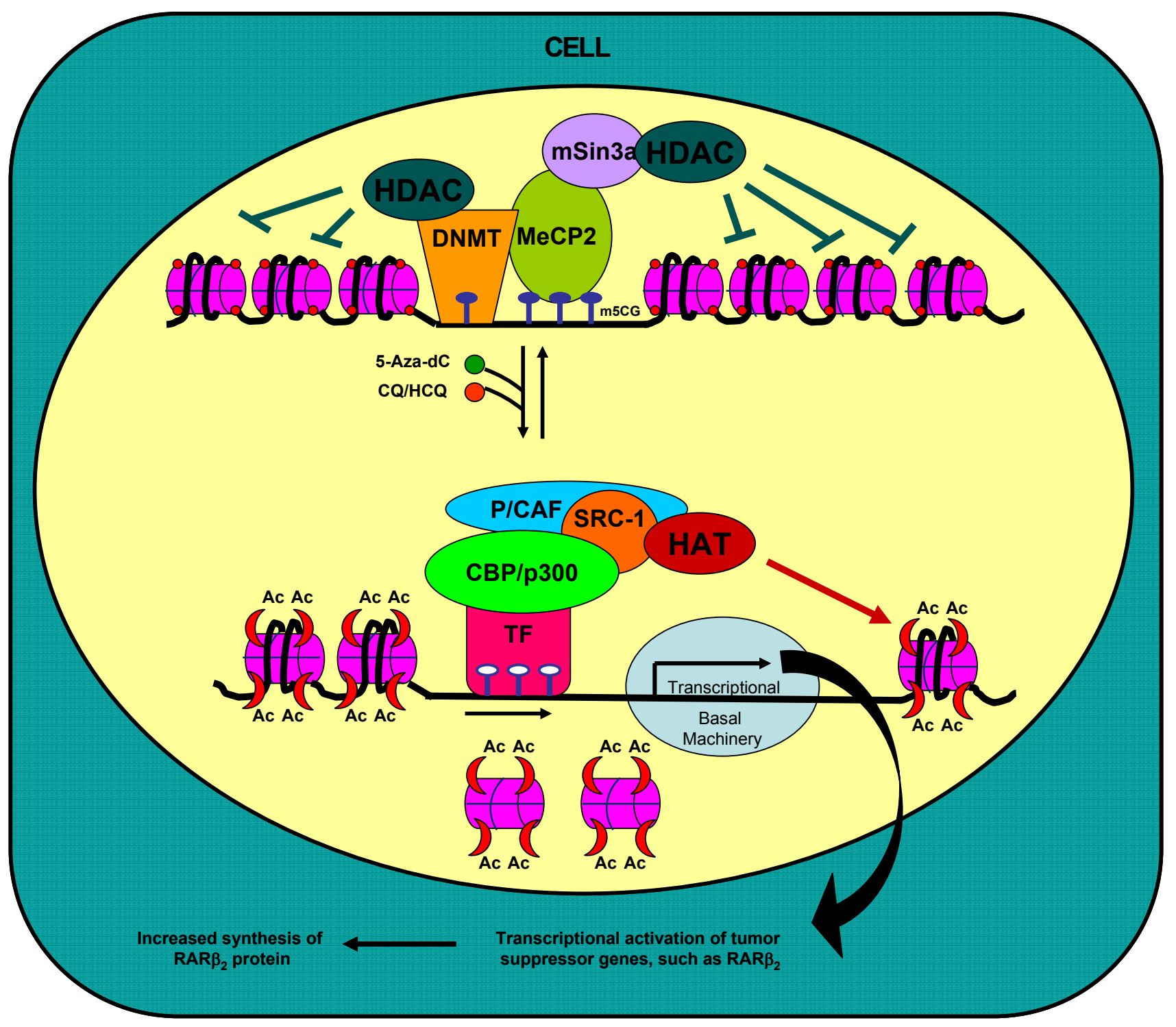

A model for gene activation by 5-Aza-dC and $\mathrm{CQ} / \mathrm{HCQ}$. Inhibitory transcription factors recruit DNA methyltransferase (DNMT), resulting in the methylation of CG dinucleotides; thereby, silencing the promoter of the target gene. Methyl-cytosine binding protein 2 (MeCP2) binds the methylated $\mathrm{CG}$ dinucleotides. MeCP2 interacts with the corepressor, mSin3, which binds to histone deacetylase (HDAC) or DNMT itself can recruit HDAC; thereby, perpetuating the inhibitory effect on transcription. The hypothesis is that 5-Aza-dC, a DNMT inhibitor, and CQ/HCQ treatment will reverse these effects via direct or indirect inhibition of HDAC. Activated transcription factors (TF) can then bind to unmethylated CG dinucleotides and recruit coactivators that form a complex with histone acetyltransferase (HAT). DNA hypomethylation will sensitize cells to histone hyperacetylation, resulting in transcriptional activation of tumor suppressor genes. 


\section{MATERIALS AND METHODS}




\section{Materials}

\subsection{Cells}

MCF-7 cells were provided by Dr. Marc Lippman (Department of Medicine, University of Michigan). MDA-MB-231 cells were provided by Dr. Mike Miller (Department of Biochemistry and Molecular Pharmacology, West Virginia University). MCF-10A cells were purchased from American Type Culture Collection (Manassas, VA). Clonal MCF-7 cells, C4 and C4-12-5, were provided by Dr. Wade Welshons (Department of Veterinary Biomedical Sciences, University of Missouri-Columbia).

\subsection{Drugs}

Chloroquine, quinidine, primaquine, quinoline, trichostatin A (TSA), all-trans retinoic acid (ATRA), 5-aza-2'-deoxycytidine (5-Aza-dC), as well as the solvent dimethyl sulfoxide (DMSO) were all purchased from Sigma Chemical Company (St. Louis, MO). Hydroxychloroquine sulfate was provided by Mylan Pharmaceuticals, Inc. (Morgantown, WV). The investigational quinoline compounds (National Service Center, NSC) were graciously provided by Dr. Robert Schultz (Developmental Therapeutics Program, National Cancer Institute, Bethesda, MD).

\subsection{Antibodies}

Acetylated histone $\mathrm{H} 3$ and $\mathrm{H} 4$ rabbit polyclonal antibodies were purchased from Upstate Biotechnology (Lake Placid, NY). E2F-1, c-myc, and $\beta$-catenin mouse monoclonal antibodies, as well as $\mathrm{RAR} \beta_{2}$ rabbit polyclonal antibody and horse radish peroxidase- 
conjugated anti-mouse IgG (SC \#2005) and anti-rabbit (SC \#2004) secondary antibodies were all purchased from Santa Cruz Biotechnology, Inc. (Santa Cruz, CA).

\section{Methods}

\subsection{Cell Culture}

Permanent cell lines derived from patients with breast carcinoma were used in these studies. MCF-7 (passage \#36-60) and MDA-MB-231 human mammary tumor cells were maintained in Dulbecco's Modified Eagle's medium (DMEM) (BioWhittaker, Walkersville, MD) supplemented with 10\% heat-inactivated fetal bovine serum (FBS) (Summit Biotechnology, Fort Collins, CO), and $0.04 \mathrm{mg} / \mathrm{ml}$ gentamicin in a $93 \%$ air $/ 7 \% \mathrm{CO} 2,37^{0} \mathrm{C}$, humidified incubator. Cells were passaged weekly when $70-80 \%$ confluent at 1:5 (MCF-7) or 1:10 ratios (MDA-MB-231). MCF-10A immortalized human mammary epithelial cells (passage \#1-15) were maintained in Mammary Epithelial Cell Growth Medium (MEGM) (Bio Whittaker) and passaged weekly at a 1:4 ratio. Cells were counted using a hemocytometer and viability was determined by trypan blue exclusion ( $0.02 \%$ trypan blue).

\subsection{Oil Red-O Assay}

MCF-7 and MDA-MB-231 cells were plated on $5 \times 5 \mathrm{~mm}^{2} 95 \%$ ethanol-washed glass

coverslips in $35 \mathrm{~mm}^{2}$ dishes at $2 \times 10^{5}$ and $1 \times 10^{5}$ cells per dish, respectively. Cells were fixed in $10 \%$ formaldehyde and $0.2 \%$ calcium acetate in phosphate buffered saline (PBS: $0.14 \mathrm{M} \mathrm{NaCl}, 2.7 \mathrm{mM} \mathrm{KCl}, 8.1 \mathrm{mM} \mathrm{NaHPO}{ }_{4} 7 \mathrm{H}_{2} \mathrm{O}, 1.5 \mathrm{mM} \mathrm{KH}_{2} \mathrm{PO}_{4}$ ) for 3 minutes and then transferred to an Oil Red-O (ORO) staining solution ( $0.5 \%$ Oil Red-O in 98\% isopropanol; diluted 6:4 in distilled water) for 10 minutes. Coverslips were washed briefly in tap water 
and then counterstained with Mayer's Hematoxylin solution (Fisher, Pittsburgh, PA) for 1 min at room temperature. After counterstaining, coverslips were rinsed again in tap water, washed in $0.4 \% \mathrm{NH}_{4} \mathrm{OH}$, and then mounted using 50\% glycerol (50:50 glycerol/water $(\mathrm{v} / \mathrm{v}))$. Lipid droplet accumulation in the cytoplasm was visualized by light microscopy (400x objective, Ortholux microscope, Ernst Leitz, Wetzlar, Germany). An ORO positive response is defined as $\geq 10 \%$ of cells containing at least 10 lipid droplets/cell. At least 300 cells were counted visually.

\subsection{Ki67 Immunohistochemical Assay}

MCF-7 $\left(2 \times 10^{5}\right)$ and MDA-MB-231 $\left(1 \times 10^{5}\right)$ cells were plated on $5 \times 5 \mathrm{~mm}^{2} 95 \%$ ethanolwashed glass coverslips in $35 \mathrm{~mm}^{2}$ dishes in DMEM/5\% FBS culture medium. Cells were fixed in 50\% acetone:50\% ethanol for 10 minutes at $4{ }^{0} \mathrm{C}$ and then washed with $0.15 \%$ bovine serum albumin (fraction V, A-9647, Sigma) in Dulbecco's phosphate-buffered saline (PBS: 0.14M NaCl, 2.7mM KCl, 8.1mM NaHPO $47 \mathrm{H}_{2} \mathrm{O}, 1.5 \mathrm{mM} \mathrm{KH}_{2} \mathrm{PO}_{4}, \mathrm{pH} 7.0$ ) (PBS-BSA). At room temperature, coverslips were incubated with peroxidase blocking solution $(0.3 \%$ hydrogen peroxide in methanol) for 10 minutes, rinsed with PBS-BSA, and incubated with $10 \%$ horse serum in PBS-BSA for 30 minutes. After incubation, primary antibody for Ki67 (MIB-1, cat \# M7240, Dako Corporation, Glostrup, Denmark) diluted 1:50 in PBS-BSA was added to the coverslips for 60 minutes, followed by a wash with PBSBSA, and incubation with secondary antibody (1:125 in PBS-BSA, biotinylated horse antimouse IgG, Vector Laboratories, Burlingame, CA) for 30 minutes. Coverslips were washed with PBS-BSA, incubated with avidin-biotin-peroxidase reagent (Vector Laboratories) for 30 minutes, and then washed again in PBS-BSA. The antigen-antibody complex was 
visualized using diaminobenzidine (Stable DAB, Research Genetics, Huntsville, AL), and counterstaining with Mayer's hematoxylin (Fisher Scientific, Pittsburgh, PA). Coverslips were subsequently dipped in $0.4 \% \mathrm{NH}_{4} \mathrm{OH}$ solution in tap water, dipped in $60 \%$ and $90 \%$ ethanol, respectively, and finally mounted using Permount (Fisher Scientific, Pittsburgh, PA). Ki67 negative cells were visualized by light microscopy (400x objective, Ortholux microscope, Ernst Leitz, Wetzlar, Germany). Cells were individually assigned with negative or positive staining, and the Ki67 negative percentage of the cell population was determined by visual counting. In each coverslip, at least 500 cells were counted. (KI67 Index $=\%$ KI67 negative cells in drug treatment / \% KI67 negative cells in control treatment)

\subsection{MTS (3-(4,5-dimethylthiazol-2-yl)-5-(3-carboxymethoxyphenyl)-2-(4-sulfophenyl)-} 2H-tetrazolium) Assay

Metabolism of MTS was used as an index of cell viability. MCF-7 and MDA-MB-231 cells were plated at $4.0 \times 10^{3}$ and $5.0 \times 10^{2}$ cells per well in 96-well plates, respectively, in $225 \mu 1$ of DMEM/5\% FBS. After 5 days of plating, fresh growth medium $(100 \mu \mathrm{l}$ DMEM $/ 5 \%$ FBS + $20 \mu \mathrm{l}$ CellTiter 96 AQueous one solution) (Promega, Madison, WI) was added. Reduction of MTS reagent to a colored formazan product was measured after a 2 hour incubation at $37^{\circ} \mathrm{C}$ by an increase in absorbance at $490 \mathrm{~nm}$ using a Spectra Max $340 \mathrm{pc}$ plate reader (Molecular Devices, Sunnyvale, CA). The MTS assay was linear under our assay conditions for 3 hours. Concentration-response data were fit by non-linear regression using Prism GraphPad software. 


\subsection{Clonogenic Survival}

MCF-7 and MDA-MB-231 cells were plated at $6 \times 10^{3}$ cells $/ 60 \mathrm{~mm}^{2}$ dish in $5 \mathrm{ml} \mathrm{DMEM} / 10 \%$ FBS and subjected to an undisturbed incubation period ( 7 or 5 days, respectively) in a $93 \%$ air $/ 7 \% \mathrm{CO} 2,37^{0} \mathrm{C}$, humidified incubator. To visualize colonies, dishes were stained with 3 $\mathrm{ml}$ of $0.5 \%$ crystal violet, $5 \%$ formalin, $50 \%$ ethanol, $0.85 \% \mathrm{NaCl}$ for 3 minutes, then rinsed with tap water. Colonies were scored using a Nikon Eclipse TS100 microscope at 20X magnification with $\geq 20 \mathrm{MCF}-7$ cells and $\geq 50 \mathrm{MDA}-\mathrm{MB}-231$ cells $=1$ colony. (Clonogenic fraction $=\#$ of colonies in control/ \# of cells plated). The clonogenic fraction of the control groups was set to 1 . Using Berenbaum's equation, the drug interactions were synergistic if: $\mathbf{A c} / \mathbf{A e}+\mathbf{B c} / \mathbf{B e}<\mathbf{1}$, where Ae and Be are the concentrations of the drugs alone, and Ac and $\mathrm{Bc}$ are the concentrations when used in combination. Therefore, the concentration of each drug in the combination that produces the specified effect is expressed as a fraction of the concentration that produces the same effect when the drug is used alone (Berenbaum, 1978; Berenbaum, 1989).

\subsection{Western Blotting}

MCF-7 (2x10 cells $/ 60 \mathrm{~mm}^{2}$ dish $)$ and MDA-MB-231 $\left(2 \times 10^{6}\right.$ cells $/ 60 \mathrm{~mm}^{2}$ dish $)$ were rinsed once with $4^{0} \mathrm{C}$ phosphate buffered saline (PBS: $0.14 \mathrm{M} \mathrm{NaCl}, 2.7 \mathrm{mM} \mathrm{KCl}, 8.1 \mathrm{mM}$ $\mathrm{NaHPO}_{4} 7 \mathrm{H}_{2} \mathrm{O}, 1.5 \mathrm{mM} \mathrm{KH}_{2} \mathrm{PO}_{4}, \mathrm{pH}$ 7.0). Total cellular proteins were collected by syringe in $200 \mu \mathrm{l}$ boiling lysis buffer (1\% SDS, $10 \mathrm{mM}$ Tris, $\mathrm{pH} 7.4)$ and chilled on ice. Proteins were boiled for 5 minutes and then centrifuged at $4^{0} \mathrm{C}, 14,000 \mathrm{rpm}$ in an Eppendorf centrifuge 5415 C (Brinkmann Instruments Inc., Westbury, NY). Protease inhibitors, 
aprotinin, leupeptin, and phenylmethyl sulfonyl fluoride at final concentrations of $1 \mathrm{mM}$, $1 \mathrm{mM}$, and $100 \mu \mathrm{M}$, respectively were added to the supernatant. Protein concentrations were determined using the BCA assay (Pierce, Rockford, IL). Following the BCA assay, a final concentration of $1 \mu \mathrm{M}$ dithiothreitol was added and protein samples were diluted in $1 \mathrm{X}$ sample buffer ( $0.32 \mathrm{M}$ Tris- $\mathrm{HCl}, 10 \%$ glycerol, $2 \% \mathrm{SDS}, 0.2 \%$ bromophenol blue, $2.5 \% 2$ mercaptoethanol, $\mathrm{pH} 6.8$ ) and then resolved on $10 \%$ or $15 \%$ acrylamide gels at $110 \mathrm{~V}$. Proteins were transferred to polyvinylidene difluoride membranes (Invitrogen) at $23 \mathrm{~V}$ for 3 hours. Membranes were blocked at $4^{0} \mathrm{C}$, overnight in 3\% non-fat dry milk/Tris buffered saline (TBS: $0.02 \mathrm{M}$ Tris, $\mathrm{pH} 7.5,0.5 \mathrm{M} \mathrm{NaCl}$ ). Membranes were then subjected to three 5 minute washes with western wash solution $(0.1 \%$ non-fat dry milk, $0.1 \%$ chick ovalbumin, $10 \%$ 10X PBS, 1\% FBS, $0.2 \%$ Tween 20 ) and incubated with acetylated histone H3 (1:5000), acetylated histone H4 (1:500), HDAC (1:5000), RARß2 (1:200) rabbit monoclonal antibodies, or c-myc (1:100) and E2F1 (1:100) mouse monoclonal antibodies in western wash solution for $3 \frac{1}{2}$ hours. Following primary antibody hybridizations, the membranes were again subjected to three 5 minute washes with western wash solution followed by one 5 minute wash with TBS. Membranes were hybridized with a 1:1000 dilution of anti-mouse or 1:5000 dilution of anti-rabbit horse radish peroxidase-conjugated secondary antibody in TBS for 45 minutes followed by three 10 minute washes in TBS. Signals were visualized by incubating the membrane with chemiluminescent peroxidase substrate for 7 minutes (Super Signal West Pico Chemiluminescent Substrate, Pierce, Rockford, IL) and exposing the membrane to film. Signals were quantitated by FluoroChem (Alpha Innotech, San Leandro, CA) spot densitometry using automatic background subtraction. 


\subsection{HDAC Fluorescent Activity Assay}

Drugs were screened for the ability to directly inhibit histone deacetylase (HDAC) activity using the HDAC Fluorescent Activity Assay (Drug Discovery kit cat \# AK-500, BIOMOL Research Laboratories, Inc. Plymouth Meeting, PA). This assay system measures histone deacetylase activity present in a commercial HeLa (human cervical cancer cell line) cell nuclear extract, which is rich in HDAC activity. Reactions were performed at room temperature in a 96-well microtiter plate. $10 \mu \mathrm{l}$ of drugs were added into appropriate wells to attain a final MTS $\mathrm{IC}_{50}$ concentration, followed by $15 \mu \mathrm{l}$ of diluted HeLa nuclear extract. HDAC reactions were initiated by adding $25 \mu$ of diluted substrate to each well and mixing thoroughly. The reactions were performed for 10 minutes after which $50 \mu l$ of the developer was added into each well of the microtiter plate to stop the HDAC reactions. The plate was subsequently incubated at room temperature for a final 10 minutes. HDAC fluorescent activity was measured using a microtiter-plate reading fluorimeter at a $360 \mathrm{~nm}$ excitation and 460nm emission wavelength (CytoFluor, Muti-well Plate Read Series 4000, PerSeptive Biosystems, Farmingham, MA) Reactions were linear for 30 minutes under these assay conditions.

\subsection{HAT Assay}

Drugs were screened using an indirect ELISA Assay (HAT Assay Kit, Upstate Biotechnology, Lake Placid, NY) for the detection of acetyl residues on biotinylated Histone H3 or Histone H4 substrate peptides. Acetylated Histone H3 or Histone H4 peptides were used as positive controls. Wells were pre-coated with the substrate peptides and then reactions were initiated by the addition of $75 \mathrm{ng}$ of recombinant PCAF, an active source of 
histone acetyltransferase enzyme, in the presence of $100 \mu \mathrm{M}$ Acetyl-CoA and HAT assay buffer. Wells were then incubated in the presence of anti-acetyl-Lysine (1:250) rabbit monoclonal antibody for 1.5 hours and anti-rabbit horse radish peroxidase-conjugated secondary antibody for 30 minutes in TBS containing $3 \%$ BSA, followed by tetramethylbenzidine substrate mixture for 10 minutes. Finally, the HRP reactions were stopped by the addition of $1 \mathrm{M}$ sulfuric acid. HAT activity was measured immediately using a Spectra Max 340pc plate reader (Molecular Devices, Sunnyvale, CA).

\subsection{Histone Extraction}

MCF-7 and MDA-MB-231 breast cancer cells were plated at a density of $1 \mathrm{X} 10^{7}$ cells/T-162 flask and $8 \times 10^{6}$ cells/T-162 flask, respectively, using DMEM supplemented with 5\% FBS and allowed to attach for 3 hours before ATRA or 5-Aza-dC treatment. After 24 hours of ATRA or 5-Aza-dC treatment, chloroquine, hydroxychloroquine, or TSA were added for the indicated time points. Cells were then harvested, rinsed with ice cold PBS, scraped into icecold lysis buffer $(10 \mathrm{mM}$ Tris- $\mathrm{HCl}, 50 \mathrm{mM}$ sodium bisulfite, $1 \%$ Triton-X-100 (v/v), 10mM $\mathrm{MgCl}_{2}, 8.6 \%$ sucrose, $\mathrm{pH}$ 6.5) and the nuclei released by Dounce homogenization. The nuclei were collected using Sorvall SS-34 rotor centrifugation and the histones were extracted from the crude nuclear pellets. The pellets were resuspended in sterile water and $0.4 \mathrm{~N} \mathrm{H}_{2} \mathrm{SO}_{4}$ and incubated at $4^{\circ} \mathrm{C}$ for 1 hour. Following centrifugation, the supernatant containing the extracted histones were mixed with acetone. The precipitate was obtained after an overnight incubation at $-20^{\circ} \mathrm{C}$. The acid-soluble histone fraction was dissolved in $60 \mu \mathrm{l}$ of $\mathrm{dH}_{2} \mathrm{O}$ and stored in $-70^{\circ} \mathrm{C}$. Histone protein concentrations were determined using the BCA assay (Pierce, Rockford, IL) and bovine serum albumin as a standard. Following 
the BCA assay, a final concentration of $1 \mu \mathrm{M}$ dithiothreitol was added to the protein samples. Equal amounts of histones were electrophoresed on SDS-15\% polyacrylamide gels. Molecular weights of the proteins were estimated based on the relative migration with colored molecular weight protein markers (RPN756, Amersham Pharmacia Biotech Inc.) Anti-acetylated histone $\mathrm{H} 3$ or $\mathrm{H} 4$ rabbit polyclonal antibodies were used for the detection of histone acetylation.

\subsection{Mass Spectrometry}

Equal amounts of acid extracted histone proteins from MCF-7 cells were electrophoresed on SDS-15\% polyacrylamide gels. Histones $\mathrm{H} 3$ and $\mathrm{H} 4$ were confirmed by Coomassie Blue staining ( $0.25 \%$ Coomassie R-250, $45 \%$ methanol, $45 \% \mathrm{dH} 2 \mathrm{O}$, and $0.1 \%$ acetic acid) for 2 hours and destaining (45\% methanol, $45 \% \mathrm{dH} 2 \mathrm{O}$, and $0.1 \%$ acetic acid) for 6 hours while changing the destain every 2 hours. Histones $\mathrm{H} 3$ and $\mathrm{H} 4$ bands were excised from the gel and placed into $0.65 \mathrm{~mL}$ low-binding microcentrifuge tubes. The bands were digested in-gel with $50 \mu \mathrm{l}$ of $100 \mathrm{ng}$ of the endoprotease trypsin in $25 \mathrm{mM} \mathrm{NH}_{4} \mathrm{HCO}_{3}$ overnight at $37^{\circ} \mathrm{C}$. Histones were separated using reverse-phase $\operatorname{HPLC}(A=0.1 \%$ Acetic Acid; $B=$ Acetonitrile with $0.1 \%$ Acetic Acid; Gradient was $5-50 \%$ B over 40 minutes, $50-90 \%$ B in one minute) C18 column [360 micron O.D. $x 75$ micron I.D. fused silica with 10 centimeters of 5 micron particle size; C18 packing material with 100 Angstrom pore size (from Phenomenex)]. Peptides were co-crystallized with equal volumes of matrix ( $\alpha$-cyano-cinnamic acid in $49.5 \%$ ethanol, $49.5 \%$ acetonitrile, and $0.1 \%$ trifluoroacetic acid). Samples were analyzed on a ThermoFinnigan LCQ Deca XP Plus ion trap with a flow rate of $300 \mathrm{~nL}$ per minute using a spray voltage of $1.5 \mathrm{kV}$ and a capillary temperature of $160^{\circ} \mathrm{C}$ to attain a positive 
ionization mode. Collision energy was set at $35 \%$ in order to perform a full scan MS followed by MS/MS of the three most abundant ions. MS/MS spectra were searched against International Protein Index (IPI) human database using Sequest Software. Acetylation sites were identified using a differential modification of 42 Daltons added to Lysine residues.

\subsection{Statistical Analysis}

Statistically significant differences $(\mathrm{P}<0.05)$ were determined using one-way analysis of variance (ANOVA). This was followed by the Dunnett's test for comparison of multiple groups with control or the Tukey-Kramer test for comparison between the different groups. 


\section{RESULTS}




\section{Chapter 1. Augmentation of the Differentiation Response using all-trans-Retinoic Acid in Combination with Chloroquine or Hydroxychloroquine}

\subsection{Selective Toxicity of Chloroquine and Hydroxychloroquine. Two cell lines}

commonly used as in vitro breast tumor cell models were chosen for experiments: MCF-7 (estrogen receptor, ER+) and MDA-MB-231 (ER-). Toxicity levels of both chloroquine and hydroxychloroquine were assayed in the MCF-7 and MDA-MB-231 breast cancer cell lines and compared to the MCF-10A normal mammary epithelial cells using the MTS assay. Mitochondrial metabolism of the substrate, MTS, is a measure of cell survival and can be applied extensively to many cell types. The assay measures dehydrogenase enzyme activity found in metabolically active cells. Cell survival was monitored using a 96-well plate format in which this tetrazolium substrate gets chemically reduced by cells into a colored formazan product that absorbs light at $490 \mathrm{~nm}$. Concentration-response analysis curves were generated to reveal significantly lower $\mathrm{IC}_{50}$ values in the breast cancer cell lines versus the normal human mammary epithelial cells, indicating that these quinolines were more toxic to the breast cancer cells (Table 1). The estimated growth inhibitory concentrations $\left(\mathrm{IC}_{25}\right.$ and $\left.\mathrm{IC}_{50}\right)$ for chloroquine and hydroxychloroquine were then used in subsequent experiments to measure cellular differentiation. 


\begin{tabular}{|c|c|c|c|c|c|c|}
\hline & \multicolumn{2}{|c|}{ MDA-MB-231 } & \multicolumn{2}{|c|}{ MCF-7 } & \multicolumn{2}{|c|}{ MCF-10A } \\
\hline & $I C_{25}(\mu \mathrm{M})$ & $1 \mathrm{C}_{50}(\mu \mathrm{M})$ & $\mathrm{IC}_{25}(\mu \mathrm{M})$ & $I C_{50}(\mu \mathrm{M})$ & $I C_{25}(\mu \mathrm{M})$ & $\mathrm{IC}_{50}(\mu \mathrm{M})$ \\
\hline Chloroquine & 7 & $\begin{array}{c}*, \#, \mathbf{h} \\
11 \pm 1.8\end{array}$ & 14 & $\begin{array}{c}*, \mathbf{h} \\
33 \pm 1.5\end{array}$ & 195 & $365 \pm 5.9$ \\
\hline Hydroxychloroquine & 12 & $\begin{array}{c}*, \# \\
28 \pm 1.4\end{array}$ & 30 & $\stackrel{*}{*}$ & 90 & $\begin{array}{c}\text { c } \\
218 \pm 3.1\end{array}$ \\
\hline
\end{tabular}

Table 1. Growth inhibitory concentrations for Chloroquine and Hydroxychloroquine. MDA-MB-231 and MCF-7 breast cancers cells, as well as MCF-10A normal breast cells, were plated at $5.0 \times 10^{2}, 4.0 \times 10^{3}$, and $2.0 \times 10^{3}$ cells per well in 96-well plates, respectively. $\mathrm{IC}_{25}$ and $\mathrm{IC}_{50}$ growth inhibitory concentrations represent the inhibition of mitochondrial metabolism of MTS following a 48hour exposure to each compound. Data are the mean \pm SEM of $\mathrm{IC}_{50}$ data in $\mathrm{n}=3$ independent experiments performed with 10 concentrations of each compound in triplicate. Statistically significant differences between cell lines and between chloroquine and hydroxychloroquine from the same cell lines are indicated:

* Statistically significant differences from MCF-10A cell line $(\mathrm{p}<0.05)$.

\# Statistically significant differences from MCF-7 cell line $(\mathrm{p}<0.05)$.

c Statistically significant differences from chloroquine in same cell line $(p<0.05)$.

h Statistically significant differences from hydroxychloroquine in same cell line $(\mathrm{p}<0.05)$. 


\subsection{Chloroquine and Hydroxychloroquine caused accumulation of cytoplasmic lipid}

droplets in MCF-7 and MDA-MB-231 breast cancer cells but not in MCF-10A normal mammary epithelial cells. Since chloroquine and hydroxychloroquine displayed selective toxicity in breast cancer cells, it was necessary to determine whether these antiproliferative agents were also capable of inducing cell differentiation. Oil Red-O is a lipophilic red dye used to stain neutral lipids in cells. Cytoplasmic lipid droplets are the immediate precursors of milk lipids and their formation is also one of the earliest phenotypes of differentiating mammary epithelial cells (Wu et al., 2000). As evidence of cellular differentiation, both chloroquine and hydroxychloroquine led to an enhanced accumulation of cytoplasmic lipid droplets detected by Oil Red-O staining in both the MCF-7 and MDA-MB-231 breast cancer cell lines after 48 hours of treatment, while neither compound caused elevated lipid droplet formation in MCF-10A normal human mammary epithelial cells (Figure 5). Direct visualization of the cellular morphology of the treated cells versus the control cells indicated that the breast cancer cells also displayed an enlarged cytoplasm, which is characteristic of cells that have undergone a more differentiated phenotype (Adan et al., 2003). 
Figure 5. Chloroquine and Hydroxychloroquine cause accumulation of cytoplasmic lipid droplets in MCF-7 and MDA-MB-231 breast cancer cells but not in MCF-10A normal mammary epithelial cells. MCF-7 and MDA-MB-231 (2x10 cells $/ 35 \mathrm{~mm}^{2}$ dish $)$ and MCF-10A $\left(1 \times 10^{5}\right.$ cells $/ 35 \mathrm{~mm}^{2}$ dish $)$ were grown on glass cover slips and treated with chloroquine or hydroxychloroquine at their respective $\mathrm{IC}_{25}$ values, or solvent (control, DMSO) for 48 hours. Cells were then stained with the Oil Red-O stain (red dots in the cytoplasm) and counterstained with the Mayer's hematoxylin stain (blue nuclei). 

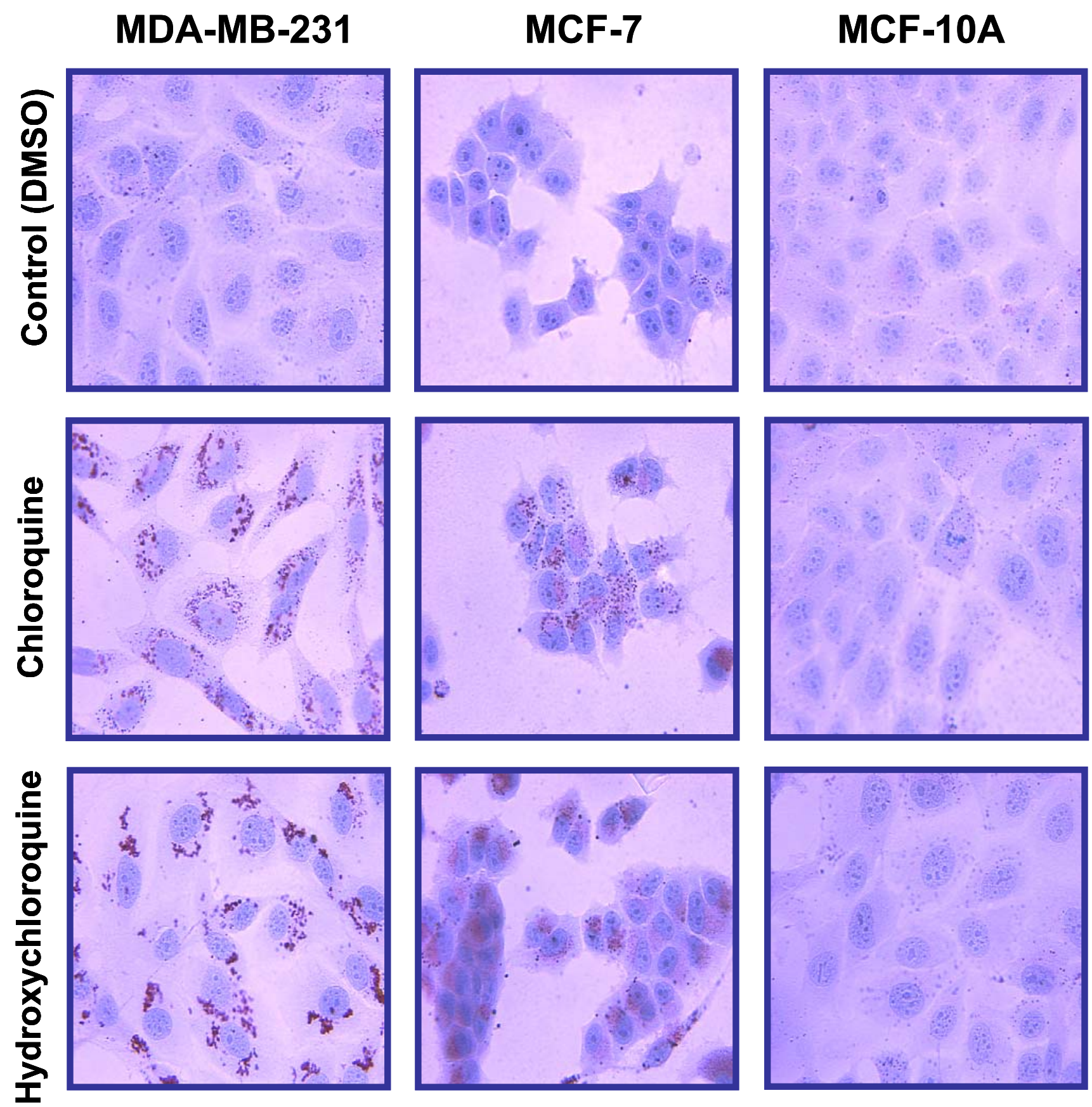


\subsection{Chloroquine increased the G0 cell population indicated by loss of Ki67 antigen in}

MCF-7 breast cancer cells. Primary markers for cellular differentiation include changes in cellular morphology as characterized by the accumulation of cytoplasmic lipid droplets (Figure 5) and exit from the cell cycle. This latter marker for cellular differentiation, cell cycle arrest in G1, can be measured by Ki67 histochemistry. Ki67 is a large nuclear protein expressed in all proliferating cells, in normal as well as in tumor cells. It is also expressed during all active phases of the cell cycle (G1, S, G2, and M-phases), but is absent in resting, or differentiating, cells (G0 phase) (Scholzen and Gerdes, 2000). Therefore, it makes it an excellent marker in determining the growth fraction of a given cell population and is used widely as a diagnostic tool in distinct neoplasms. For this reason, Ki67 protein was measured in MCF- 7 breast cancer cells after 48 hours of treatment with chloroquine (Figure 6). Compared to the control, which primarily has brown staining for the presence of Ki67 protein, the chloroquine-treated group contained many more blue cells indicative of cells that have arrested in G0. 


\section{MCF-7}

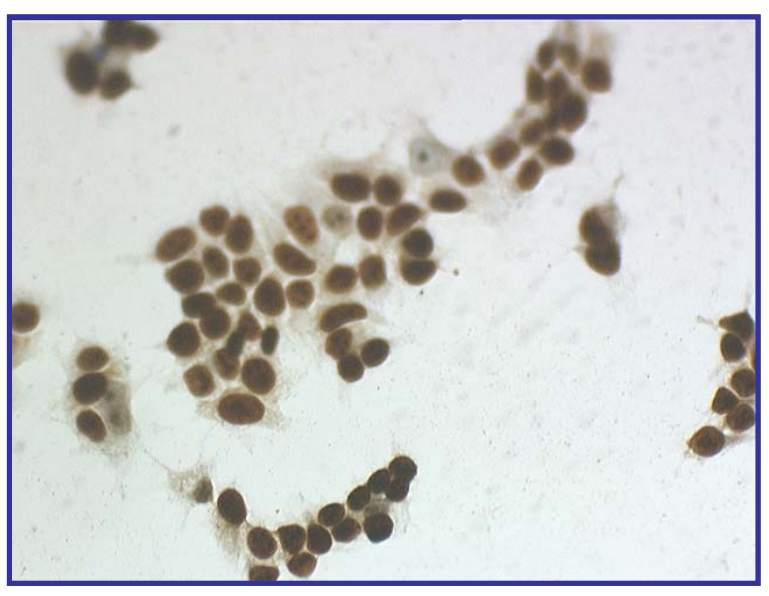

Control (DMSO)

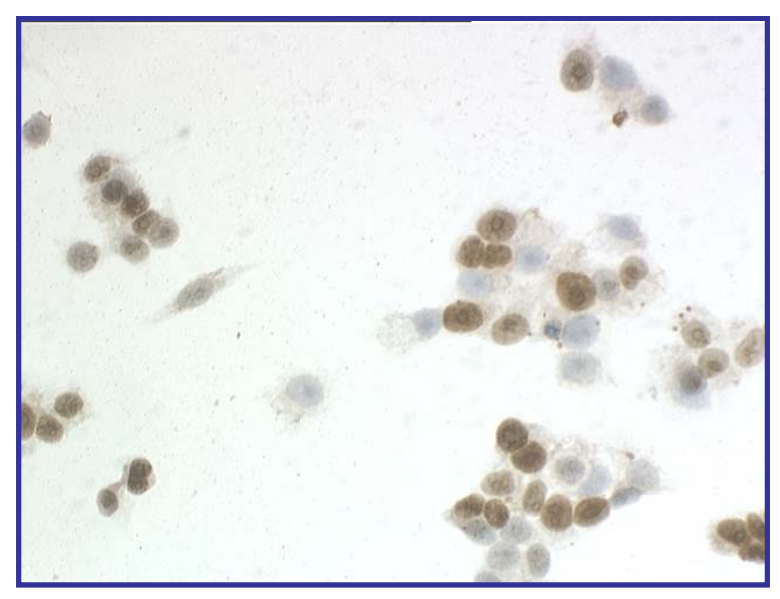

Chloroquine $\left(\mathrm{IC}_{50}\right)$

Figure 6. Ki67 immunohistochemical staining of MCF-7 cells. Control or $33 \mu \mathrm{M}$ chloroquine-treated MCF-7 cells were grown on glass cover slips for 48 hours and then assayed for Ki67 immunoreactivity. Brown staining indicates the presence of Ki67 protein and cycling cells. Blue staining is indicative of cells that have exited from the cell cycle into a Ki67 negative state. 


\subsection{MCF-7 and MDA-MB-231 cell survival in response to Chloroquine and ATRA. So}

far, both chloroquine and hydroxychloroquine showed to be promising candidates for breast cancer prevention and treatment. To identify whether the use of a drug combination modulating epigenetic events would lower the concentration of chloroquine or hydroxychloroquine needed to produce the differentiation response, all-trans-Retinoic acid (ATRA) was used in subsequent studies. First, as a screening assay, the mitochondrial metabolism of MTS was used as an index for cell survival. Cells were pretreated with ATRA 48 hours before treatment with chloroquine (Figure 7). Two different concentrations of chloroquine were used in this experiment: $\mathrm{MCF}-7 \mathrm{IC}_{50}$ value, $33 \mu \mathrm{M}$, and $10 \mu \mathrm{M}$, which is close to the estimated MDA-MB-231 $\mathrm{IC}_{50}$ value as well as the clinically safe concentration with no known side effects (Singhal et al., 1989). The combination of ATRA with chloroquine sensitized both the MCF-7 and MDA-MB-231 cell lines to growth inhibition. ATRA $(1 \mu \mathrm{M})$ significantly decreased cell survival in both cell lines when used in combination with the $\mathrm{IC}_{50}$ concentration and the clinically safe concentration of chloroquine. These results support the hypothesis that combination of ATRA with chloroquine would augment the antiproliferative effects of chloroquine. 


\section{Cell Survival}

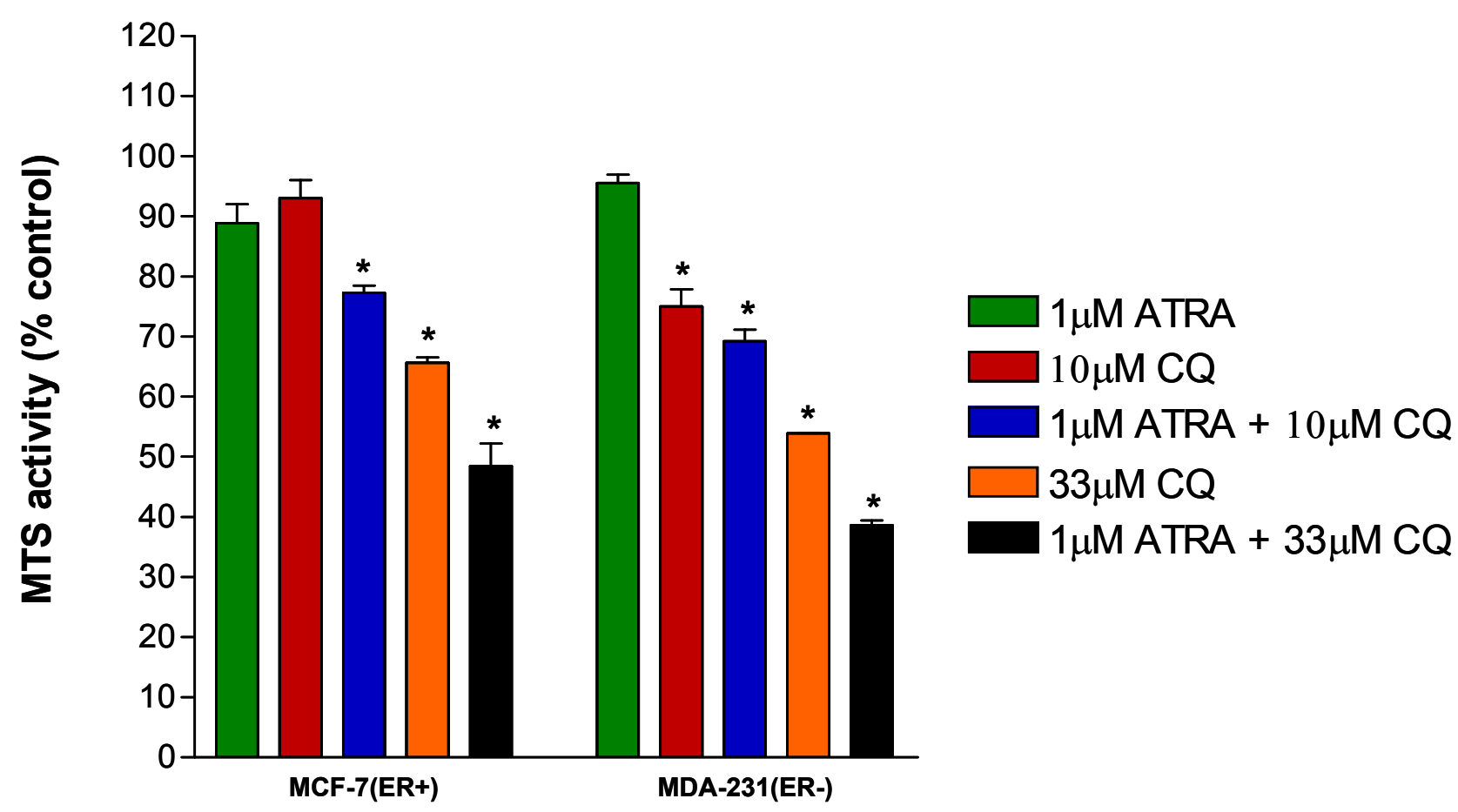

Figure 7. Inhibition of MCF-7 and MDA-MB-231 cell survival. On day 0, MCF-7 and MDA-MB-231 cells were plated at $4.0 \times 10^{3}$ and $5.0 \times 10^{2}$ cells per well in 96-well plates, respectively, in $225 \mu \mathrm{l}$ of DMEM/5\% FBS for 5 days. Cells were incubated and ATRA was added on day 1 , followed by the addition of chloroquine (CQ) on day 3 . On day 5,48 hours after CQ addition, mitochondrial metabolism of MTS was measured after a 2 hour incubation at $37^{\circ} \mathrm{C}$ by an increase in absorbance at 490nm using a Spectra Max 340pc plate reader (Molecular Devices, Sunnyvale, CA). Data are the mean \pm SEM of 3 independent experiments performed with 5 replicates per treatment. Statistically significant differences from the control are indicated $(* \mathrm{p}<0.05)$. 


\subsection{Combination of Chloroquine or Hydroxychloroquine with ATRA inhibited growth}

of human breast cancer cell lines. Although the MTS assay is a good screening tool for measuring antiproliferative activity, the effects of chloroquine or hydroxychloroquine with ATRA on cell growth and viability were also measured by visually counting the number of viable cells in MCF-7 and MDA-MB-231 breast cancer cell lines and comparing them to MCF-10A normal epithelial cells (Figure 8). MCF-7, MDA-MB-231, and MCF-10A were replica-plated in DMEM/5\% FBS (tumor cells) or MEGM (normal cells) medium and pretreated with $1 \mu \mathrm{M}$ ATRA 24 hours before treatment with $\mathrm{MCF}-7 \mathrm{IC}_{50}$ levels of chloroquine or hydroxychloroquine. Cell growth was counted using a hemocytometer and viability was assessed by trypan blue exclusion on the indicated days to generate growth curves. The data suggest that while chloroquine and hydroxychloroquine alone suppressed growth of the breast cancer cell lines, the combination of these antimalarials with ATRA lead to an enhanced growth inhibition. The combination of chloroquine with ATRA lead to 84\% (Day 5) and 78\% (Day 8) maximum reduction in growth of MDA-MB-231 and MCF-7 cells, respectively. The combination of hydroxychloroquine with Aza caused 89\% (Day 5) and $82 \%$ (Day 8) maximum reduction in growth of MDA-MB-231 and MCF-7 cells, respectively. Chloroquine and hydroxychloroquine also inhibited the growth of MCF-10A cells. Perhaps the antiproliferative effect seen in the MCF-10A cells may be due to the fact that they are immortalized. Nevertheless, ATRA did not sensitize the MCF-10A cells to further growth inhibition when combined with these antimalarials. These results support the hypothesis that combination of ATRA with chloroquine or hydroxychloroquine would augment the antiproliferative effects of the antitumor quinolines. ATRA in combination with hydroxychloroquine showed to have the most promise in decreasing cell survival. 
Figure 8. Inhibition of growth in MCF-7 and MDA-MB-231 breast cancer cells compared to MCF-10A normal mammary epithelial cells. MCF-7 or MDA-MB-231 cells $\left(2 \times 10^{5} / 35 \mathrm{~mm}^{2}\right.$ dish $)$, and MCF-10A normal cells $\left(1 \times 10^{5} / 35 \mathrm{~mm}^{2}\right.$ dish $)$ were plated and allowed to attach for 3 hours before ATRA addition (Day 0). On day 1, cells were incubated in the presence of solvent (control, DMSO) or MCF-7 $\mathrm{IC}_{50}$ levels of chloroquine (CQ) or hydroxychloroquine (HCQ). Cells were harvested and viable cells were counted on the indicated days to generate the growth curves. Data represent the mean of duplicate determinations in three independent experiments. 
Figure 8A. MDA-MB-231

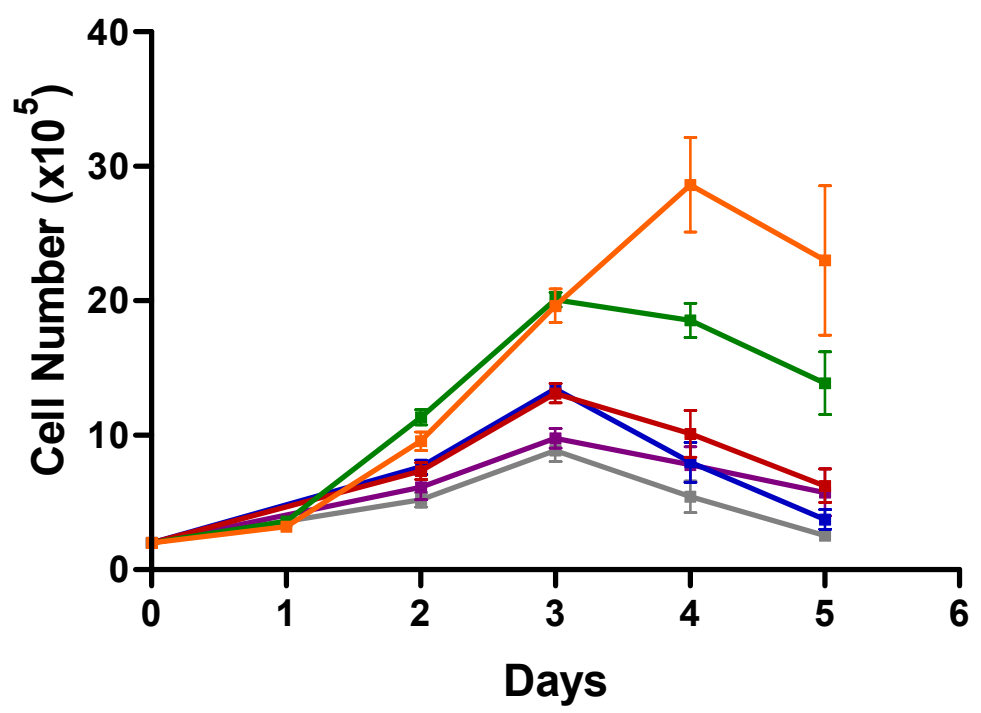

$=$ Control

$=1 \mu \mathrm{M}$ ATRA

$=33 \mu \mathrm{M} \mathrm{CQ}$

$-1 \mu \mathrm{M}$ ATRA $+33 \mu \mathrm{M} \mathrm{CQ}$

$=57 \mu \mathrm{M} \mathrm{HCQ}$

$-1 \mu \mathrm{M} \mathrm{ATRA}+57 \mu \mathrm{M} \mathrm{HCQ}$

Figure 8B. MCF-7

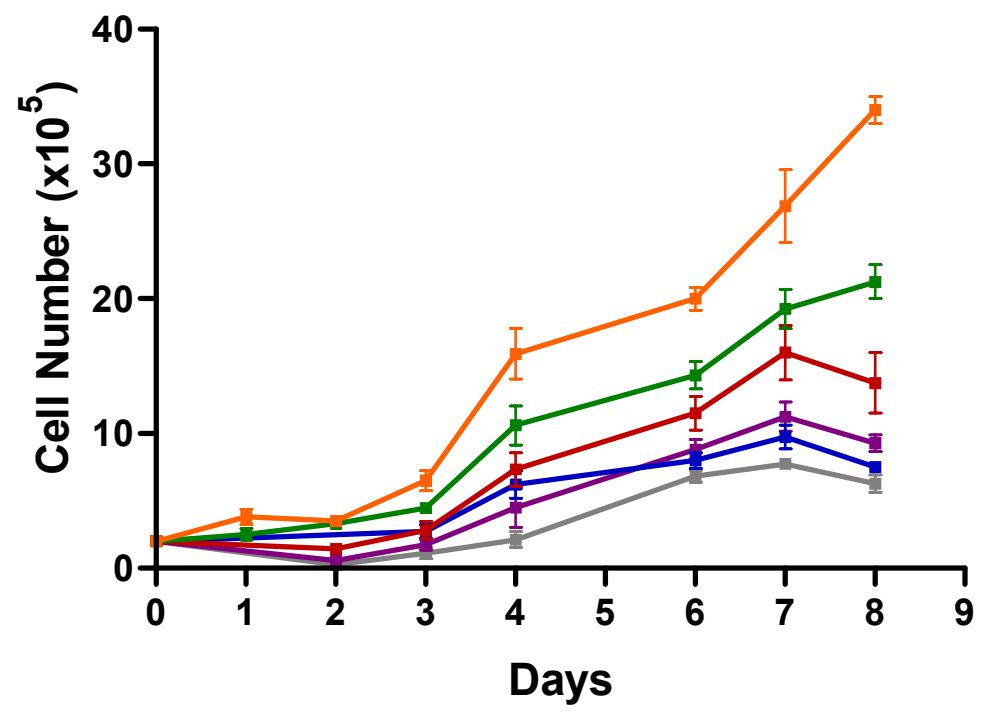

Figure 8C. MCF-10A

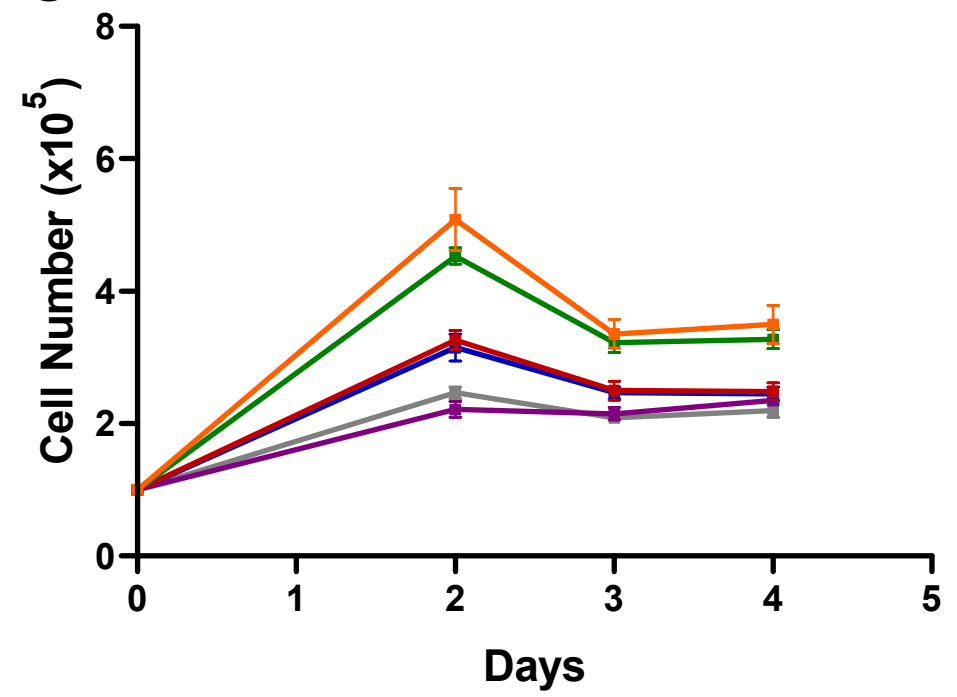




\subsection{Combination of Chloroquine or Hydroxychloroquine with ATRA reduced tumor}

cell clonogenic survival. The MTS assay offers broad applicability and is suitable as a screening assay for drug activity. Cell growth curves are more reliable and are a better in vitro tool for the depiction of cell survival. Nevertheless, it is pertinent to have a better appreciation for in vivo conditions in the breast cancer cell lines by using a much more sensitive assay for tumor cell survival. Since cancer cells undergo unlimited division and even a single cell may be the source of a repopulating clone, successful cancer therapy must assure the eradication of all clonogenic tumor cells from the organism. The clonogenic survival assay is a classical method for testing cellular sensitivity to different doses of cytotoxic and genotoxic anticancer agents in vitro. It is used to measure the fraction of cells able to form colonies. This assay seems to be one of the most sensitive tests for predicting the responsiveness of a tumor to clinical treatment (Kumala et al., 2003; West et al., 1997). Thus, this method was adopted to predict the effect of chloroquine and hydroxychloroquine upon pretreatment with ATRA on tumor cell survival (Figure 9 and Table 2).

MDA-MB-231 and MCF-7 cell clonogenic survival was assessed using crystal violet staining and visual colony inspection. Because MDA-MB-231 cells have a more rapid doubling time compared with MCF-7 cells, MDA-MB-231 cells were allowed a shorter five day incubation period prior to end point analysis. Overall, the clonogenic survival assays showed that the combination of ATRA with the quinolines significantly decreased breast cancer clonogenic survival more than either chloroquine or hydroxychloroquine alone. Table 2 shows that clonogenic survival of MDA-MB-231 cells exposed to combination of $1 \mu \mathrm{M}$ ATRA with chloroquine for seven days, was reduced by $82 \%$ compared to control cells exposed to solvent alone, whereas combination of $1 \mu \mathrm{M}$ ATRA with 
hydroxychloroquine was reduced by $92 \%$. In MCF-7 cells, clonogenic survival was reduced by $76 \%$ upon combination treatment with ATRA and chloroquine and by $83 \%$ with ATRA and hydroxychloroquine.

The results were recalculated using the method of Berenbaum (Berenbaum, 1978; Berenbaum, 1989) to test for synergy. The interaction of ATRA with chloroquine or hydroxychloroquine showed to be synergistic in both the MDA-MB-231 and MCF-7 breast cancer cell lines. These results support the hypothesis that combination of ATRA with chloroquine or hydroxychloroquine would augment the antiproliferative effects of the antitumor quinolines. Once again, ATRA in combination with hydroxychloroquine showed to have the most promise in decreasing tumor cell survival. Clonogenic survival was also assayed in the MCF-10A normal epithelial cells ( $\mathrm{n}=2)$; however, these cells did not form discrete colonies $(\geq 20$ cells $=1$ colony $)$ with or without treatment. 


\section{Control}

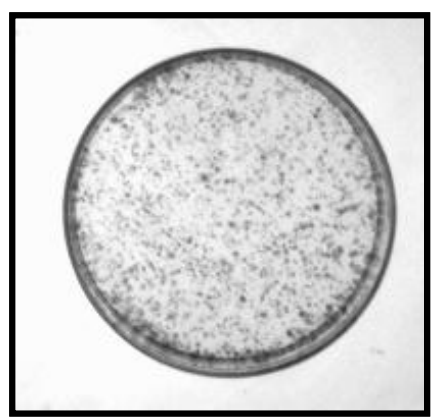

ATRA

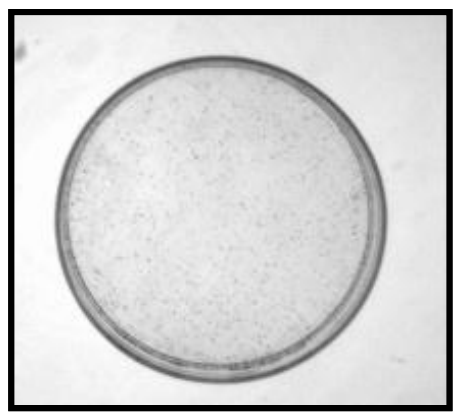

CQ

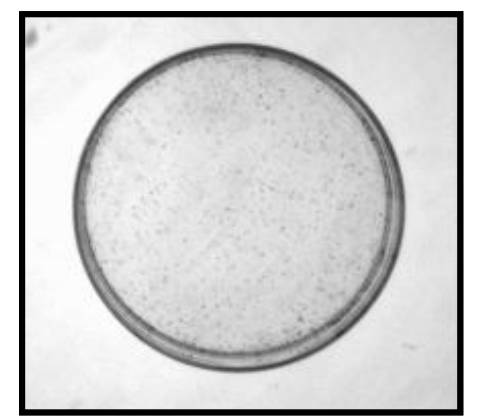

ATRA + CQ

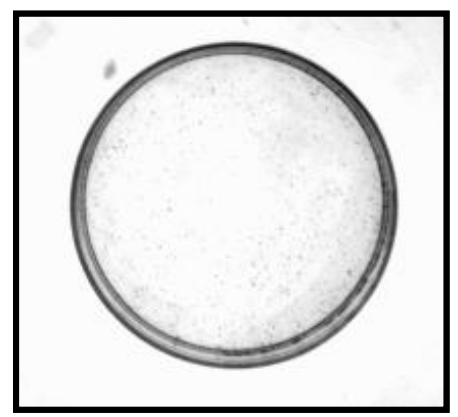

Figure 9. MCF-7 cell clonogenic survival. Cells were pretreated with either solvent (control, DMSO) or chloroquine $(\mathrm{CQ}, 33 \mu \mathrm{M}) \pm$ ATRA $(1 \mu \mathrm{M})$ as performed for the growth curves. $6 \times 10^{3}$ pretreated cells were plated in $60 \mathrm{~mm}^{2}$ dish and subjected to 7 days of an undisturbed incubation period. Colonies were visualized by staining the dishes with $3 \mathrm{ml}$ of $0.5 \%$ crystal violet, $5 \%$ formalin, $50 \%$ ethanol, $0.85 \% \mathrm{NaCl}$ for 3 minutes, then rinsing with tap water. 


\begin{tabular}{|c|c|c|}
\hline & $\begin{array}{l}\text { MDA-MB-231 } \\
\text { Clonogenic Fraction }\end{array}$ & $\begin{array}{c}\text { MCF-7 } \\
\text { Clonogenic Fraction }\end{array}$ \\
\hline ATRA & $0.473 *$ & $0.452 *$ \\
\hline $\mathbf{C Q}$ & $0.310^{*}, \mathbf{a}$ & $0.554 *$ \\
\hline HCQ & $0.197^{*}, \mathbf{a , b}$ & $0.325^{*, \mathbf{a}, \mathbf{b}}$ \\
\hline ATRA + CQ & $0.180^{*, \mathbf{a}, \mathbf{b}}$ & $0.239^{*}, \mathbf{a , b}$ \\
\hline ATRA + HCQ & $0.084^{*}, \mathbf{a , b , c , c , d}$ & $0.170^{*}, \mathbf{a , b , c}$ \\
\hline
\end{tabular}

Table 2. Tumor cell clonogenic survival using ATRA. MDA-MB- 231 or MCF-7 cells $\left(2 \times 10^{5} / 35 \mathrm{~mm}^{2}\right.$ dish) were plated and allowed to attach for 3 hours before addition of solvent (control, DMSO) or MCF-7 $\mathrm{IC}_{50}$ levels of chloroquine $(\mathrm{CQ}, 33 \mu \mathrm{M})$ or hydroxychloroquine $(\mathrm{HCQ}, 57 \mu \mathrm{M}) \pm$ ATRA $(1 \mu \mathrm{M})$. MDA-MB-231 and MCF-7 cells were harvested on days 3 and 4 , respectively, and replated at a cloning cell density of $6 \times 10^{3}$ cells $/ 60 \mathrm{~mm}^{2}$ dishes in $5 \mathrm{ml} \mathrm{DMEM} / 10 \% \mathrm{FBS}$ and subjected to an undisturbed incubation period (5 or 7 days, respectively). Colonies were visualized by staining the dishes with $3 \mathrm{ml}$ of $0.5 \%$ crystal violet, $5 \%$ formalin, $50 \%$ ethanol, $0.85 \% \mathrm{NaCl}$ for 3 minutes, then rinsing with tap water. Colonies were scored using a Nikon Eclipse TS100 microscope at 20X magnification with $\geq 20$ MCF-7 cells and $\geq 50$ MDA-MB-231 cells $=1$ colony. The data are represented as clonogenic fractions, where the clonogenic fraction of the control groups was set to equal 1 . Data are the mean of 3 independent experiments performed in duplicates.

* Statistically significant differences from the control $(\mathrm{p}<0.05)$.

a Statistically significant differences from ATRA alone $(p<0.05)$.

b Statistically significant differences from CQ alone $(\mathrm{p}<0.05)$.

c Statistically significant differences from HCQ alone $(\mathrm{p}<0.05)$.

d Statistically significant differences from ATRA $+C Q(p<0.05)$. 


\subsection{Combination of Chloroquine or Hydroxychloroquine with ATRA caused}

enhanced accumulation of cytoplasmic lipid droplets in MCF-7 and MDA-MB-231

breast cancer cells. The data presented above showed that the combination of chloroquine or hydroxychloroquine with ATRA reduced cell and clonogenic survival in human breast cancer cells more than either quinoline alone. Therefore, it was necessary to determine whether ATRA in combination with chloroquine or hydroxychloroquine was also capable of augmenting the differentiation response. As evidence of cellular differentiation, pretreatment with $1 \mu \mathrm{M}$ ATRA led to an enhanced accumulation of cytoplasmic lipid droplets detected by Oil Red-O (ORO) staining in both the MCF-7 and MDA-MB-231 breast cancer cell lines after 24 hours of quinoline treatment (Figure 10). The differentiation response was greater than either chloroquine or hydroxychloroquine alone at both the $\mathrm{IC}_{25}$ and $\mathrm{IC}_{50}$ levels and was significantly greater than the control (DMSO).

MDA-MB-231 cells treated with chloroquine alone at $\mathrm{IC}_{25}$ and $\mathrm{IC}_{50}$ showed a $74 \%$ and $88 \%$ increase in lipid droplets, respectively, compared with $89 \%$ and $95 \%$ increase in cells pretreated with ATRA. Hydroxychloroquine alone showed a $76 \%$ and $83 \%$ increase in lipid droplets at its $\mathrm{MDA}-\mathrm{MB}-231 \mathrm{IC}_{25}$ and $\mathrm{IC}_{50}$ values, respectively, compared with $92 \%$ and $93 \%$ increase in cells pretreated with ATRA.

MCF-7 cells treated with chloroquine alone at $\mathrm{IC}_{25}$ and $\mathrm{IC}_{50}$ showed a $74 \%$ and $85 \%$ increase in lipid droplets, respectively, compared with $93 \%$ and $92 \%$ increase in cells pretreated with ATRA, while hydroxychloroquine alone showed a $72 \%$ and $79 \%$ increase in lipid droplets at $\mathrm{IC}_{25}$ and $\mathrm{IC}_{50}$ values, respectively, compared with $88 \%$ and $90 \%$ increase in cells pretreated with ATRA. 
In summary, these results support the hypothesis that the differentiation response by chloroquine or hydroxychloroquine, would be augmented when combined with $1 \mu \mathrm{M}$ ATRA. Pretreatment of MDA-MB-231 or MCF-7 breast cancer cells with ATRA in combination with treatment with the $\mathrm{IC}_{25}$ values of either chloroquine or hydroxychloroquine, showed a greater percentage of ORO positive cells than either of the quinoline alone at their respective $\mathrm{IC}_{50}$ values. Therefore, combination therapy seems to lower the concentration of chloroquine or hydroxychloroquine needed to achieve the same differentiation response. ATRA in combination with either chloroquine or hydroxychloroquine showed to have promise in enhancing the differention response. 
Figure 10. Oil Red-O (ORO) Histochemistry: Enhanced accumulation of cytoplasmic lipid droplets in MCF-7 and MDA-MB-231 breast cancer cells using Chloroquine or Hydroxychloroquine in combination with ATRA. A.) MCF-7 $\left(2 \times 10^{5}\right.$ cells $/ 35 \mathrm{~mm}^{2}$ dish) were plated and treated with $1 \mu \mathrm{M}$ ATRA. 24 hours later, cells were treated with solvent (control, DMSO) or chloroquine $\left(\mathrm{CQ}, \mathrm{IC}_{25}=14 \mu \mathrm{M}\right)$ for another 24 hours and then stained with the ORO stain (red dots in the cytoplasm) and counterstained with the Mayer's hematoxylin stain (blue nuclei). B.) MCF-7 and MDA-MB-231 cells were plated on 5x5 $\mathrm{mm}^{2} 95 \%$ ethanol-washed glass coverslips in $35 \mathrm{~mm}^{2}$ dishes at $2 \times 10^{5}$ and $1 \times 10^{5}$ cells per dish, respectively. Cells were pretreated with $1 \mu \mathrm{M}$ ATRA for 24 hours and then treated with chloroquine (CQ) or hydroxychloroquine (HCQ) at their respective $\mathrm{IC}_{50}$ and $\mathrm{IC}_{25}$ values for another 24 hours. The ORO assay was performed and lipid droplet accumulation in the cytoplasm was visualized by light microscopy. At least 300 cells were counted visually. Data represents the mean of 3 independent experiments (+/- SEM). Statistically significant differences from the control are indicated $(* \mathrm{p}<0.05)$. 
A.

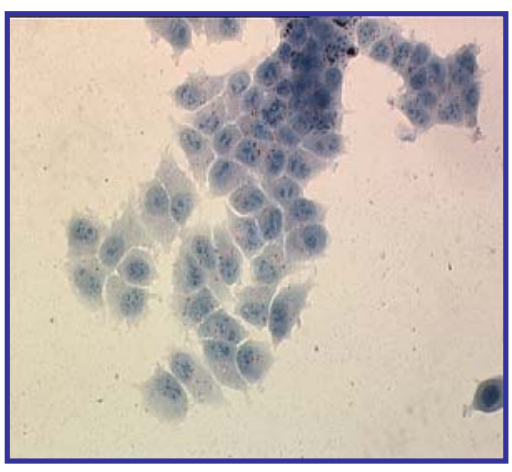

Control
MCF-7
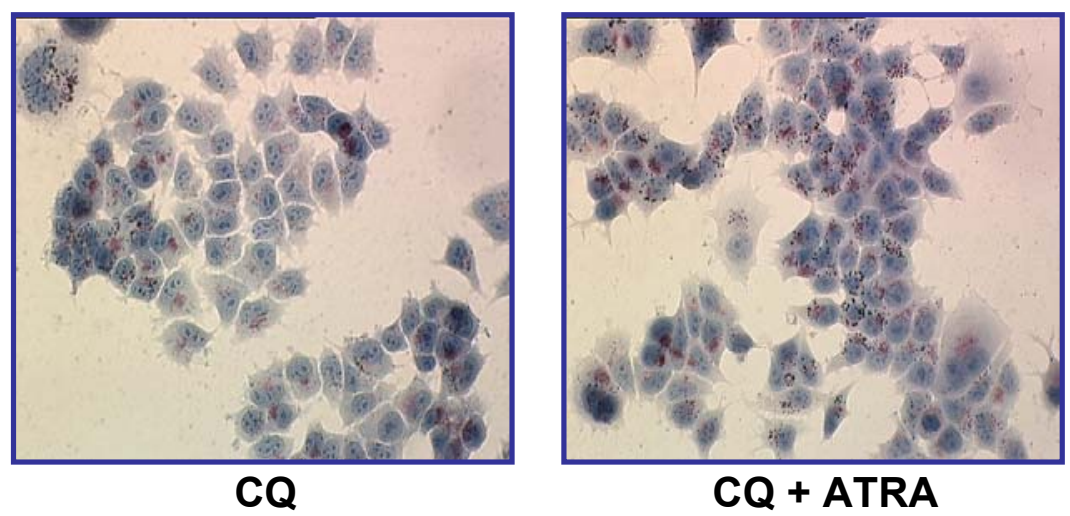

B.

MCF-7

MDA-MB-231
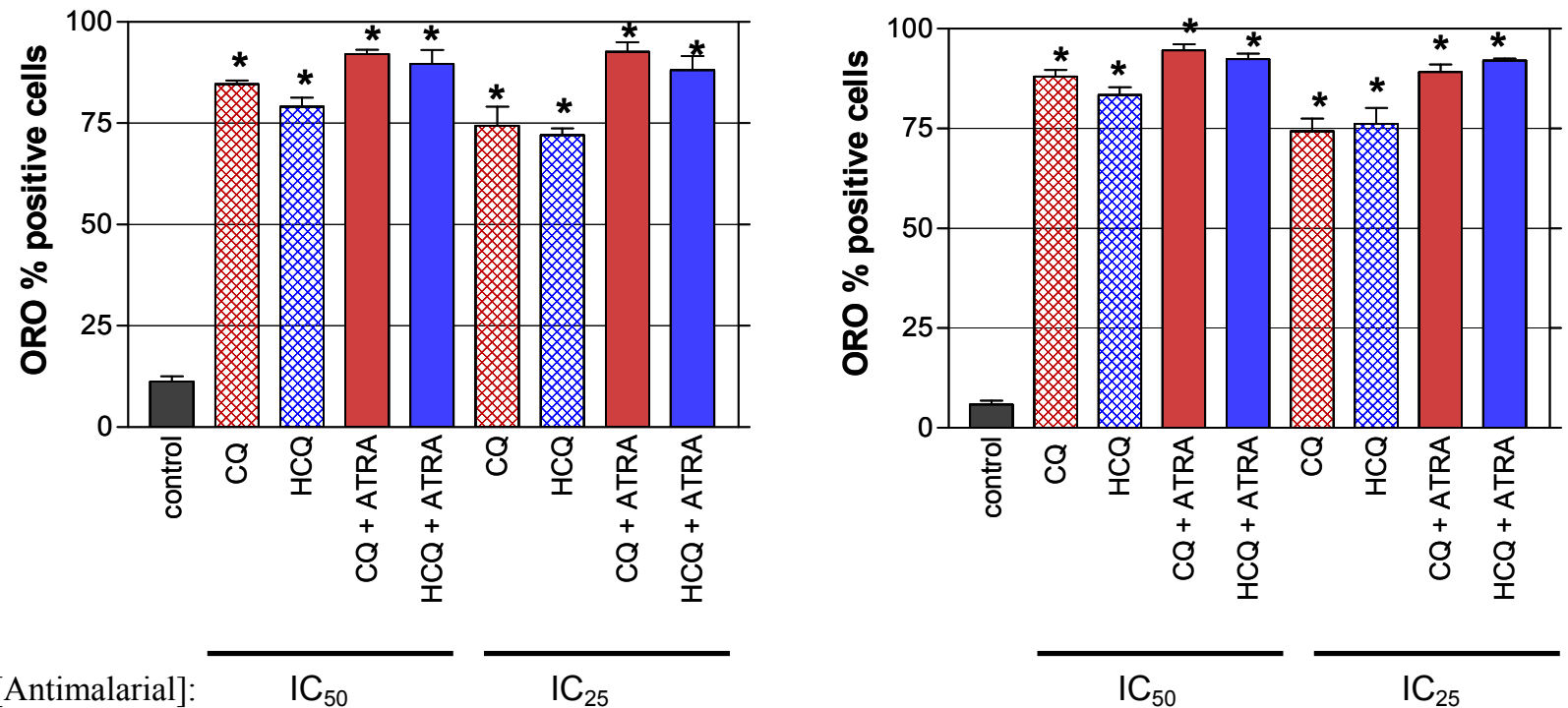


\subsection{Combination of Chloroquine or Hydroxychloroquine with ATRA elevated the}

Ki67 index. Since combination treatment of chloroquine or hydroxychloroquine with ATRA enhanced the accumulation of cytoplasmic lipid droplets in both the MCF-7 and MDA-MB-231 breast cancer cell lines, it was necessary to see whether it also increased the G0 cell population as measured by loss of Ki67 antigen in order to further validate the differentiation response. Ki67 protein was measured in both MCF-7 and MDA-MB-231 breast cancer cells after 24 hours of treatment with chloroquine or hydroxychloroquine at $\mathrm{IC}_{25}$ and $\mathrm{IC}_{50}$ MTS values \pm 24 hour pretreatment with $1 \mu \mathrm{M}$ ATRA (Figure 11 ). The results showed that the combination of ATRA with either chloroquine or hydroxychloroquine elevated the Ki67 index in both the MCF-7 and MDA-MB-231 breast cancer cells. The increased Ki67 index is indicative of a greater percentage of cells that have exited from the cell cycle into a differentiated Ki67 negative state. The differentiation response was greater than either chloroquine or hydroxychloroquine alone at both the $\mathrm{IC}_{25}$ and $\mathrm{IC}_{50}$ levels.

MDA-MB-231 cells treated with chloroquine alone at $\mathrm{IC}_{25}$ and $\mathrm{IC}_{50}$ showed a $\mathrm{Ki67}$ index of 6.1 and 9.7, respectively, compared with an increased Ki67 index of 11.7 and 14.4 in cells pretreated with ATRA. Hydroxychloroquine alone showed a Ki67 index of 7.6 and 9.2 at its MDA-MB-231 $\mathrm{IC}_{25}$ and $\mathrm{IC}_{50}$ values, respectively, compared with an increased Ki67 index of 12.2 and 14.0 in cells pretreated with ATRA.

MCF-7 cells treated with chloroquine alone at $\mathrm{IC}_{25}$ and $\mathrm{IC}_{50}$ showed a $\mathrm{Ki67}$ index of 6.9 and 8.3, respectively, compared with an increased Ki67 index of 8.9 and 9.6 in cells pretreated with ATRA, while hydroxychloroquine alone showed a Ki67 index of 5.8 and 6.6 at $\mathrm{IC}_{25}$ and $\mathrm{IC}_{50}$ values, respectively, compared with an increased $\mathrm{Ki} 67$ index of 6.6 and 8.2 in cells pretreated with ATRA. 
These experiments provide evidence that the differentiation response measured by increase in the $\mathrm{G} 0$ cell population can be augmented with pretreatment with $1 \mu \mathrm{M}$ ATRA more than either chloroquine or hydroxychloroquine alone. Although the antitumor antimalarials alone displayed an enhanced Ki67 index, pretreatment with ATRA lowered the concentration of chloroquine or hydroxychloroquine needed to achieve the same response. Pretreatment of MDA-MB-231 or MCF-7 breast cancer cells with ATRA in combination with treatment with the $\mathrm{IC}_{25}$ values of either chloroquine or hydroxychloroquine showed a modest increase in Ki67 index than either of the quinolines alone at their $\mathrm{IC}_{50}$ values. 
Figure 11. KI67 Histochemistry: Increase in G0 cell population in both MCF-7 and MDA-MB-231 breast cancer cells treated with Chloroquine or Hydroxychloroquine in combination with ATRA. A.) $\mathrm{MCF}-7\left(2 \times 10^{5}\right.$ cells $/ 35 \mathrm{~mm}^{2}$ dish $)$ were pretreated with $1 \mu \mathrm{M}$ ATRA 24 hours prior to addition of solvent (control, DMSO) or chloroquine (CQ, $\left.\mathrm{IC}_{25}=14 \mu \mathrm{M}\right) .24$ hours later, Ki67 immunoreactivity was assayed. Brown staining indicates the presence of Ki67 protein and cycling cells. Blue staining indicates Ki67 negative or G0 cells. B.) MCF-7 and MDA-MB-231 cells were plated on $5 \times 5 \mathrm{~mm}^{2} 95 \%$ ethanol-washed glass coverslips in $35 \mathrm{~mm}^{2}$ dishes at $2 \times 10^{5}$ and $1 \times 10^{5}$ cells per dish, respectively. Cells were pretreated with $1 \mu \mathrm{M}$ ATRA 24 hours prior to chloroquine (CQ) or hydroxychloroquine (HCQ) addition at their respective $\mathrm{IC}_{50}$ and $\mathrm{IC}_{25}$ values. $\mathrm{KI} 67$ immunoreactivity was assayed 24 hours post-antimalarial treatment. KI67 negative percentage of the cell population was determined by visual counting. At least 500 cells were counted. (KI67 Index $=\%$ KI67 negative cells in drug treatment $/ \%$ KI67 negative cells in control treatment). Data represents the mean of 3 independent experiments (+/- SEM). Statistically significant differences from the control are indicated $(* \mathrm{p}<0.05)$. 
A.

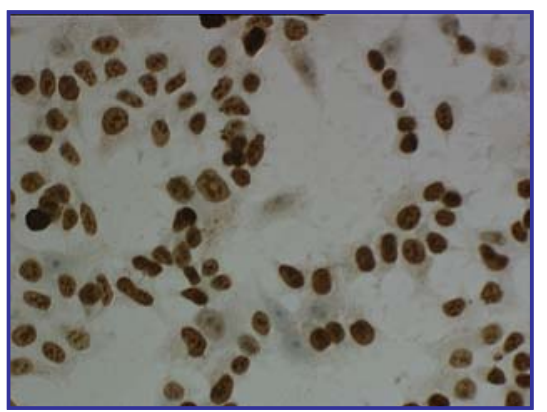

Control

MCF-7

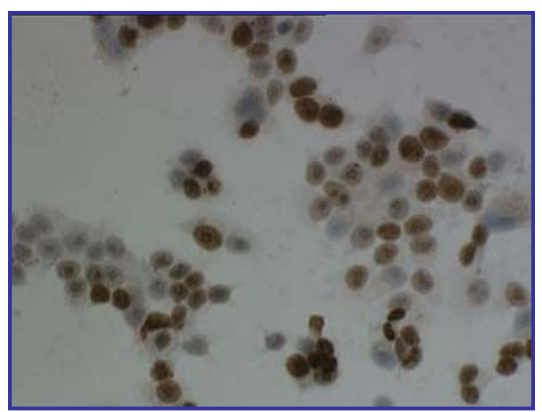

CQ

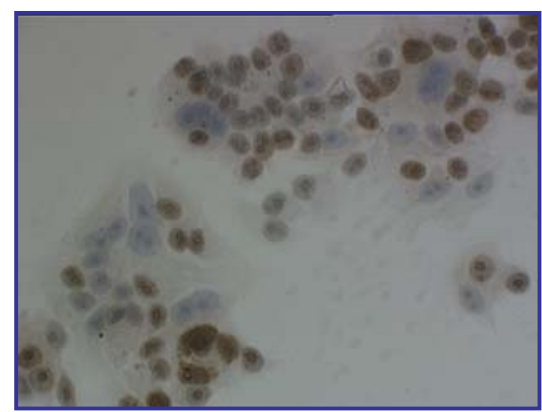

CQ + ATRA

B.

MCF-7

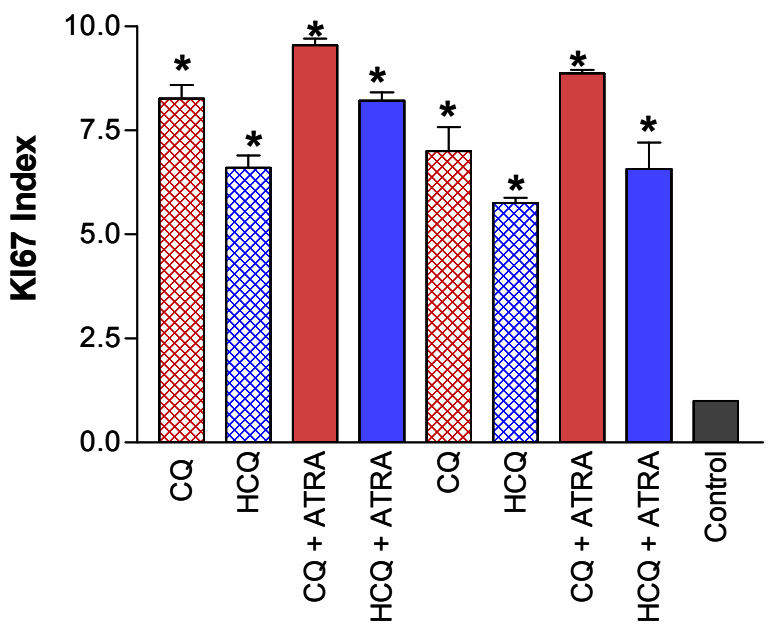

[Antimalarial]: $\quad \mathrm{IC}_{50}$

$\mathrm{IC}_{25}$

MDA-MB-231

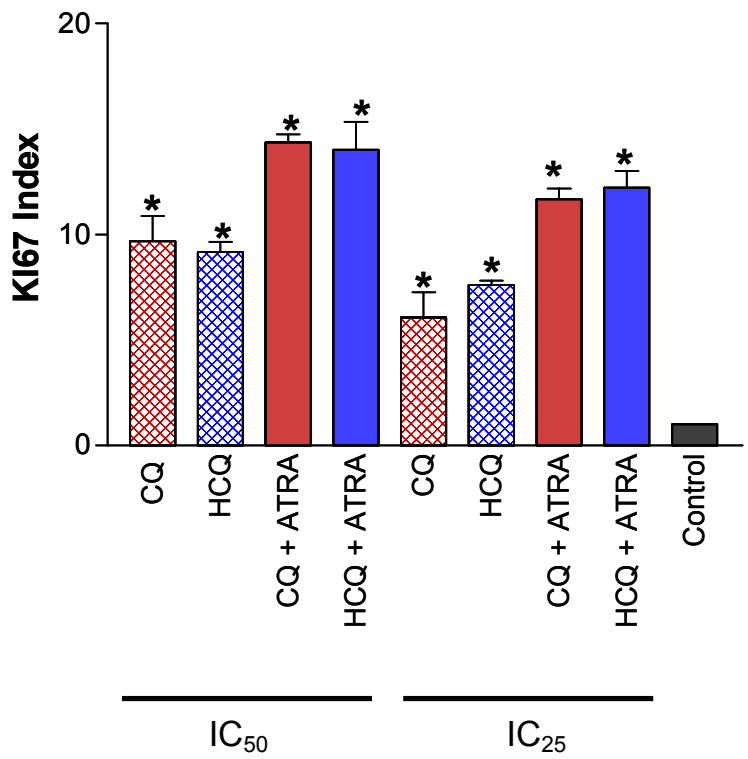




\subsection{Downregulation of E2F-1 protein in MCF-7 breast cancer cells in response to}

Chloroquine and ATRA. Alterations in the regulation of a key cell cycle regulatory protein, E2F-1, was measured by Western blotting (Figure 12). E2F-1, which is tightly bound to the retinoblastoma $(\mathrm{Rb})$ protein, interacts with HDAC to enhance cell cycle progression by stimulating the G1-S cell cycle transition (Martinez-Balbas et al., 2000). In order for cells to undergo differentiation, downregulation of E2F-1 is an essential precondition (Yamasaki et al., 1996); therefore, E2F-1 protein levels were assessed in order to confirm G1 cell cycle arrest as seen in the data above. Although the clinically safe concentration of ATRA is $10 \mu \mathrm{M}$, lower $(1 \mu \mathrm{M})$ and higher $(100 \mu \mathrm{M})$ concentrations of ATRA were tested in combination with the $\mathrm{IC}_{50}$ value of chloroquine in order to assess: (1) if lower concentrations would be permitted for maximum therapeutic effects, (2) or if the response is altered at higher concentrations. The lower concentration of ATRA $(1 \mu \mathrm{M})$ had been used in all of the previous experiments; however, $10 \mu \mathrm{M}$ and $100 \mu \mathrm{M}$ ATRA are also used in subsequent studies for a better understanding of the differentiation response. E2F-1 protein was downregulated in $\mathrm{MCF}-7$ breast cancer cells in response to combination treatment of chloroquine and ATRA. Chloroquine caused a $60 \%, 67 \%$, and $72 \%$ decrease in E2F-1 protein levels when combined with 1,10 , and $100 \mu \mathrm{M}$ ATRA, respectively. The response was statistically significant, but yet a modest effect. Nevertheless, it supports the hypothesis that that combination of ATRA with chloroquine would augment the differentiation response as shown by downregulation of E2F-1 cell cycle regulatory protein. 


\section{Figure 12. E2F-1 protein expression in MCF-7 cells following treatment with}

Chloroquine \pm ATRA. MCF-7 $\left(2 \times 10^{6}\right.$ cells $/ 60 \mathrm{~mm}^{2}$ dish $)$ were pretreated with 1 , 10, or $100 \mu \mathrm{M}$ ATRA for 24 hours before chloroquine $\left(\mathrm{CQ}, \mathrm{IC}_{50}=33 \mu \mathrm{M}\right)$ addition for another 24 hours. Total cellular proteins were isolated and $80 \mu \mathrm{g}$ of whole cell extract proteins were resolved on a 10\% acrylamide gel and analyzed by Western blot. Signals were quantitated by FluoroChem (Alpha Innotech, San Leandro, CA) spot densitometry using automatic background subtraction after normalization to $\beta$-catenin levels. Data shown represents the mean of three experiments \pm SEM.

* Statistically significant differences from the control $(\mathrm{p}<0.05)$.

a Statistically significant differences from CQ alone $(\mathrm{p}<0.05)$.

b Statistically significant differences from $1 \mu \mathrm{M}$ ATRA + CQ $(\mathrm{p}<0.05)$. 

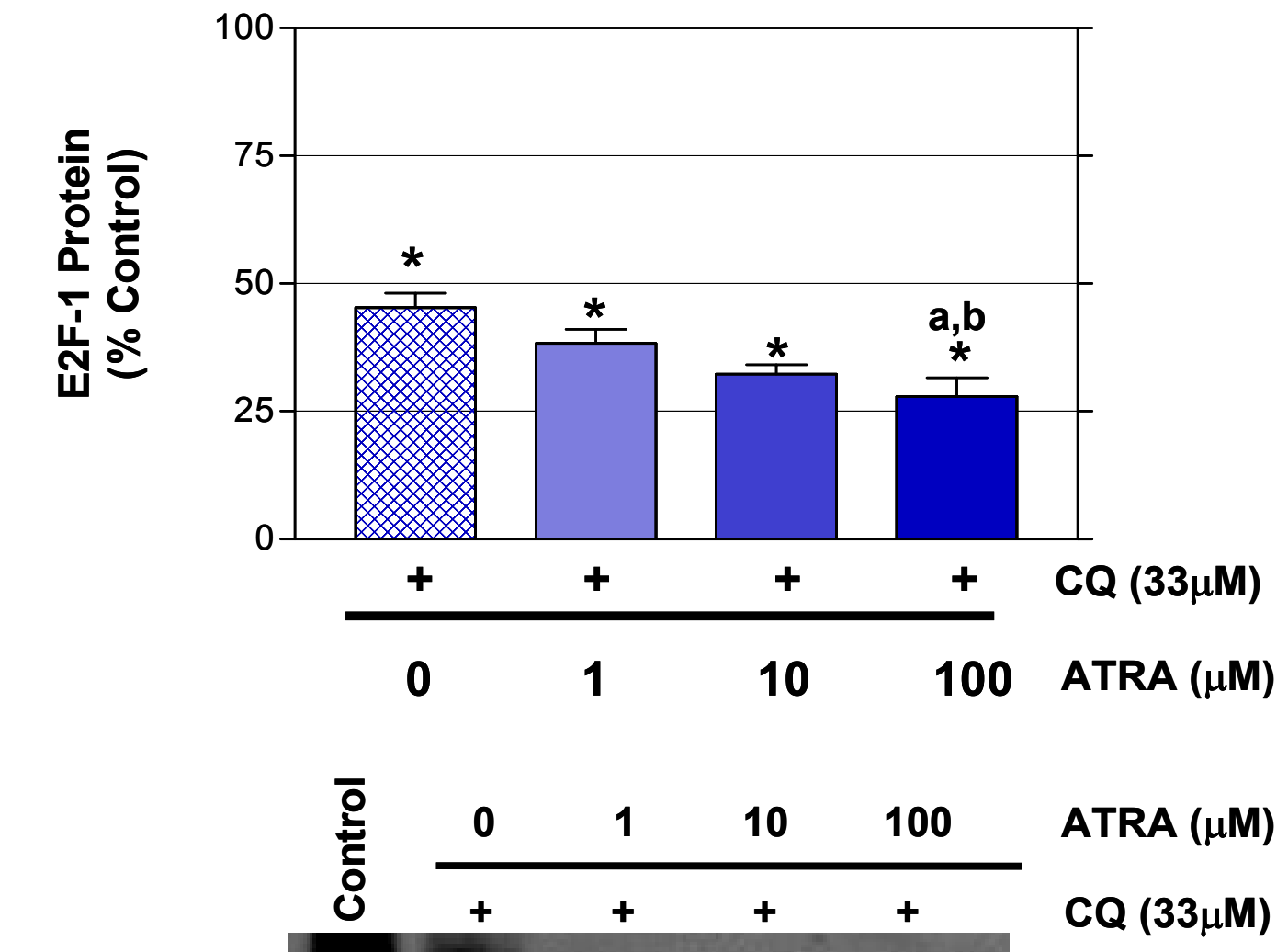

$\beta$-catenin $\rightarrow$ 


\subsection{Downregulation of c-myc protein in MCF-7 breast cancer cells in response to}

Chloroquine and ATRA. c-myc, a protooncogene which codes for proteins that stimulate cell division, is a key regulator of cell cycle progression, cell differentiation, and apoptosis (Melkoumian et al., 2002; Spaventi et al., 1993). It is hypothesized that in order for cells to undergo differentiation, downregulation of c-myc protein may be an essential step in controlling the cell cycle regulatory profile. In order to confirm the cellular differentiation response seen in the above results, alterations in the level of c-myc protein was measured by Western blotting (Figure 13). c-myc protein was downregulated in MCF-7 breast cancer cells in response to combination treatment of chloroquine and ATRA. Chloroquine caused a $66 \%, 69 \%$, and $79 \%$ decrease in c-myc protein levels when combined with 1,10 , and $100 \mu \mathrm{M}$ ATRA, respectively; therefore, the cells experienced an enhanced downregulation of c-myc protein with increased concentration of ATRA. The effect was modest even though the response was statistically significant. Nevertheless, the results support the hypothesis that that combination of ATRA with chloroquine would augment the differentiation response as shown by downregulation of c-myc cell cycle regulatory protein. 


\section{Figure 13. c-myc protein expression in MCF-7 cells following treatment with}

Chloroquine \pm ATRA. MCF-7 $\left(2 \times 10^{6}\right.$ cells $/ 60 \mathrm{~mm}^{2}$ dish $)$ were pretreated with 1 , 10 , or $100 \mu \mathrm{M}$ ATRA for 24 hours before chloroquine $\left(\mathrm{CQ}, \mathrm{IC}_{50}=33 \mu \mathrm{M}\right)$ addition for another 24 hours. Total cellular proteins were isolated and $80 \mu \mathrm{g}$ of whole cell extract proteins were resolved on a 10\% acrylamide gel and analyzed by Western blot. Signals were quantitated by FluoroChem (Alpha Innotech, San Leandro, CA) spot densitometry using automatic background subtraction after normalization to $\beta$-catenin levels. Data shown represents the mean of three experiments \pm SEM.

* Statistically significant differences from the control $(\mathrm{p}<0.05)$.

a Statistically significant differences from CQ alone $(\mathrm{p}<0.05)$.

b Statistically significant differences from $1 \mu \mathrm{M}$ ATRA + CQ $(\mathrm{p}<0.05)$.

c Statistically significant differences from $10 \mu \mathrm{M}$ ATRA + CQ $(\mathrm{p}<0.05)$. 

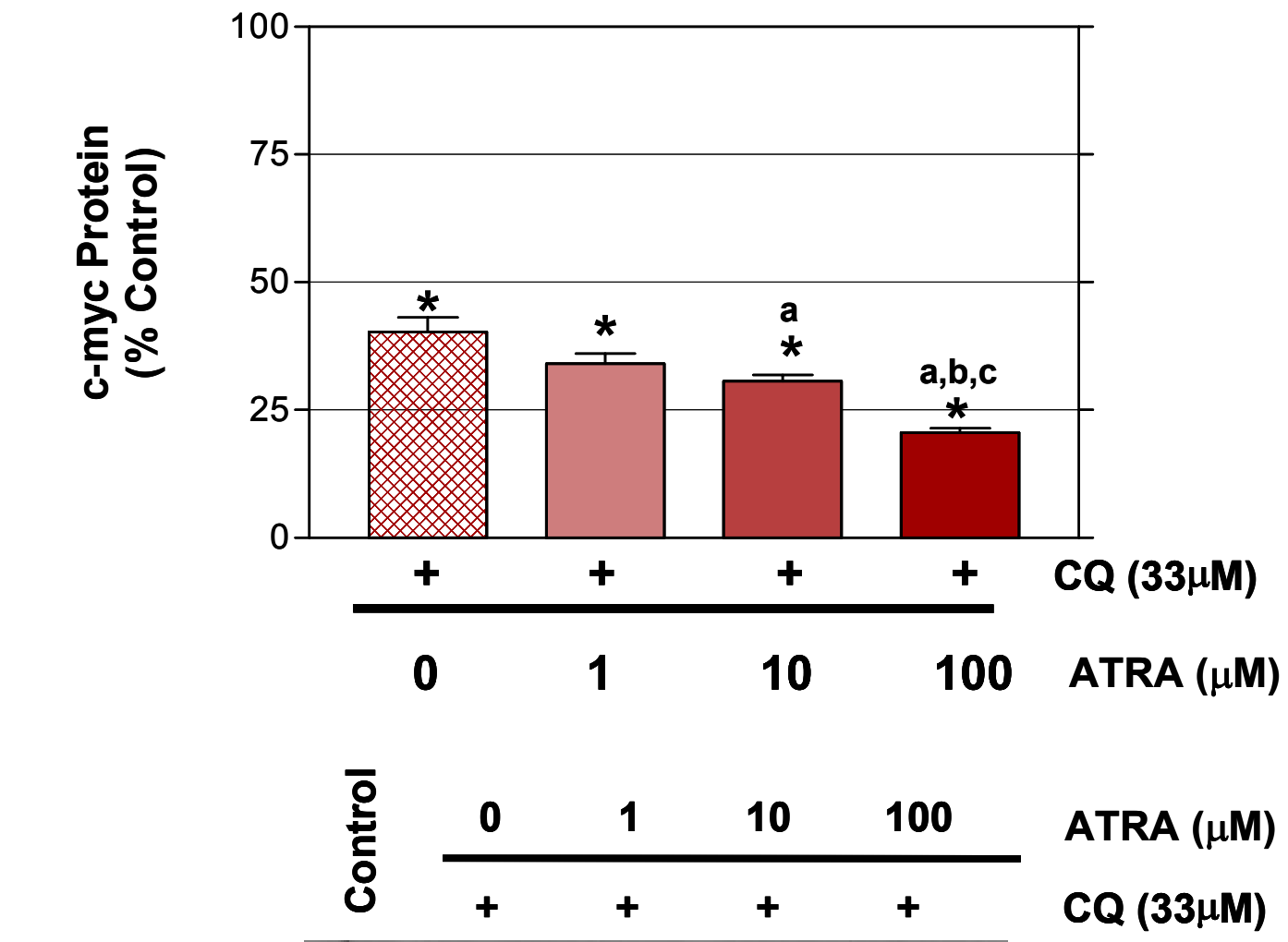

$c-m y c \rightarrow$

$\beta$-catenin $\rightarrow$ 


\section{Chapter 2. Augmentation of the Differentiation Response using 5-Aza-2'- deoxycytidine in Combination with Chloroquine or Hydroxychloroquine}

\subsection{Combination of Chloroquine or Hydroxychloroquine with 5-Aza-dC inhibited}

growth of human breast cancer cell lines. To identify whether the use of another drug combination modulating epigenetic events would lower the concentration of chloroquine or hydroxychloroquine needed to produce the differentiation response, 5-Aza-dC (Aza) was used in subsequent studies. The antiproliferative effects of both CQ or HCQ in combination with Aza were first assessed. The effects of these quinolines with Aza on cell growth were also measured by visually counting the number of viable cells in MCF-7 and MDA-MB-231 breast cancer cell lines and comparing them to MCF-10A normal epithelial cells (Figure 14). MCF-7, MDA-MB-231, and MCF-10A were replica-plated in DMEM/5\% FBS (tumor cells) or MEGM (normal cells) medium and treated with MCF-7 $\mathrm{IC}_{50}$ levels of chloroquine or hydroxychloroquine and the lowest concentration of Aza $(1 \mu \mathrm{M})$. Cells growth was counted using a hemocytometer and viability was assessed by trypan blue exclusion on the indicated days to generate growth curves. The results showed that while chloroquine alone suppressed growth in the breast cancer cell lines, the combination of chloroquine with Aza lead to a $58 \%$ (Day 4) and 55\% (Day 6) maximum reduction in growth of MDA-MB-231 and MCF-7 cells, respectively. Hydroxychloroquine alone also inhibited growth in the breast cancer cell lines; however, the combination of hydroxychloroquine with Aza caused a 83\% (Day 4) and 65\% (Day 8) maximum reduction in growth of MDA-MB-231 and MCF-7 cells, respectively. While chloroquine and hydroxychloroquine also inhibited the growth of MCF-10A normal cells, Aza did not sensitize the normal cells to further growth inhibition 
when combined with these antimalarials. Nevertheless, these results support the hypothesis that combination of Aza with chloroquine or hydroxychloroquine would augment the antiproliferative effects of the antitumor quinolines. Aza in combination with hydroxychloroquine showed to have the most promise in decreasing cell survival, especially in the MDA-MB-231 breast cancer cell line. 
Figure 14. Inhibition of growth in MCF-7 and MDA-MB-231 breast cancer cells compared to MCF-10A normal mammary epithelial cells. MCF-7 or MDA-MB-231 cells $\left(2 \times 10^{5} / 35 \mathrm{~mm}^{2}\right.$ dish $)$, and MCF-10A normal cells $\left(1 \times 10^{5} / 35 \mathrm{~mm}^{2}\right.$ dish $)$ were plated and allowed to attach for 3 hours before 5-Aza-dC (Aza) addition (Day 0). On day 1, cells were incubated in the presence of solvent (control, DMSO) or MCF-7 $\mathrm{IC}_{50}$ levels of chloroquine (CQ) or hydroxychloroquine (HCQ). Cells were harvested and viable cells were counted on the indicated days to generate the growth curves. Data represents the mean of duplicate determinations in three independent experiments. 
Figure 14A. MDA-MB-231

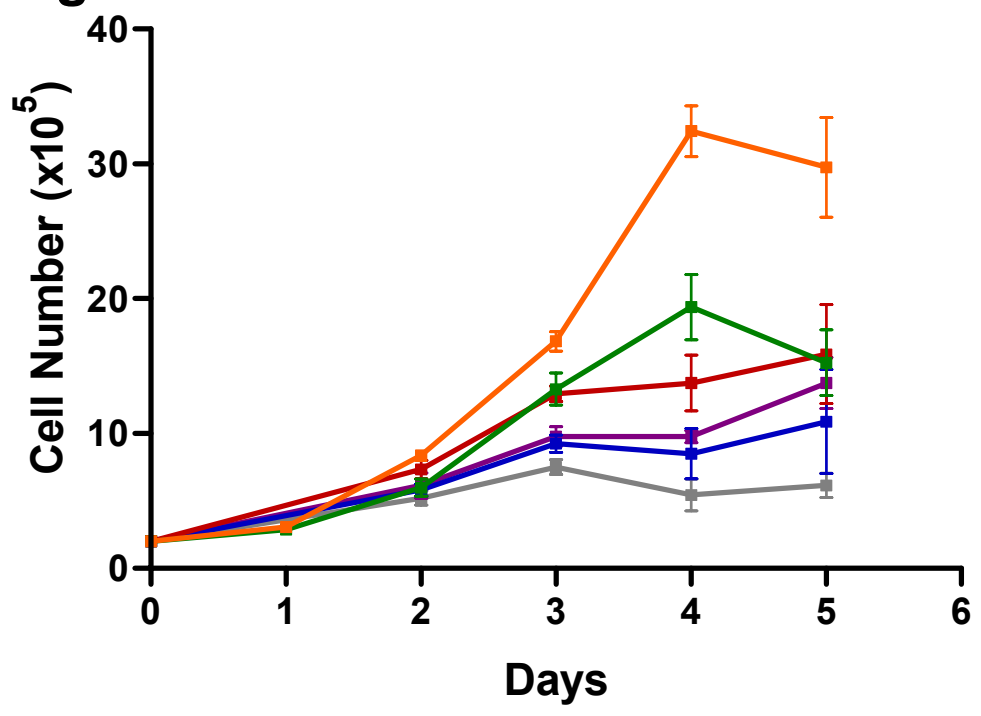

$=$ Control

$-1 \mu \mathrm{M}$ Aza

$-33 \mu \mathrm{M} \mathrm{CQ}$

$\rightarrow 1 \mu \mathrm{M} \mathrm{Aza}+33 \mu \mathrm{M} \mathrm{CQ}$

$-57 \mu \mathrm{M} \mathrm{HCQ}$

$\rightarrow-1 \mu \mathrm{M} \mathrm{Aza}+57 \mu \mathrm{M} \mathrm{HCQ}$

Figure 14B. MCF-7

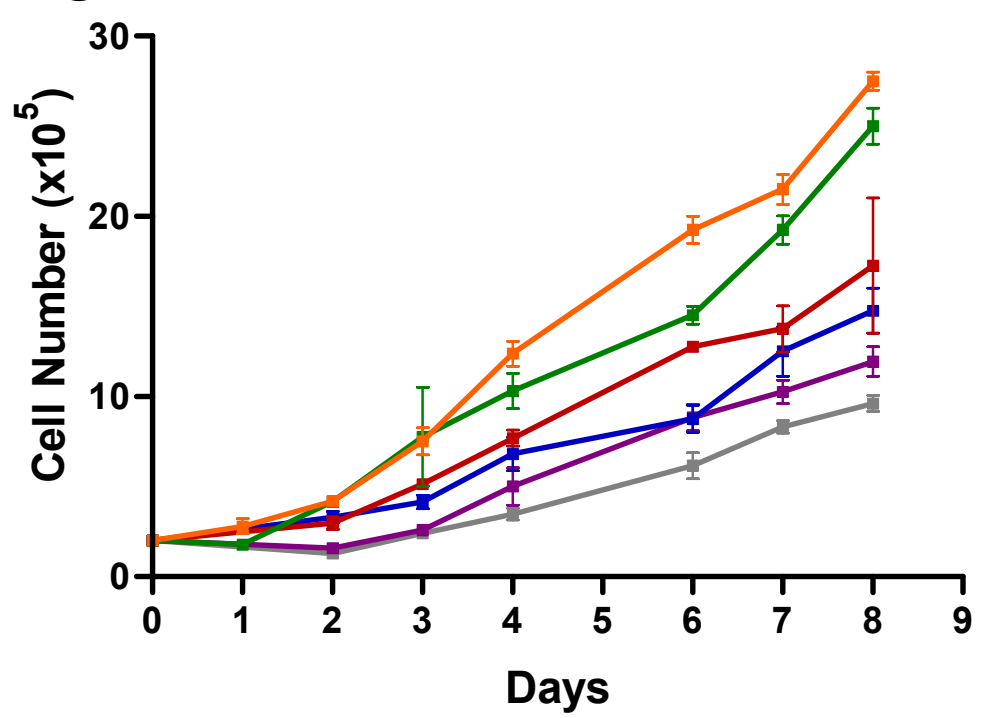

Figure 14C. MCF-10A

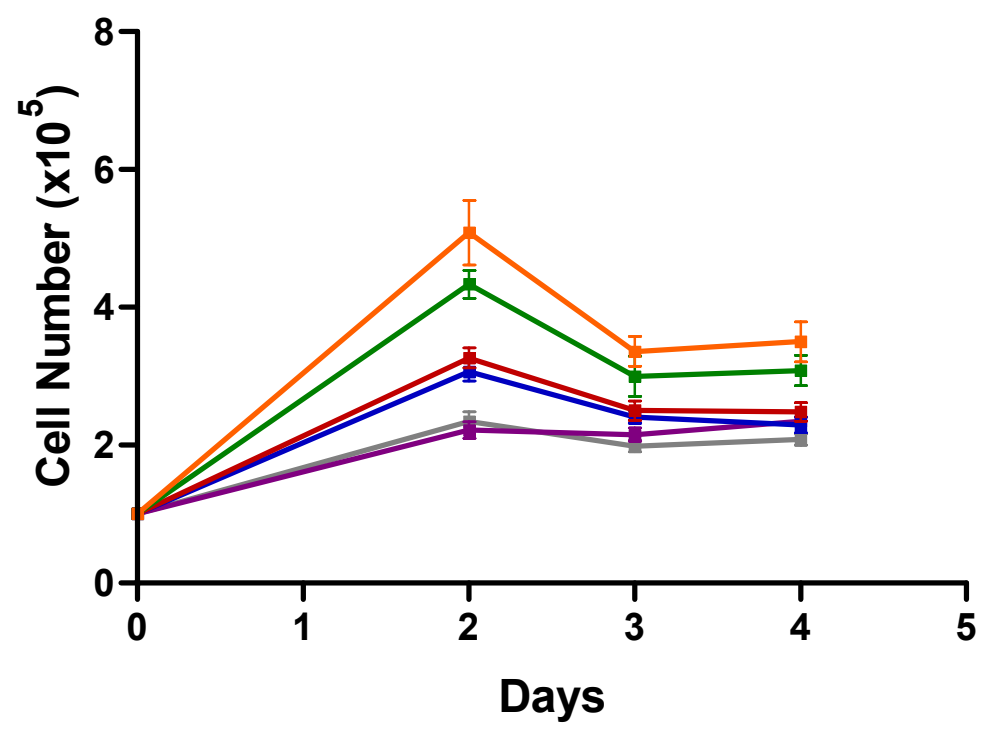




\subsection{Combination of Chloroquine or Hydroxychloroquine with 5-Aza-dC reduced}

tumor cell clonogenic survival. The effect of chloroquine and hydroxychloroquine with Aza on tumor cell survival is shown in Table 3. MDA-MB-231 and MCF-7 cell clonogenic survival was assessed using crystal violet staining and visual colony inspection. Although, Aza did not have a great effect in reducing tumor cell clonogenic survival in MCF-7 cells, the combination of Aza with the quinolines significantly decreased breast cancer clonogenic survival more than either chloroquine or hydroxychloroquine alone in the MDA-MB-231 breast cancer cells. Clonogenic survival of MDA-MB-231 cells exposed to combination of $1 \mu \mathrm{M}$ Aza with chloroquine for seven days, was reduced by $82 \%$ compared to control cells exposed to solvent alone, whereas combination of $1 \mu \mathrm{M}$ Aza with hydroxychloroquine was reduced by $91 \%$. On the other hand, in MCF-7 cells clonogenic survival was reduced by $56 \%$ upon combination treatment with Aza and chloroquine and by $68 \%$ with Aza and hydroxychloroquine compared to control cells exposed to solvent.

The results were recalculated using the method of Berenbaum (Berenbaum, 1978; Berenbaum, 1989) to test for synergy. The interaction of Aza with chloroquine or hydroxychloroquine showed to be synergistic in only the MDA-MB-231 breast cancer cell line. The uncloned early passage MCF-7 $(\mathrm{ER}+)$ breast cancer cell line was not sensitized significantly to the antiproliferative effects of the combination of Aza with the quinolines using clonogenic survival as the endpoint; however, using the MTS metabolism assay, the combination of Aza with CQ or HCQ did sensitize clonal ER- and ER+ MCF-7 cell lines to growth inhibition indicating that the response was not dictated by ER expression. However, a growing body of evidence suggest that ER-cells, such as the MDA-MB-231 cells, which have a hypermethylated estrogen receptor gene promoter, are more sensitive than ER+ cells 
to the effects of Aza (Ferguson et al., 1997; Yang et al., 2001; Worm et al., 2001) Since the clonogenic survival assays are more sensitive and reliable than the MTS assay, the results support the hypothesis that combination of Aza with chloroquine or hydroxychloroquine would augment the antiproliferative effects of the antitumor quinolines, but only in the MDA-MB-231 cell line and not in the MCF-7 cell line. Aza in combination with hydroxychloroquine showed to have the most promise in decreasing tumor cell survival in the MDA-MB-231 cell line. Clonogenic survival was also assayed in the MCF-10A normal epithelial cells $(n=2)$; however, these cells did not form discrete colonies $(\geq 20$ cells $=$ 1 colony) with or without treatment. 


\begin{tabular}{|c|c|c|}
\cline { 2 - 3 } \multicolumn{1}{c|}{} & MDA-MB-231 & MCF-7 \\
\hline Clonogenic Fraction & Clonogenic Fraction \\
\hline CQ & $0.433^{*}$ & $0.606^{*}$ \\
\hline HCQ & $0.317^{*}$ & $0.564^{*}$ \\
\hline Aza + CQ & $0.210^{*, \mathbf{a}}$ & $0.334^{*, \mathbf{a}, \mathbf{b}}$ \\
\hline Aza + HCQ & $0.182^{*, \mathbf{a}, \mathbf{b}}$ & $0.436^{*, \mathbf{a}}$ \\
\hline & $0.094^{*, \mathbf{a}, \mathbf{b}, \mathbf{c}}$ & $0.322^{*, \mathbf{a}, \mathbf{b}}$ \\
\hline
\end{tabular}

Table 3. Tumor clonogenic survival using 5-Aza-dC. MDA-MB-231 or MCF-7 cells $\left(2 \times 10^{5} / 35 \mathrm{~mm}^{2}\right.$ dish) were plated and allowed to attach for 3 hours before 5-Aza-dC (Aza, $1 \mu \mathrm{M}$ ) addition. Cells were incubated in the presence of solvent (control, DMSO) or MCF-7 $\mathrm{IC}_{50}$ levels of chloroquine (CQ, $\left.33 \mu \mathrm{M}\right)$ or hydroxychloroquine (HCQ, $\left.57 \mu \mathrm{M}\right) 24$ hours later. MDA-MB-231 and MCF-7 cells were harvested on days 3 and 4, respectively, and replated at a cloning cell density of $6 \times 10^{3}$ cells $/ 60 \mathrm{~mm}^{2}$ dishes in $5 \mathrm{ml}$ DMEM/10\% FBS and subjected to an undisturbed incubation period (5 or 7 days, respectively). Colonies were visualized by staining the dishes with $3 \mathrm{ml}$ of $0.5 \%$ crystal violet, $5 \%$ formalin, $50 \%$ ethanol, $0.85 \% \mathrm{NaCl}$ for 3 minutes, then rinsing with tap water. Colonies were scored using a Nikon Eclipse TS100 microscope at 20X magnification with $\geq 20$ MCF-7 cells and $\geq 50$ MDA-MB231 cells $=1$ colony. The data are represented as clonogenic fractions, where the clonogenic fraction of the control groups was set to equal 1. Data are the mean of 3 independent experiments performed in duplicates.

* Statistically significant differences from the control $(\mathrm{p}<0.05)$.

a Statistically significant differences from Aza alone $(p<0.05)$.

b Statistically significant differences from CQ alone $(\mathrm{p}<0.05)$.

c Statistically significant differences from HCQ alone $(\mathrm{p}<0.05)$. 


\subsection{Combination of Chloroquine or Hydroxychloroquine with 5-AzadC caused}

enhanced accumulation of cytoplasmic lipid droplets in MCF-7 and MDA-MB-231

breast cancer cells. The data presented above showed that the combination of chloroquine or hydroxychloroquine with Aza reduced cell and clonogenic survival in MDA-MB-231 human breast cancer cells more than either quinoline alone. Therefore, it was necessary to determine whether Aza in combination with chloroquine or hydroxychloroquine was also capable of augmenting the differentiation response. Cellular differentiation was still assessed in the MCF-7 cells even though combination treatment did not sensitize them to an enhanced inhibition of clonogenic survival. As evidence of cellular differentiation, combination treatment with $1 \mu \mathrm{M}$ Aza led to a modest accumulation of cytoplasmic lipid droplets detected by Oil Red-O staining in both the MDA-MB-231 and MCF-7 breast cancer cell lines after 48 hours of treatment (Figure 15). The differentiation response was greater than either chloroquine or hydroxychloroquine alone at both the $\mathrm{IC}_{25}$ and $\mathrm{IC}_{50}$ levels.

MDA-MB-231 cells treated with chloroquine alone at $\mathrm{IC}_{25}$ and $\mathrm{IC}_{50}$ showed a $76 \%$ and $90 \%$ increase in lipid droplets, respectively, compared with $90 \%$ and $97 \%$ increase in cells pretreated with Aza. Hydroxychloroquine alone showed an $84 \%$ and $87 \%$ increase in lipid droplets at its MDA-MB-231 $\mathrm{IC}_{25}$ and $\mathrm{IC}_{50}$ values, respectively, compared with $93 \%$ and $96 \%$ increase in cells pretreated with Aza.

MCF-7 cells treated with chloroquine alone at $\mathrm{IC}_{25}$ and $\mathrm{IC}_{50}$ showed a $81 \%$ and $83 \%$ increase in lipid droplets, respectively, compared with $85 \%$ and $88 \%$ increase in cells pretreated with Aza, while hydroxychloroquine alone showed a $71 \%$ and $80 \%$ increase in lipid droplets at $\mathrm{IC}_{25}$ and $\mathrm{IC}_{50}$ values, respectively, compared with $85 \%$ and $92 \%$ increase in cells pretreated with Aza. 
In summary, these experiments provide evidence that the differentiation response by the antitumor quinolines, chloroquine or hydroxychloroquine, can be modestly enhanced with pretreatment with $1 \mu \mathrm{M}$ Aza. Pretreatment of MDA-MB-231 or MCF-7 breast cancer cells with Aza in combination with treatment with the $\mathrm{IC}_{25}$ values of either chloroquine or hydroxychloroquine, showed a greater percentage of ORO positive cells than either of the quinolines alone at their respective $\mathrm{IC}_{50}$ values. Therefore, combination therapy with $1 \mu \mathrm{M}$ Aza seems to lower the concentration of chloroquine or hydroxychloroquine needed to achieve the same differentiation response. 
Figure 15. Oil-Red-O (ORO) Histochemistry: Enhanced accumulation of cytoplasmic lipid droplets in MCF-7 and MDA-MB-231 breast cancer cells using Chloroquine or Hydroxychloroquine in combination with 5-Aza-dC. A.) MDA-MB-231 (1x10 cells $/ 35$ $\mathrm{mm}^{2}$ dish) were plated and treated with $1 \mu \mathrm{M}$ 5-Aza-dC (Aza). 24 hours later, cells were treated with solvent (control, DMSO) or hydroxychloroquine (HCQ, $\left.\mathrm{IC}_{25}=12 \mu \mathrm{M}\right)$ for another 24 hours and then stained with the ORO stain (red dots in the cytoplasm) and counterstained with the Mayer's hematoxylin stain (blue nuclei). B.) MCF-7 and MDAMB-231 cells were plated on $5 \times 5 \mathrm{~mm}^{2} 95 \%$ ethanol-washed glass coverslips in $35 \mathrm{~mm}^{2}$ dishes at $2 \times 10^{5}$ and $1 \times 10^{5}$ cells per dish, respectively. Cells were pretreated with $1 \mu \mathrm{M}$ Aza for 24 hours and then treated with chloroquine (CQ) or hydroxychloroquine (HCQ) at their respective $\mathrm{IC}_{50}$ and $\mathrm{IC}_{25}$ values for another 24 hours. The ORO assay was performed and lipid droplet accumulation in the cytoplasm was visualized by light microscopy. At least 300 cells were counted visually. Data represents the mean of 2 independent experiments (+/- range). 
A.

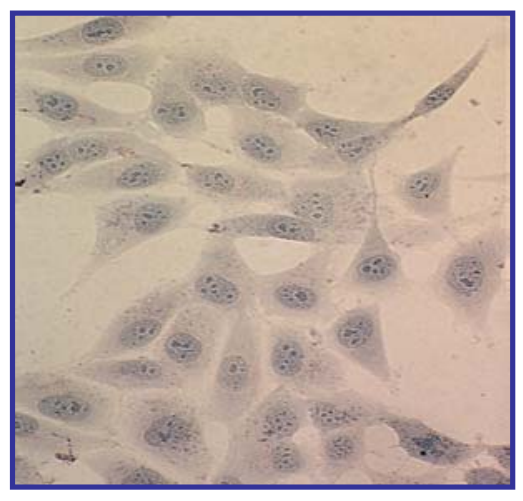

Control

MDA-MB-231

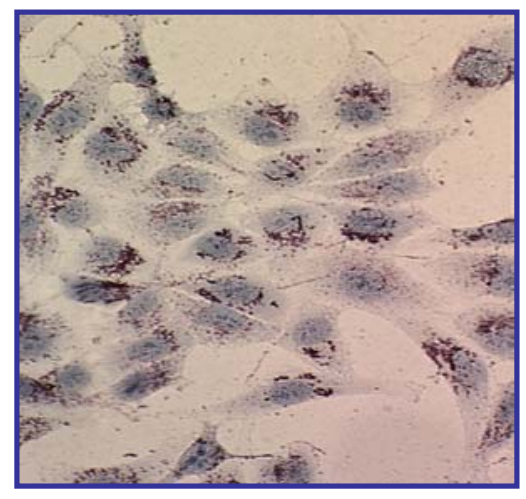

HCQ

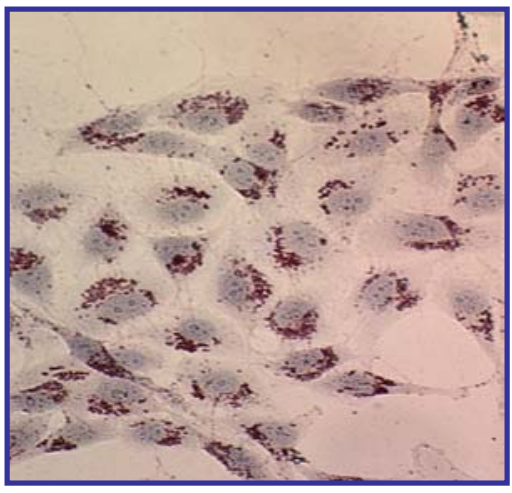

HCQ + Aza
B.

MCF-7

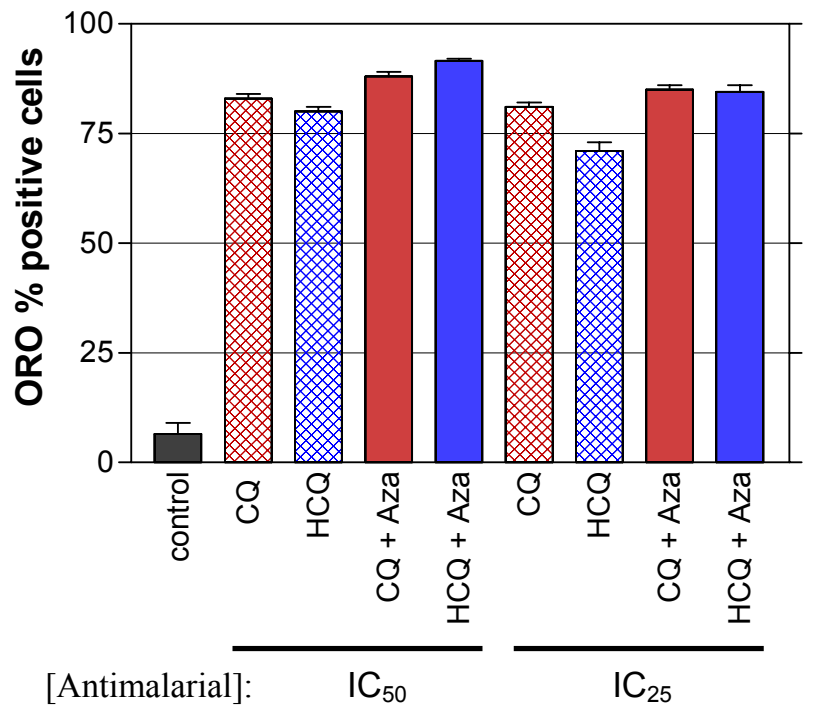

MDA-MB-231

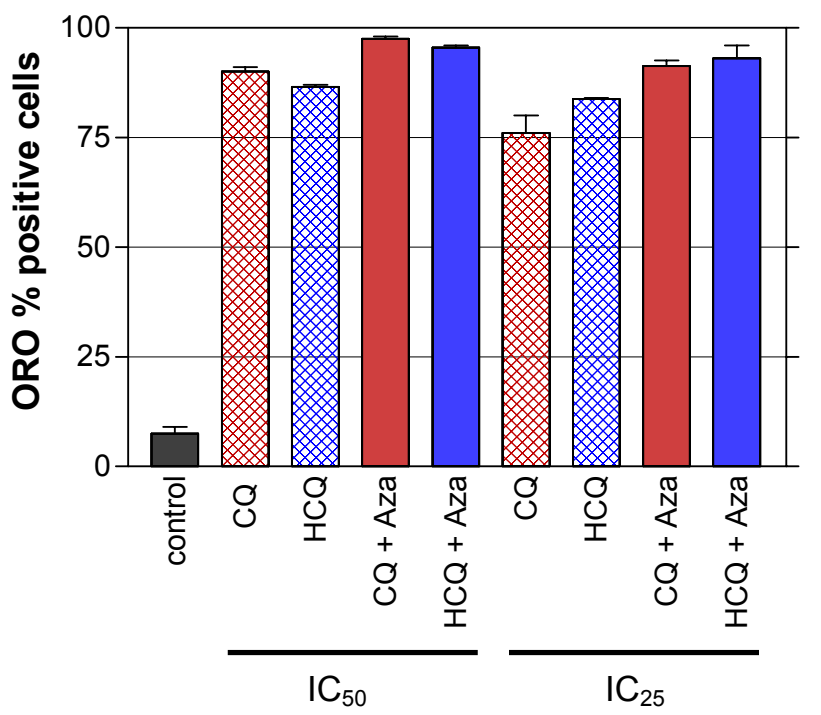




\subsection{Combination of Chloroquine or Hydroxychloroquine with 5-Aza-dC elevated the}

Ki67 index. To further test for differentiation, the G0 cell population in the breast cancer cell lines was measured using the Ki67 index. The Ki67 index offers more reliability and biological relevance in the assessment of cellular differentiation compared with lipid droplet accumulation. Ki67 protein was measured in both MCF-7 and MDA-MB-231 breast cancer cells after pretreatment with $1 \mu \mathrm{M}$ Aza and 24 hours of treatment with chloroquine or hydroxychloroquine at $\mathrm{IC}_{25}$ and $\mathrm{IC}_{50} \mathrm{MTS}$ values (Figure 16). The results showed that the combination of Aza with either chloroquine or hydroxychloroquine elevated the Ki67 index the most in the MDA-MB-231 breast cancer cells compared with the MCF-7 cells. The differentiation response was greater than either chloroquine or hydroxychloroquine alone at both the $\mathrm{IC}_{25}$ and $\mathrm{IC}_{50}$ levels.

MDA-MB-231 cells treated with chloroquine alone at $\mathrm{IC}_{25}$ and $\mathrm{IC}_{50}$ showed a $\mathrm{Ki67}$ index of 8.5 and 11.0, respectively, compared with an increased Ki67 index of 13.0 and 15.3 in cells pretreated with ATRA. Hydroxychloroquine alone showed a Ki67 index of 7.8 and 9.5 at its MDA-MB-231 $\mathrm{IC}_{25}$ and $\mathrm{IC}_{50}$ values, respectively, compared with an increased Ki67 index of 12.1 and 14.3 in cells pretreated with ATRA.

MCF-7 cells treated with chloroquine alone at $\mathrm{IC}_{25}$ and $\mathrm{IC}_{50}$ showed a $\mathrm{Ki} 67$ index of 6.2 and 8.1, respectively, compared with an increased Ki67 index of 6.7 and 8.7 in cells pretreated with Aza, while hydroxychloroquine alone showed a Ki67 index of 5.8 and 5.5 at $\mathrm{IC}_{25}$ and $\mathrm{IC}_{50}$ values, respectively, compared with an increased $\mathrm{Ki} 67$ index of 6.2 and 7.4 in cells pretreated with Aza.

These experiments provide evidence in support of the hypothesis that the differentiation response measured by increase in the G0 cell population can be augmented 
with pretreatment with $1 \mu \mathrm{M}$ Aza more than either chloroquine or hydroxychloroquine alone. The differentiation response was more pronounced in the MDA-MB-231 cells versus the MCF-7 cells. These results along with the tumor cell clonogenic survival data suggest that the combination of Aza with either chloroquine or hydroxychloroquine sensitized the MDAMB-231 (ER-) cells more than the MCF-7 (ER+) cells to growth inhibition and differentiation. MDA-MB-231 cells were used in subsequent experiments to assess histone acetylation status upon treatment with Aza. 
Figure 16. KI67 Histochemistry: Increased G0 cell population in both MCF-7 and MDA-MB-231 breast cancer cells treated with Chloroquine or Hydroxychloroquine in combination with 5-Aza-dC. A.) $\mathrm{MCF}-7\left(2 \times 10^{5}\right.$ cells $/ 35 \mathrm{~mm}^{2}$ dish $)$ were pretreated with $1 \mu \mathrm{M}$ 5-Aza-dC 24 hours prior to treatment with solvent (control, DMSO) or hydroxychloroquine $\left(\mathrm{HCQ}, \mathrm{IC}_{25}=30 \mu \mathrm{M}\right) \pm($ Aza). 24 hours later, Ki67 immunoreactivity was assayed. Brown staining indicates the presence of Ki67 protein and cycling cells. Blue staining indicates Ki67 negative or G0 cells. B.) MCF-7 and MDA-MB-231 cells were plated on $5 \times 5 \mathrm{~mm}^{2} 95 \%$ ethanol-washed glass coverslips in $35 \mathrm{~mm}^{2}$ dishes at $2 \times 10^{5}$ and $1 \times 10^{5}$ cells per dish, respectively. Cells were pretreated with $1 \mu \mathrm{M} 5$-Aza-dC 24 hours before addition of chloroquine (CQ) or hydroxychloroquine (HCQ) at their respective $\mathrm{IC}_{50}$ and $\mathrm{IC}_{25}$ values. 24 hours later, Ki67 immunoreactivity was assayed. KI67 negative percentage of the cell population was determined by visual counting. At least 500 cells were counted. (KI67 Index $=\%$ KI67 negative cells in drug treatment / \% KI67 negative cells in control treatment). Data represents the mean of 2 independent experiments $(+/-$ range). 
A.

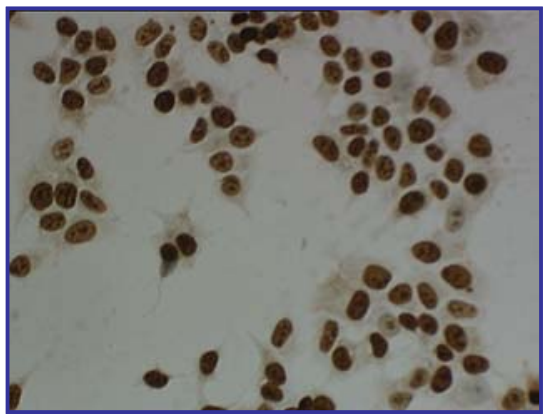

Control

MCF-7

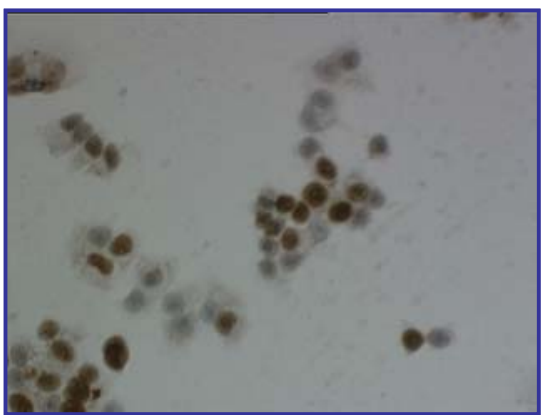

HCQ

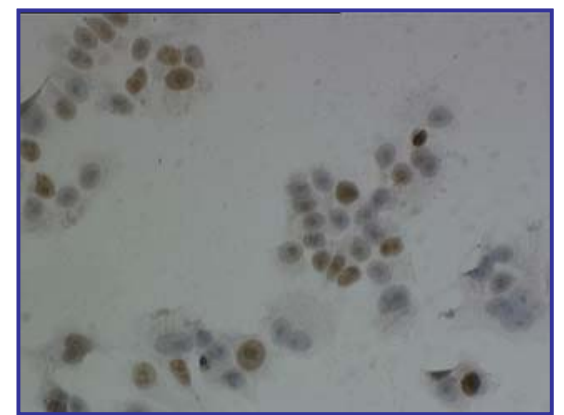

$H C Q+A z a$
B.

MCF-7

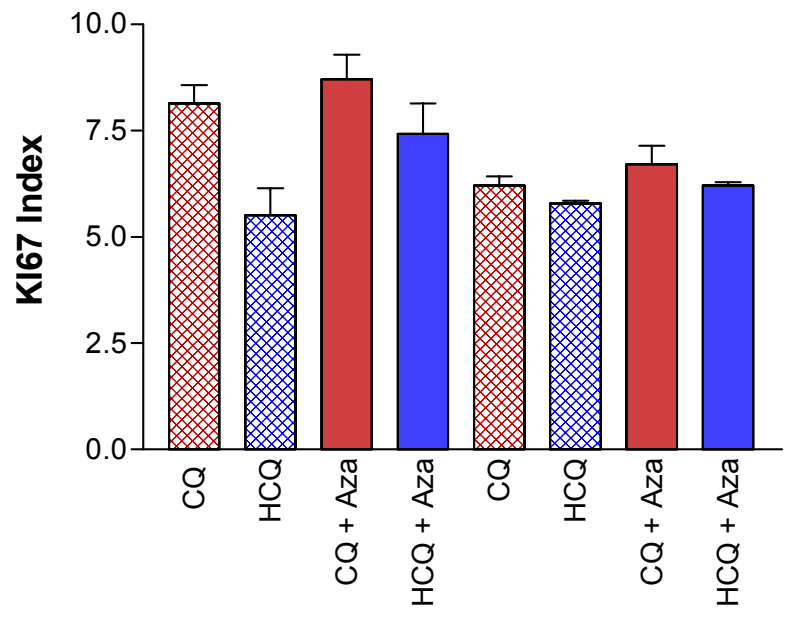

[Antimalarial]: $\quad \mathrm{IC}_{50}$
$\mathrm{IC}_{25}$

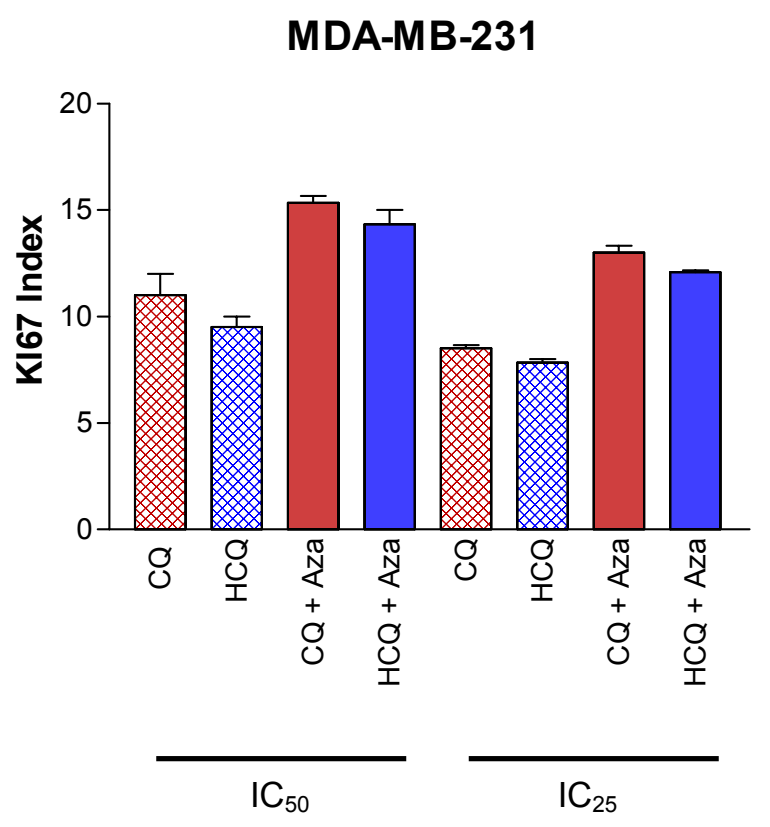




\section{Chapter 3. Histone H3/H4 Hyperacetylation Status in Response to Combination Treatment with Antitumor Quinolines}

\subsection{Effect of combination treatment of Chloroquine or Hydroxychloroquine with 5-}

Aza-dC on acetylated histone H4, HDAC, and RAR $\beta 2$ protein levels in MDA-MB-231 breast cancer cells. The central goal of these studies was to explore whether a drug combination modulating epigenetic events would sensitize breast cancer cells to the antitumor activity of chloroquine or hydroxychloroquine. To test whether pretreatment with 5-Aza-dC (Aza) would alter the acetylation status of histones due to hypomethylation, western blot analyses were conducted to evaluate acetylated histone H4 and HDAC protein levels. $\mathrm{RAR} \beta_{2}$ protein levels were also assessed since it has been suggested that methylation may be responsible for the lack of $\mathrm{RAR} \beta_{2}$ gene expression in cancer cell lines (Yang et al., 2002). Histone proteins were extracted from MDA-MB-231 cells pretreated with $1 \mu \mathrm{M}$ Aza for 24 hours prior to chloroquine or hydroxychloroquine addition for different time points (Figure 17). Trichostatin A (TSA) was used as a positive control for HDAC inhibition and histone hyperacetylation.

By 4 hours after chloroquine addition, there was a 56\% reduction in HDAC protein levels in cells that were pretreated with Aza compared with a 40\% reduction in cells with no pretreatment and only chloroquine addition. Also by 4 hours after chloroquine treatment, there was significant induction of histone hyperacetylation with a 6.6 fold increase in acetylated histone $\mathrm{H} 4$ protein in cells pretreated with Aza compared to cells with solvent alone. By 8 hours after chloroquine treatment, there was a significant 4.4 fold increase in RAR $\beta_{2}$ protein in cells pretreated with Aza and this increase was sustained even at 24 hours. 
By 4 hours after hydroxychloroquine addition, there was a $42 \%$ reduction in HDAC protein levels in cells that were pretreated with Aza compared with a 37\% reduction in cells with no pretreatment and only hydroxychloroquine addition. Also by 4 hours after hydroxychloroquine treatment, there was significant induction of histone hyperacetylation with a 4.5 fold increase in acetylated histone $\mathrm{H} 4$ protein in cells pretreated with Aza compared to cells with solvent alone. There was a maximum increase in $\mathrm{RAR} \beta_{2}$ protein levels in cells pretreated with Aza by 12 hours after hydroxychloroquine treatment. Increased $R A R \beta_{2}$ protein levels were sustained even at 24 hours.

These results support the hypothesis that combination of Aza with chloroquine or hydroxychloroquine would increase histone $\mathrm{H} 4$ acetylation status via inhibition of HDAC protein and therefore, increase $\mathrm{RAR} \beta_{2}$ tumor suppressor protein levels. These results combined with cell survival and differentiation assays, suggest that Aza in combination with either chloroquine or hydroxychloroquine are promising agents for the generation of safer and less toxic chemotherapeutic agents for the prevention and treatment of ER- breast cancer. 
Figure 17. HDAC, acetylated histone $H 4$, and $R A R \beta_{2}$ protein levels in MDA-MB-231 cells following treatment with Chloroquine or Hydroxychloroquine \pm Aza. $2 \times 10^{6}$ or $6 \times 10^{8}$ MDA-MB-231 cells were allowed to attach for 3 hours prior to treatment with $1 \mu \mathrm{M}$ Aza for whole cell or histone extraction, respectively. 24 hours after Aza addition, cells were treated with control (DMSO), trichostatin A (TSA, 300nM), chloroquine (CQ, $\left.\mathrm{IC}_{50}=11 \mu \mathrm{M}\right)$, or hydroxychloroquine $\left(\mathrm{HCQ}, \mathrm{IC}_{50}=28 \mu \mathrm{M}\right)$. At $0.5,4,8,12$, and 24 hours after TSA and quinoline treatment, either whole cell lysates were prepared or total histone proteins were isolated using acid-extraction. $80 \mu \mathrm{g}$ of proteins from whole cell lysates or $20 \mu \mathrm{g}$ of purified histone proteins were resolved on a $10 \%$ or $15 \%$ acrylamide gel, respectively, and analyzed by Western blot. Signals were quantitated by FluoroChem (Alpha Innotech, San Leandro, CA) spot densitometry using automatic background subtraction. Statistically significant differences from the control in three independent experiments are indicated $(\underline{\mathrm{p}<0.05})$. 

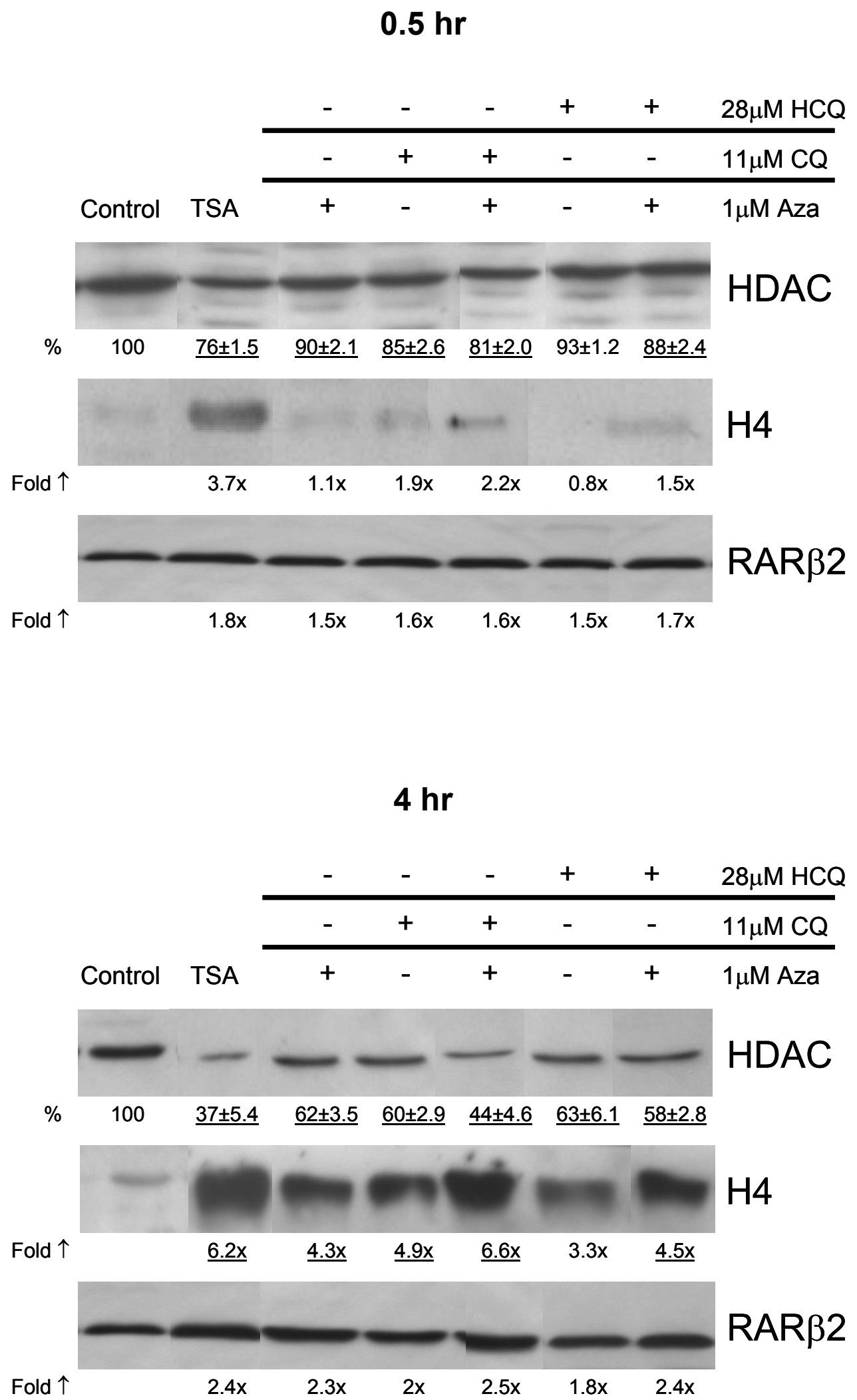


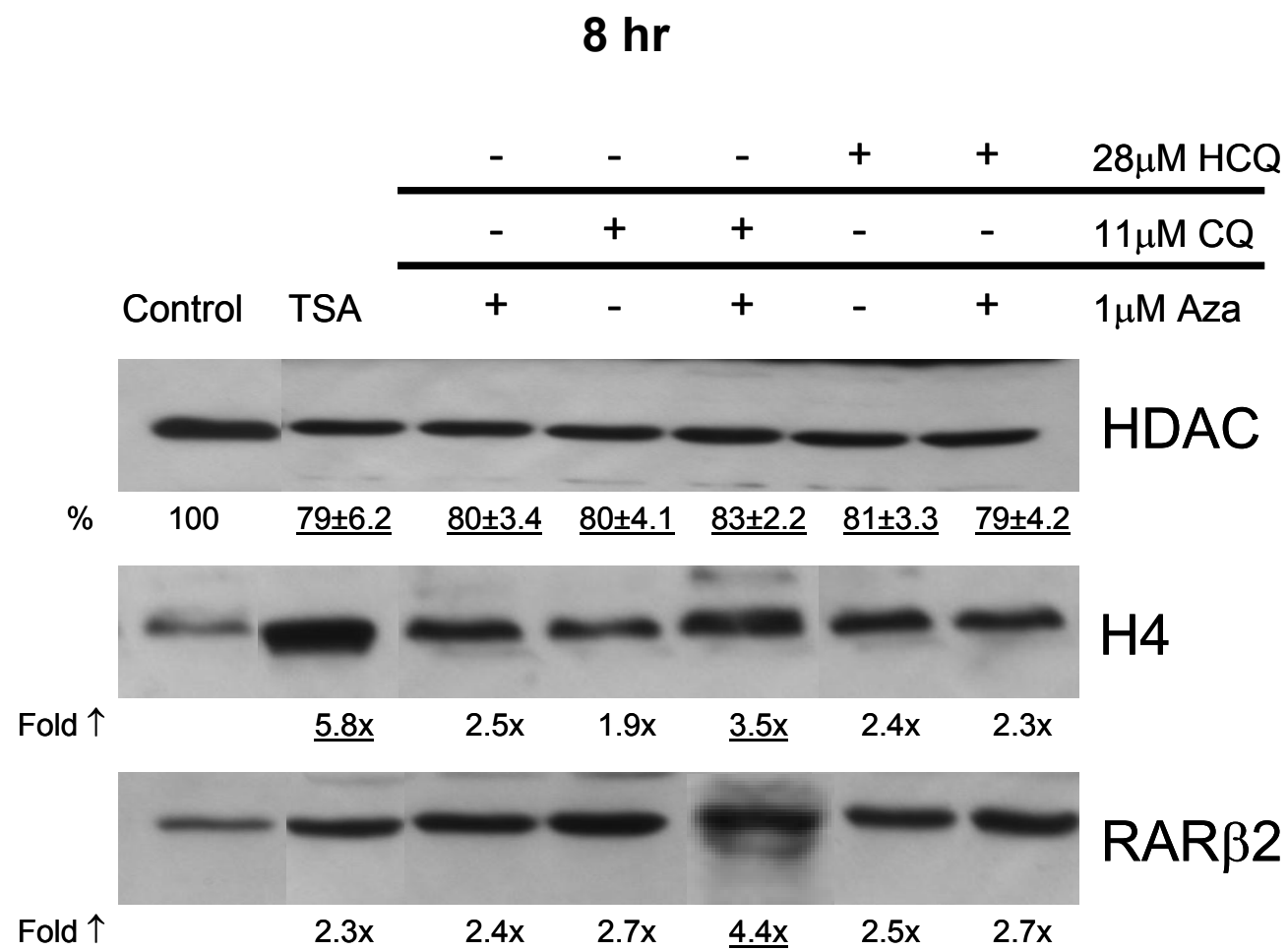

$12 \mathrm{hr}$
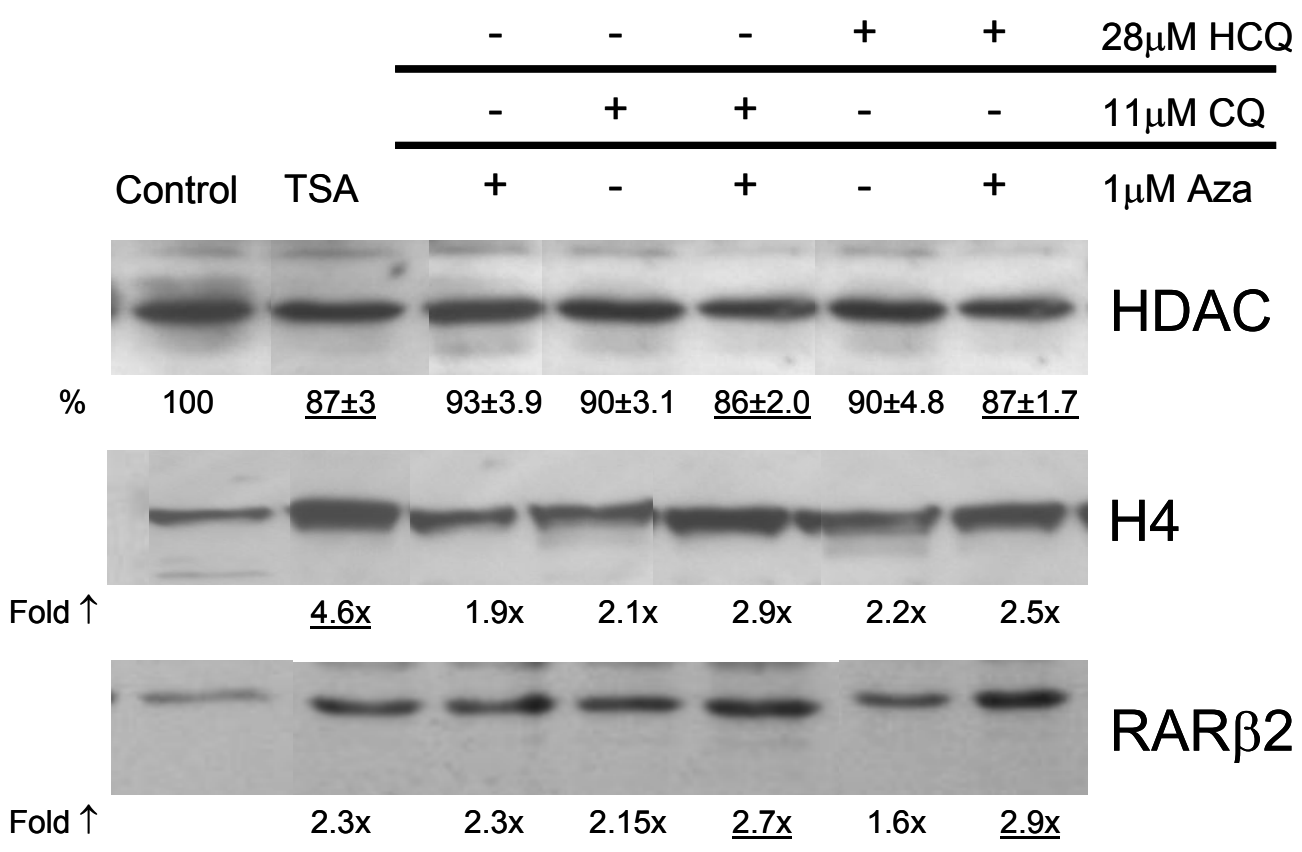


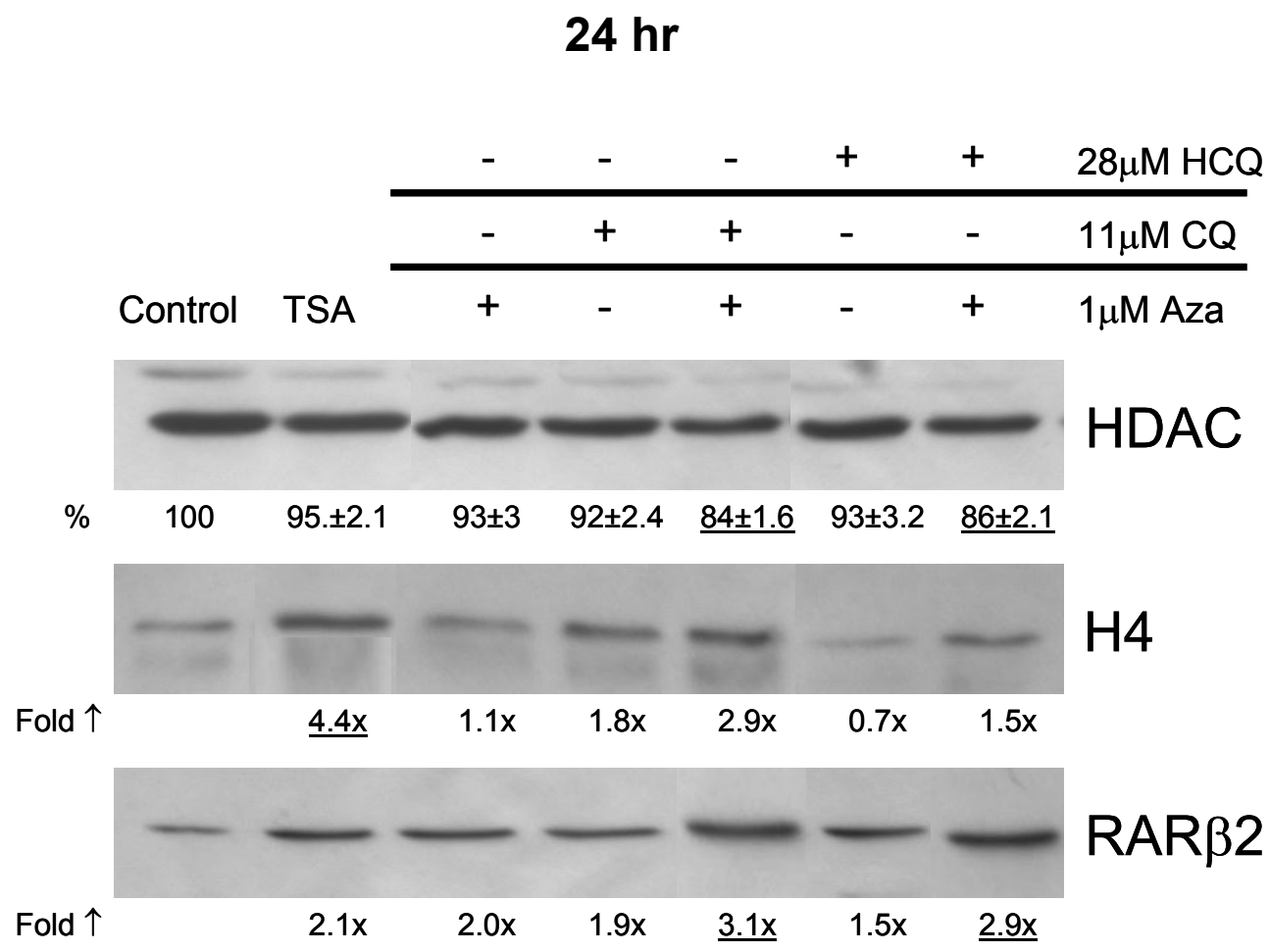




\subsection{Effect of combination treatment of Chloroquine or Hydroxychloroquine with}

ATRA on acetylated histone H3/H4, HDAC, and RAR $\beta 2$ protein levels in MCF-7 breast cancer cells. The central goal of these studies was to test whether a drug combination modulating epigenetic events would sensitize breast cancer cells to the antitumor activity of chloroquine or hydroxychloroquine. To examine whether pretreatment with ATRA would alter the acetylation status of histones, western blot analyses were conducted to assess acetylated histone $\mathrm{H} 4$ and HDAC protein levels. The RAR $\beta_{2}$ gene is silenced in human carcinoma cells. Since growing evidence suggests that retinoids exert their chemopreventive effects by RAR $\beta_{2}$ induction (Lotan et al., 1995; Yang et al., 2002), RAR $\beta_{2}$ protein levels were also assessed. Whole cell lysates or histone proteins were extracted from MCF-7 cells pretreated with $1 \mu \mathrm{M}$ ATRA for 24 hours prior to chloroquine or hydroxychloroquine addition for different time points (Figure 18). Trichostatin A (TSA) was used as a positive control for HDAC inhibition and histone hyperacetylation.

By 4 hours after chloroquine addition, there was a 33\%, 33\%, and 36\% reduction in HDAC protein levels in cells that were pretreated with 1,10 , or $100 \mu \mathrm{M}$ ATRA, respectively, compared with a $27 \%$ reduction in cells with no pretreatment and only chloroquine addition. By 8 hours after chloroquine treatment, there was a significant induction of histone hyperacetylation with a 3.9 fold increase in acetylated histone H4 protein and a 3.4 fold increase in acetylated histone $\mathrm{H} 3$ protein in cells pretreated with $100 \mu \mathrm{M}$ ATRA compared to cells with solvent alone. There was a pronounced histone H3 hyperacetylation response even by $0.5 \mathrm{hr}$ in cells pretreated with $1 \mu \mathrm{M}$ ATRA and increased levels were sustained even at 12 hours. By 12 hours after chloroquine treatment, there was a significant induction of RAR $\beta_{2}$ protein levels in cells pretreated with Aza and this increase 
was sustained even at 24 hours. Cells pretreated with $1 \mu \mathrm{M}$ ATRA showed the greatest increase in $\mathrm{RAR} \beta_{2}$ protein levels.

By 4 hours after hydroxychloroquine addition, there was a 35\%, 31\%, and $41 \%$ reduction in HDAC protein levels in cells that were pretreated with 1,10 , or $100 \mu \mathrm{M}$ ATRA, respectively, compared with a $30 \%$ reduction in cells with no pretreatment and only hydroxychloroquine addition. By 8 hours after hydroxychloroquine treatment, there was a significant induction of histone hyperacetylation with a 4.2 fold increase in acetylated histone $\mathrm{H} 4$ protein and a 5.6 fold increase in acetylated histone $\mathrm{H} 3$ protein in cells pretreated with $100 \mu \mathrm{M}$ ATRA compared to cells with solvent alone. By 12 hours after hydroxychloroquine treatment, there was a significant induction of $\mathrm{RAR} \beta_{2}$ protein levels in cells pretreated with ATRA and this increase was sustained even at 24 hours. Cells pretreated with $1 \mu \mathrm{M}$ ATRA showed the greatest increase in RAR $\beta_{2}$ protein levels.

These results support the hypothesis that combination of ATRA with chloroquine or hydroxychloroquine would increase histone $\mathrm{H} 4$ acetylation status via inhibition of HDAC protein and therefore, increase $\mathrm{RAR} \beta_{2}$ tumor suppressor protein levels. These results combined with cell survival and differentiation assays, suggest that ATRA in combination with either chloroquine or hydroxychloroquine are promising agents for the generation of safer and less toxic chemotherapeutic agents for the prevention and treatment of both ERand ER+ breast cancers. 
Figure 18. HDAC, acetylated histone $\mathrm{H3} / \mathrm{H} 4$, and RAR $\beta_{2}$ protein levels in MCF-7 cells following treatment with Chloroquine or Hydroxychloroquine \pm ATRA. $2 \times 10^{6}$ or $1 \times 10^{7} \mathrm{MCF}-7$ cells were allowed to attach for 3 hours prior to treatment with 1 , 10 , or $100 \mu \mathrm{M}$ ATRA for whole cell or histone extraction, respectively. 24 hours after ATRA addition, cells were treated with control (DMSO), trichostatin A (TSA, 300nM), chloroquine $\left(\mathrm{CQ}, \mathrm{IC}_{50}=33 \mu \mathrm{M}\right)$, or hydroxychloroquine $\left(\mathrm{HCQ}, \mathrm{IC}_{50}=57 \mu \mathrm{M}\right)$. At $0.5,4,8,12$, and 24 hours after TSA and antimalarial treatment, either whole cell lysates were prepared or total histone proteins were isolated using acid-extraction. $80 \mu \mathrm{g}$ of proteins from whole cell lysates or $20 \mu \mathrm{g}$ of purified histone proteins were resolved on a $10 \%$ or $15 \%$ acrylamide gel, respectively, and analyzed by Western blot. Signals were quantitated by FluoroChem (Alpha Innotech, San Leandro, CA) spot densitometry using automatic background subtraction. Statistically significant differences from the control in three independent experiments are indicated $(\underline{\mathrm{p}<0.05})$. 

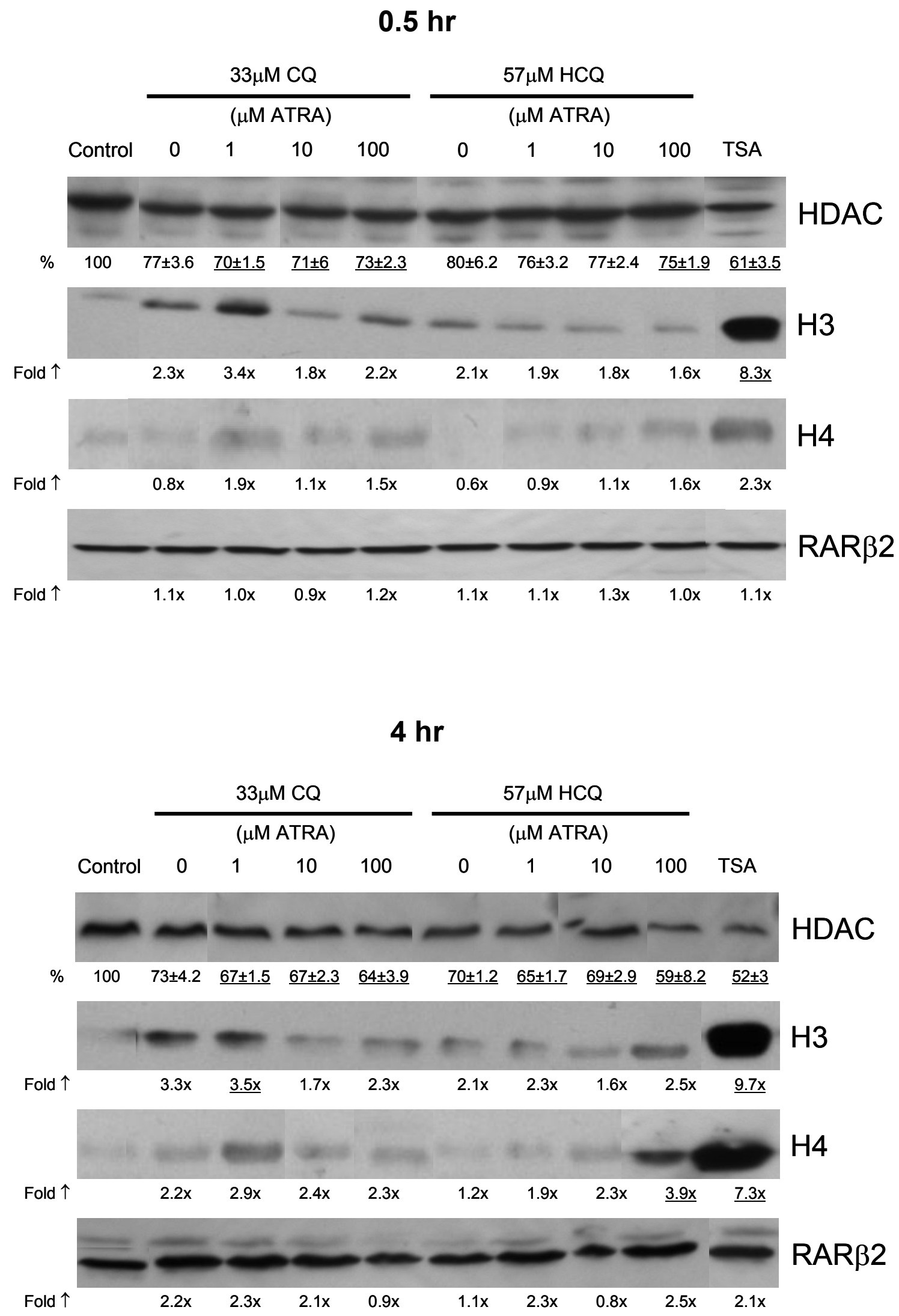


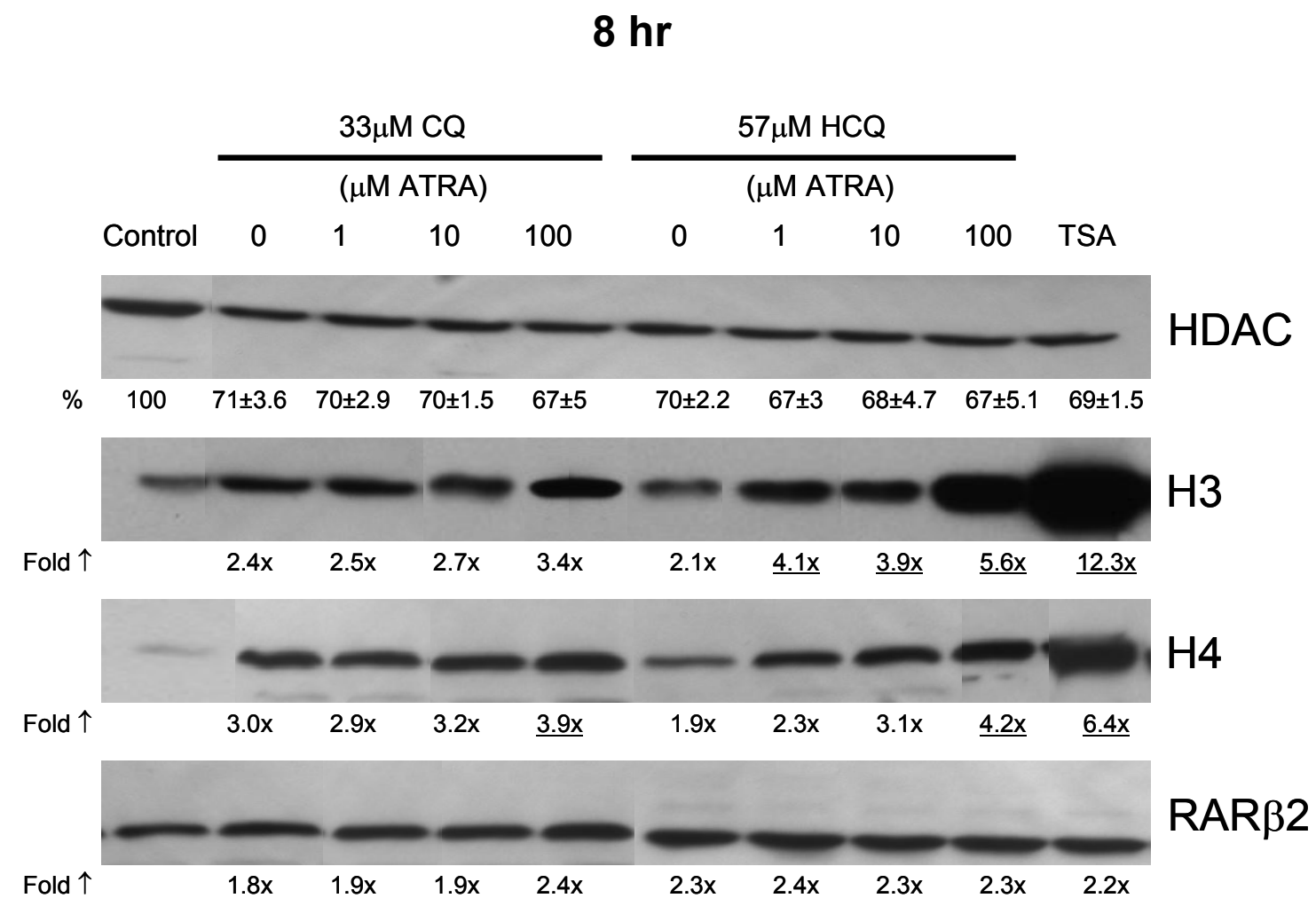

\section{$12 \mathrm{hr}$}

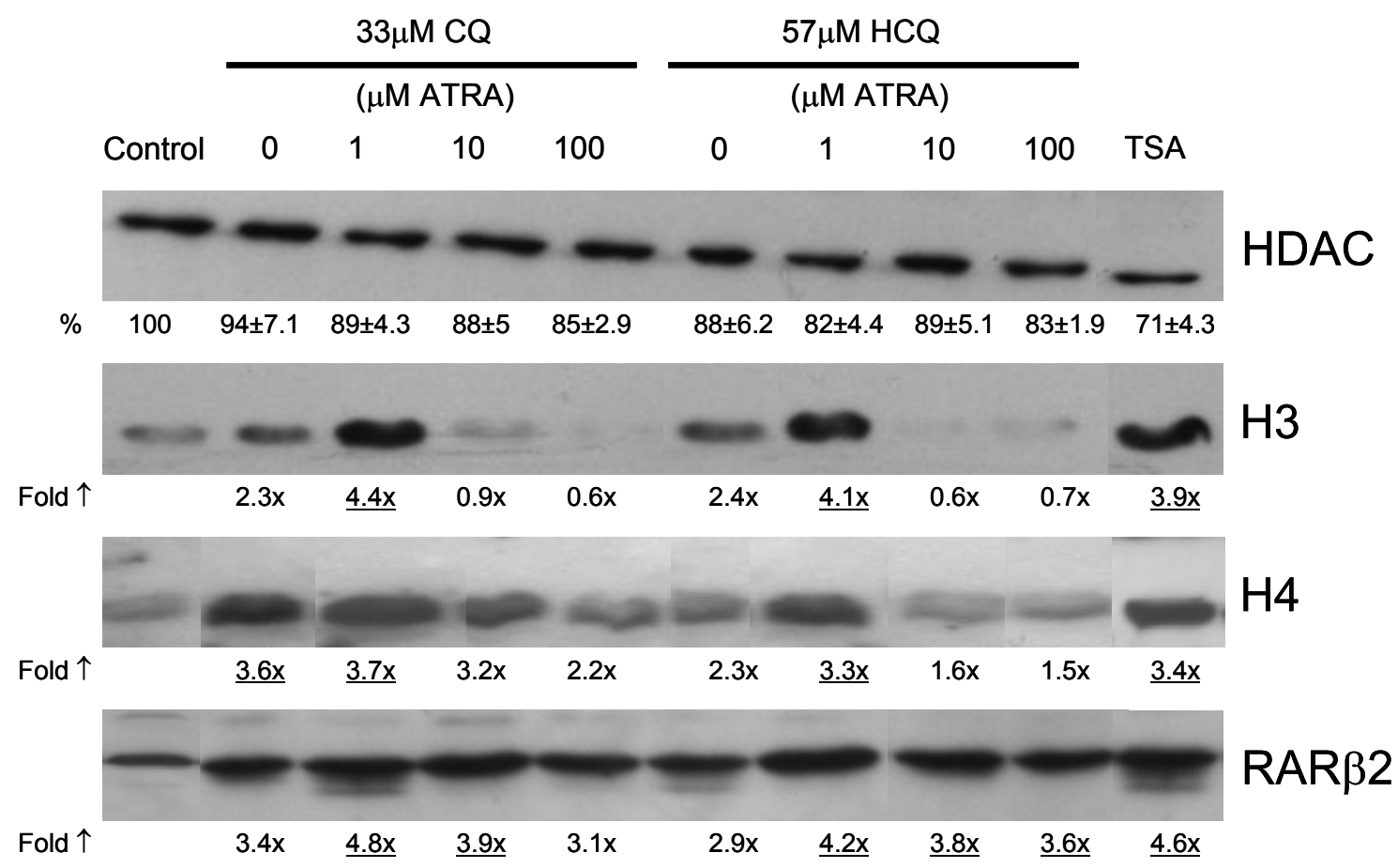




\section{$24 \mathrm{hr}$}

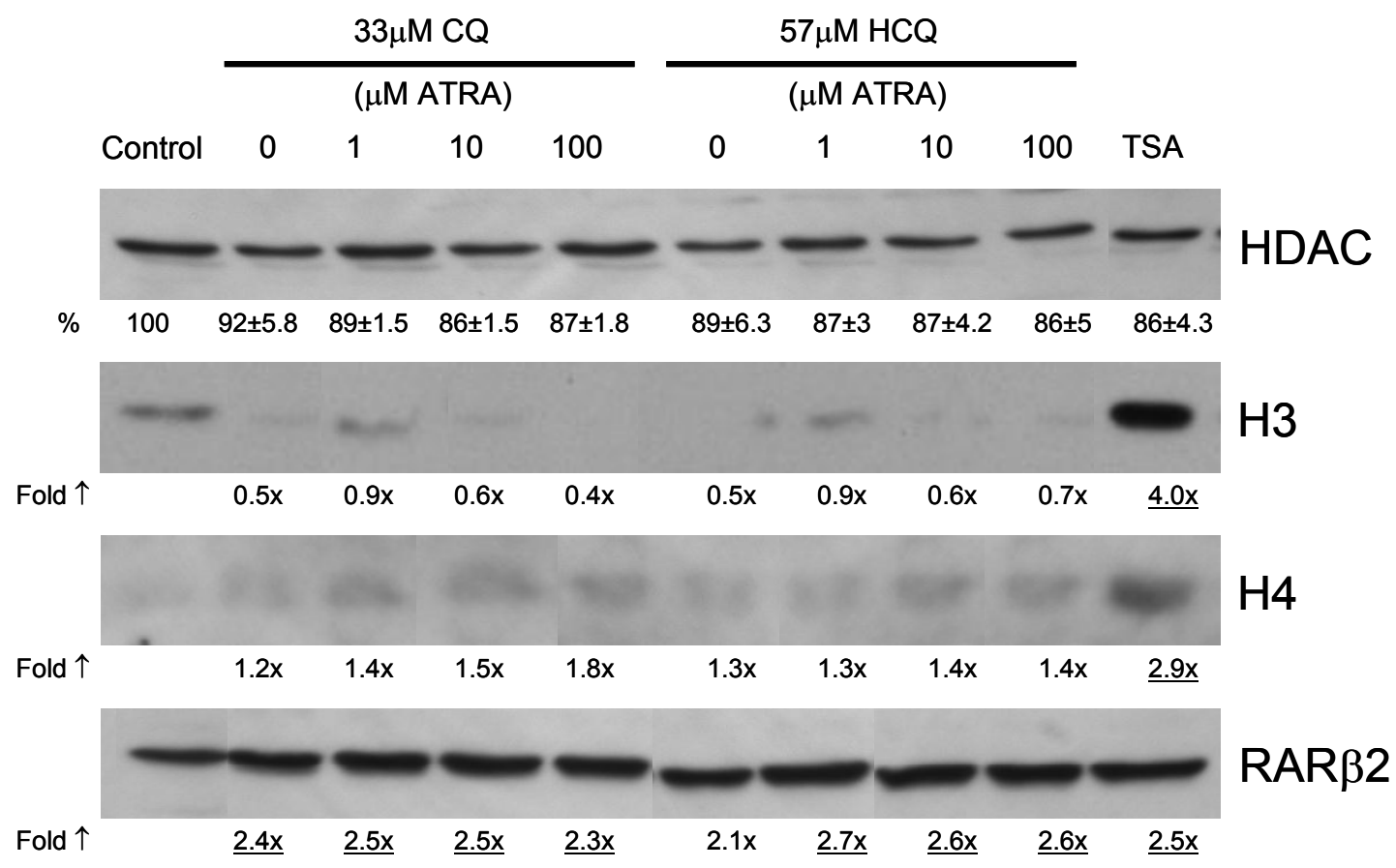




\subsection{Histone Deacetylase (HDAC) Activity of Chloroquine or Hydroxychloroquine \pm}

ATRA. To examine whether the HDAC protein levels observed in the Western blotting experiments (Figure 18) were directly or indirectly inhibited by chloroquine or hydroxchloroquine \pm pretreatment with ATRA, HDAC fluorescent activity was measured (Figure 19). This assay system measures histone deacetylase activity present in a commercial HeLa (human cervical cancer cell line) cell nuclear extract, which is rich in HDAC activity. The HDAC substrate contains an acetylated Lysine side chain. Upon incubation of the substrate with the HeLa nuclear extract, HDAC-mediated deacetylation sensitizes the substrate so that it becomes a fluorophore with addition of a developer.

The potent HDAC inhibitor, TSA, was used as a positive control. To our surprise, $1 \mu \mathrm{M}$ ATRA alone showed a statistically significant inhibitory effect on HDAC activity. Direct inhibition of HDAC activity by ATRA was sustained, but not decreased further upon combination treatment with either chloroquine or hydroxychloroquine. As a control, ATRA was added after the developer to make certain that the decrease in fluorescence intensity was not due to ATRA quenching fluorescence (Sundaram et al., 1998), but rather due to its direct inhibition of the HDAC enzyme. HDAC inhibition might contribute to both MCF-7 and MDA-MB-231 cell differentiation in response to ATRA, but not to the differentiation quinolines. To date, there are no other publications showing that ATRA acts as a direct HDAC inhibitor. Therefore, ATRA might exert its therapeutic effects as a differentiation agent by modulating HDAC enzyme activity.

The results from the HDAC activity assay combined with cell survival and differentiation assays, suggest that ATRA in combination with either chloroquine or hydroxychloroquine are promising agents for the generation of safer and less toxic 
chemotherapeutic agents for the prevention and treatment of both ER- and ER+ breast cancers. To understand the role of either chloroquine or hydroxychloroquine alone and with ATRA on histone acetylation status, mass spectrometry needed to be used to generate a profile on the level and site of histone acetylation upon treatment with the most promising combination of agents. Since ATRA in combination with HCQ had the most significant inhibitory effect on clonogenic survival, and since clonogenic survival is the most sensitive test for predicting the responsiveness of a tumor to clinical treatment, the combination of ATRA with HCQ was assessed subsequently by mass spectrometry to measure its effect on histone $\mathrm{H} 3$ and histone $\mathrm{H} 4$ acetylation sites. 


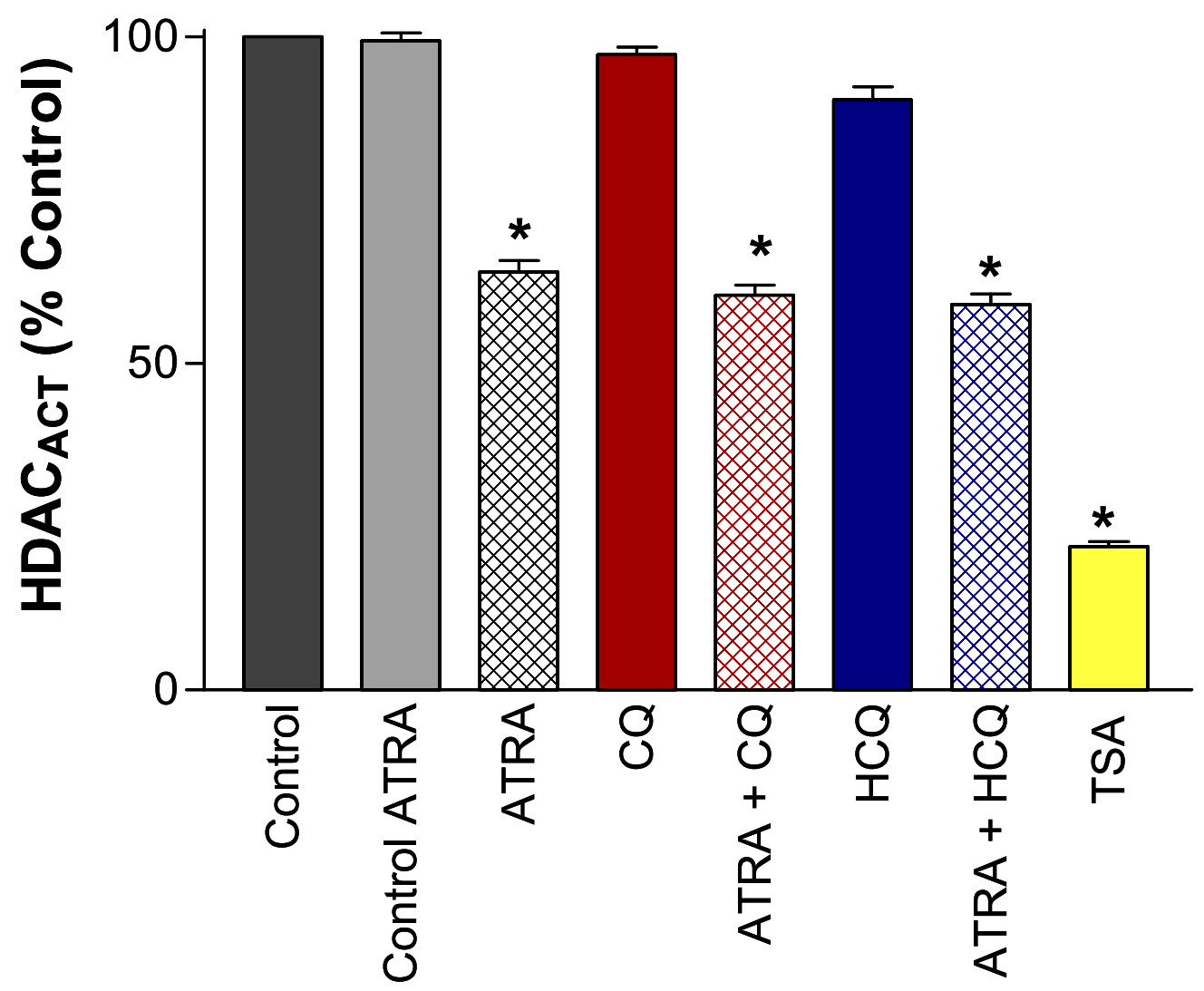

Figure 19. Histone Deacetylase (HDAC) Fluorescent Activity of Chloroquine or Hydroxychloroquine \pm ATRA. Drugs were screened for the ability to directly inhibit histone deacetylase (HDAC) activity in HeLa cell nuclear extracts using the HDAC Fluorescent Activity Assay. TSA (35nM) was used as a positive control. Chloroquine $\left(\mathrm{MCF}-7 \mathrm{IC}_{50}=33 \mu \mathrm{M}\right)$ or hydroxychloroquine $\left(\mathrm{MCF}-7 \mathrm{IC}_{50}=57 \mu \mathrm{M}\right) \pm 1 \mu \mathrm{M}$ ATRA were tested for HDAC activity. Data are the mean of $n=3$ experiments \pm SEM performed in triplicates per treatment. Statistically significant differences from the control are indicated $\left({ }^{*} \mathrm{p}<0.05\right)$. 
3.4 Identification of acetylated histone $\mathrm{H3}$ by mass spectrometry. Since an 8 hour treatment with HCQ displayed the greatest overall histone acetylation profile (Figure 18), histone H3 samples at this time-point were resolved by SDS-PAGE and visualized using Coomassie Blue staining. The histone $\mathrm{H} 3$ band was excised and digested with the endoprotease, trypsin. The resulting tryptic peptides were analyzed by mass spectrometry to determine their individual mass values. Mass values for the specific peptide sequences of the $\mathrm{N}$-terminal portion of histone $\mathrm{H} 3$ were attained by matching the measured masses with expected calculated mass values acquired from the International Protein Index (IPI) human database using Sequest Software. Acetylation sites were identified using a differential modification of 42 Daltons added to Lysine residues. Peptide sequences of histone H3 showed 13 possible acetylation sites at $\operatorname{Lys}(\mathrm{K})-4,9,14,18,23,27,36,37,56,64,79,115$, and 122 (Figure 20A).

Control cells treated with solvent (DMSO) only, displayed acetylated Lysine residues at all possible sites except for $\mathrm{K} 4$ and $\mathrm{K} 9$ of the N-terminal tail. Cells treated with hydroxychloroquine only showed acetylated Lysine residues at all possible sites except for K4; however, cells pretreated with $1 \mu \mathrm{M}$ ATRA before hydroxychloroquine addition displayed acetylated Lysine residues at all possible sites including K4. Cells treated with only TSA (positive control) also were acetylated at all possible Lysine sites. These results were consistent with the hypothesis of a "zip" model for histone H4, whereby acetylation proceeds from the direction of the nucleosome towards the N-terminal tail Lysine residues, and deacetylation proceeds in the reverse direction (Zhang et al., 2002).

A representative MS/MS peptide sequence from each treatment group is also shown (Figure 20B-E) to depict acetylation at lysine sites on the N-terminal tail of histone H3. The 
MS/MS spectra generated is the result of fragmentation of peptides that primarily occur at the amide bond (-CO-NH-) between two amino acid residues. The most commonly observed fragmentation ions are $\mathrm{b}$ and $\mathrm{y}$ ions. $\mathrm{B}$ ions are sequence-specific fragment ions derived from the $\mathrm{N}$-terminus and $\mathrm{y}$ ions are from the $\mathrm{C}$-terminus. Attempts were made to quantitate these peptide sequences in order to measure global acetylation levels. However, because the $\mathrm{N}$-terminal tail is more basic, there is a possibility of attaining a higher charge ratio, which would lead to a more complex fragmentation pattern and high background noise level and thereby, decrease the level of confidence in the identification of the peptide sequence. In order to increase the level of confidence, an in-solution protein purification using HPLC, rather than an in-gel tryptic digest, would be the preferred method-of-choice because it would increase the recovery of peptide sequences with lower charge ratios. Nevertheless, the data from the peptide sequences provide a working-model, consistent with the Zhang's "zip" model for acetylation. 
Figure 20. Histone $\mathbf{H 3}$ acetylation status in MCF-7 cells. A.) $1 \times 10^{7} \mathrm{MCF}-7$ cells were either pretreated with $1 \mu \mathrm{M}$ ATRA or not for 24 hours. Cells were then treated with solvent (DMSO; control), trichostatin A (TSA, 300nM), or hydroxychloroquine $\left(\mathrm{CQ}, \mathrm{IC}_{50}=57 \mu \mathrm{M}\right)$ for 8 hours. Total histone proteins were isolated using acid-extraction protocol from Upstate. $20 \mu \mathrm{g}$ of purified histone proteins were resolved on a $15 \%$ acrylamide gel and confirmed by Coomassie Blue staining. Histone H3 bands were excised, trypsin digested, and separated using reverse-phase HPLC with C18 column. Samples were analyzed on a ThermoFinnigan LCQ Deca XP Plus ion trap. MS/MS spectra were searched against International Protein Index (IPI) human database using Sequest Software. Acetylation sites were identified using a differential modification of 42 Daltons added to Lysine residues in two independent experiments. B-E.) MS/MS spectra of a histone H3 peptide sequence in MCF-7 cells for each treatment group. 
A.

\section{Acetylated Histone H3}

ARTKQTARKS T TGGKAPRKQL ATKAARKSAP ATGGVKKPHR YRPGTVALRE \begin{tabular}{ccc}
$\mathbf{5 6}$ & $\mathbf{6 4}$ & \multicolumn{79}{c}{} & \\
IRRYQKSTEL LIRKLPFQRL VREIAQDFKT & DLRFQSSAVM & ALQEACEAYL
\end{tabular} VGLFEDTNLC AIHAKRVTIM PKDIQLARRI RGERA

\section{Control (DMSO)}

ARTKQTARKS TGGKAPRKQL ATKAARKSAP ATGGVKKPHR YRPGTVALRE $\begin{array}{llll}56 & 64 & 79 & \\ \text { IRRYQKSTEL LIRKLPFQRL VREIAQDFKT } & \text { DLRFQSSAVM ALQEACEAYL }\end{array}$ VGLFEDTNLC AIHAKRVTIM PKDIQLARRI RGERA

\section{Hydroxychloroquine}

ARTKQTARKS TGGKAPRKQL ATKAARKSAP ATGGVKKPHR YRPGTVALRE

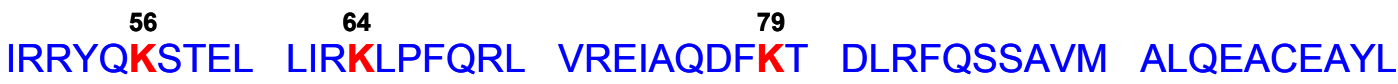
VGLFEDTNLC AIHAKRVTIM PKDIQLARRI RGERA

\section{ATRA + Hydroxychloroquine}

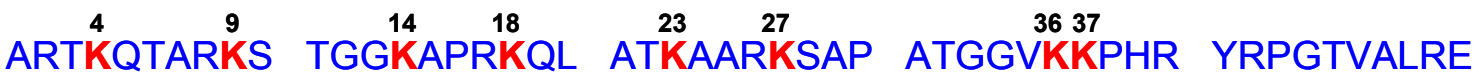

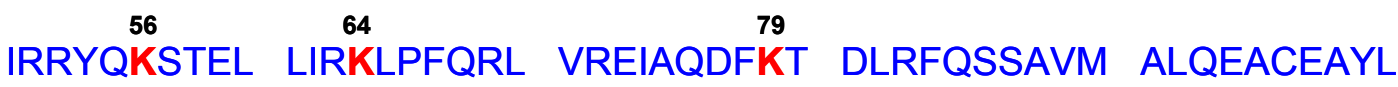
VGLFEDTNLC AIHAKRVTIM PKDIQLARRI RGERA

\section{TSA}

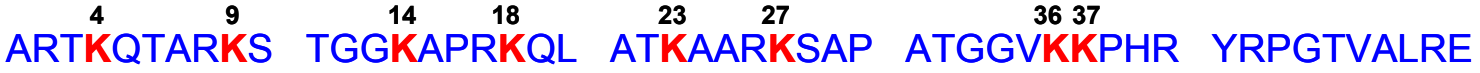
$\begin{array}{cccc}56 & 64 & 79 & \\ \text { IRRYQKSTEL LIRKLPFQRL VREIAQDFKT } & \text { DLRFQSSAVM ALQEACEAYL }\end{array}$ VGLFEDTNLC AIHAKRVTIM PKDIQLARRI RGERA 


\section{B. Control (DMSO)}

\begin{tabular}{|c|c|c|c|c|c|c|c|c|c|}
\hline Seq & $\#$ & $\mathbf{b}$ & $\mathbf{y}$ & $\mathbf{( + 1 )}$ & Seq & $\#$ & $\mathbf{b}$ & $\mathbf{y}$ & $(\mathbf{+ 1})$ \\
\hline $\mathrm{A}$ & 1 & 72 & 1531.9 & 14 & $\mathrm{R}$ & 8 & 913.5 & 775.4 & 7 \\
$\mathrm{R}$ & 2 & 228.1 & 1460.8 & 13 & $\mathrm{~K}$ & 9 & 1041.6 & 619.3 & 6 \\
$\mathrm{~T}$ & 3 & 329.2 & 1304.7 & 12 & $\mathrm{~S}$ & 10 & 1128.7 & 491.2 & 5 \\
$\mathrm{~K}$ & 4 & 457.3 & 1203.7 & 11 & $\mathrm{~T}$ & 11 & 1229.7 & 404.2 & 4 \\
$\mathrm{Q}$ & 5 & 585.3 & $\mathbf{1 0 7 5 . 6}$ & 10 & $\mathrm{G}$ & 12 & 1286.7 & 303.2 & 3 \\
$\mathrm{~T}$ & 6 & 686.4 & 947.5 & 9 & $\mathrm{G}$ & 13 & 1343.8 & 246.1 & 2 \\
$\mathrm{~A}$ & 7 & $\mathbf{7 5 7 . 4}$ & 846.5 & 8 & *K & 14 & 1513.8 & 189.1 & 1 \\
\hline
\end{tabular}

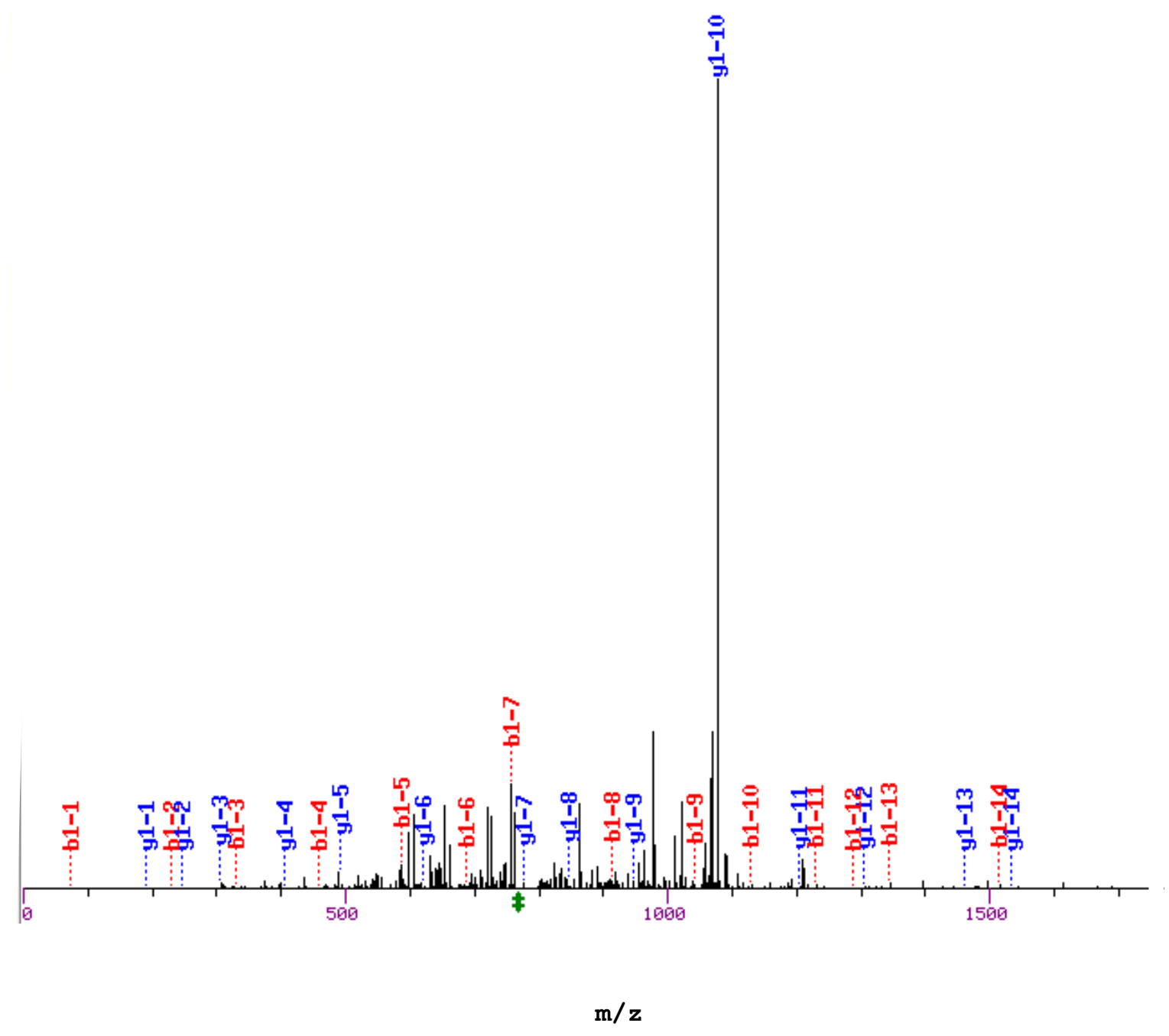




\section{Hydroxychloroquine}

\begin{tabular}{|c|c|c|c|c|c|c|c|c|c|}
\hline Seq & \# & b & $y$ & $(+1)$ & Seq & \# & b & $y$ & $(+1)$ \\
\hline A & 1 & 72 & 2651.5 & 23 & G & 13 & 1385.8 & 1323.7 & 11 \\
\hline $\mathrm{R}$ & 2 & 228.1 & 2580.4 & 22 & $\star_{\mathrm{K}}$ & 14 & 1555.8 & 1266.7 & 10 \\
\hline $\mathrm{T}$ & 3 & 329.2 & 2424.3 & 21 & A & 15 & 1626.9 & 1096.6 & 9 \\
\hline K & 4 & 457.3 & 2323.3 & 20 & P & 16 & 1723.9 & 1025.6 & 8 \\
\hline$Q$ & 5 & 585.3 & 2195.2 & 19 & $\mathrm{R}$ & 17 & 1880.0 & 928.5 & 7 \\
\hline $\mathrm{T}$ & 6 & 686.4 & 2067.1 & 18 & $\star_{\mathrm{K}}$ & 18 & 2050.1 & 772.4 & 6 \\
\hline A & 7 & 757.4 & 1966.1 & 17 & $Q$ & 19 & 2178.2 & 602.3 & 5 \\
\hline $\mathrm{R}$ & 8 & 913.5 & 1895 & 16 & L & 20 & 2291.3 & 474.3 & 4 \\
\hline$\star_{\mathrm{K}}$ & 9 & 1083.6 & 1738.9 & 15 & A & 21 & 2362.3 & 361.2 & 3 \\
\hline S & 10 & 1170.7 & 1568.8 & 14 & $\mathrm{~T}$ & 22 & 2463.4 & 290.2 & 2 \\
\hline $\mathrm{T}$ & 11 & 1271.7 & 1481.8 & 13 & $\star_{\mathrm{K}}$ & 23 & 2633.5 & 189.1 & 1 \\
\hline G & 12 & 1328.7 & 1380.8 & 12 & & & & & \\
\hline
\end{tabular}

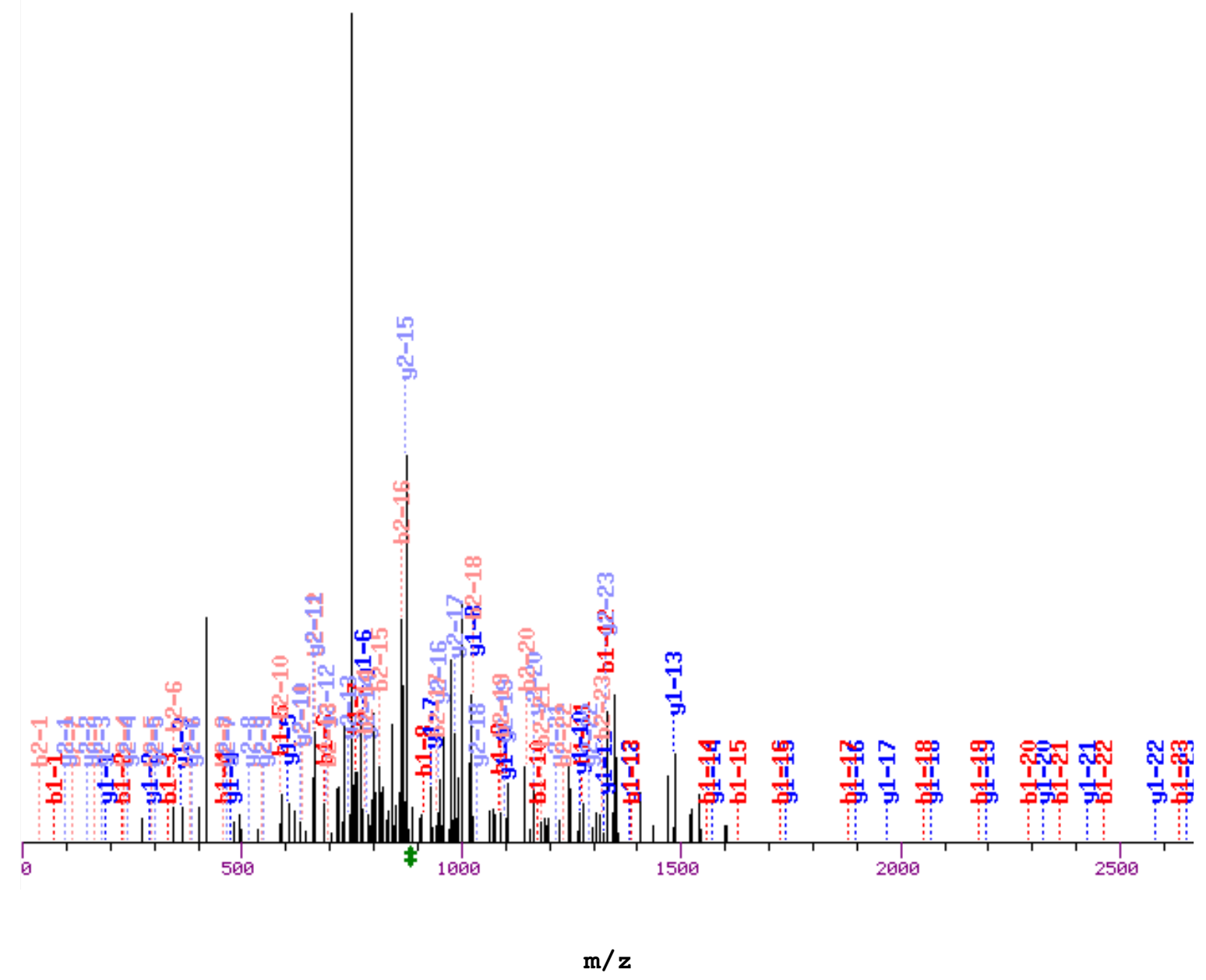




\section{ATRA + Hydroxychloroquine}

\begin{tabular}{|c|c|c|c|c|c|c|c|c|c|c|}
\hline Seq & $\#$ & $\mathbf{b}$ & $\mathbf{y}$ & $\mathbf{( + 1 )}$ & Seq & $\#$ & $\mathbf{b}$ & $\mathbf{y}$ & $\mathbf{( + 1 )}$ \\
\hline $\mathrm{A}$ & 1 & 72 & 2110.1 & 18 & $\mathrm{~S}$ & 10 & 1212.7 & 985.5 & 9 \\
$\mathrm{R}$ & 2 & 228.1 & 2039.1 & 17 & $\mathrm{~T}$ & 11 & 1313.7 & 898.5 & 8 \\
$\mathrm{~T}$ & 3 & 329.2 & 1883.0 & 16 & $\mathrm{G}$ & 12 & 1370.7 & $\mathbf{7 9 7 . 4}$ & 7 \\
$\star \mathrm{K}$ & 4 & 499.3 & 1782.0 & 15 & $\mathrm{G}$ & 13 & 1427.8 & 740.4 & 6 \\
$\mathrm{Q}$ & 5 & 627.3 & 1611.9 & 14 & $\star \mathrm{K}$ & 14 & 1597.8 & 683.4 & 5 \\
$\mathrm{~T}$ & 6 & 728.4 & 1483.8 & 13 & $\mathrm{~A}$ & 15 & 1668.9 & 513.3 & 4 \\
$\mathrm{~A}$ & 7 & $\mathbf{7 9 9 . 4}$ & 1382.8 & 12 & $\mathrm{P}$ & 16 & 1765.9 & 442.3 & 3 \\
$\mathrm{R}$ & 8 & 955.5 & 1311.7 & 11 & $\mathrm{R}$ & 17 & 1922 & 345.2 & 2 \\
$\star \mathrm{K}$ & 9 & $\mathbf{1 1 2 5 . 6}$ & 1155.6 & 10 & $\star \mathrm{K}$ & 18 & 2092.1 & 189.1 & 1 \\
\hline
\end{tabular}

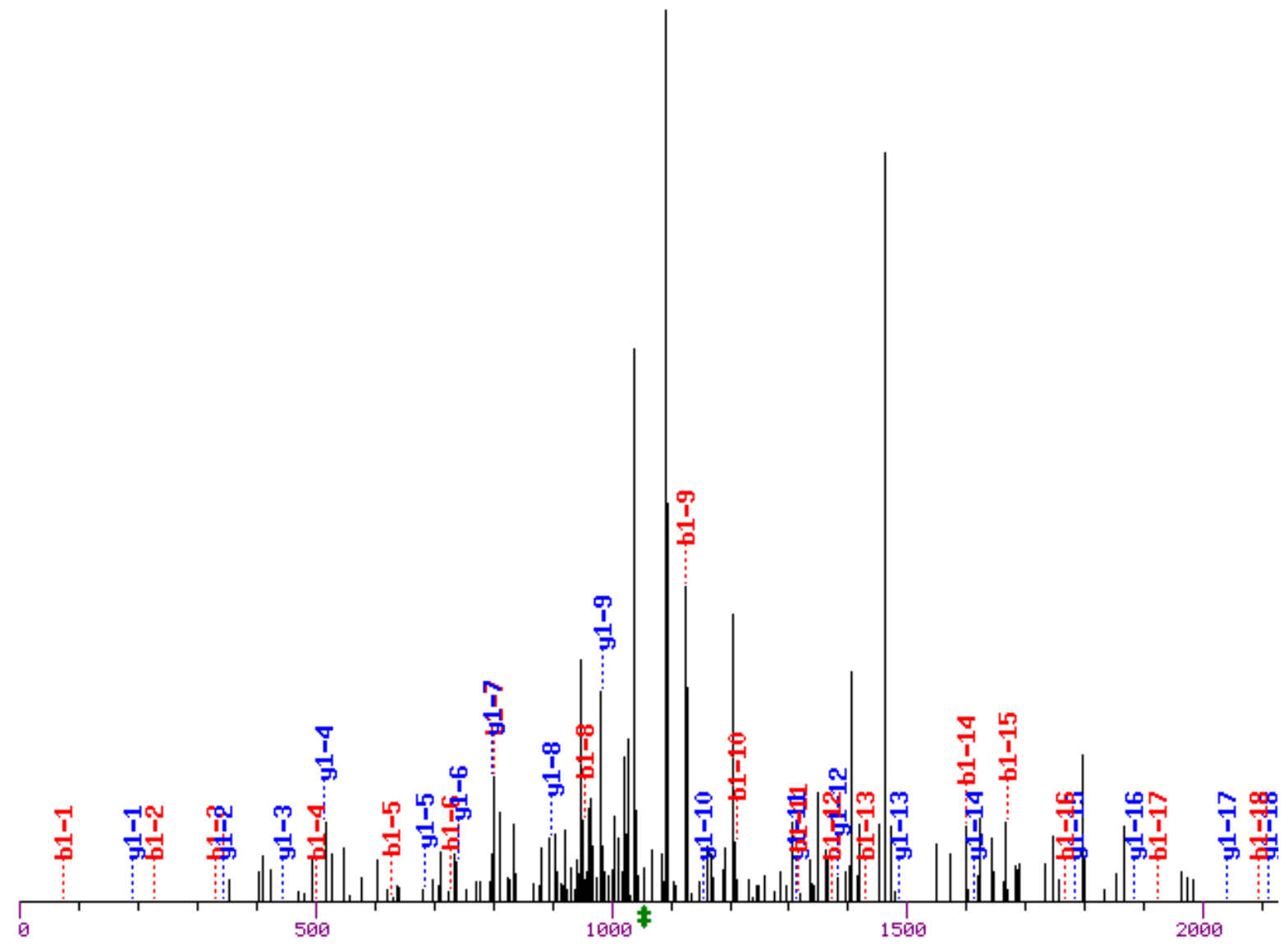

$\mathrm{m} / \mathrm{z}$ 


\section{E. Trichostatin A (TSA)}

\begin{tabular}{|c|c|c|c|c|c|c|c|c|c|}
\hline Seq & $\#$ & b & $y$ & $(+1)$ & Seq & \# & b & y & $(+1)$ \\
\hline A & 1 & 72 & 2693.5 & 23 & G & 13 & 1427.8 & 1323.7 & 11 \\
\hline R & 2 & 228.1 & 2622.4 & 22 & $* \mathrm{~K}$ & 14 & 1597.8 & 1266.7 & 10 \\
\hline $\mathrm{T}$ & 3 & 329.2 & 2466.3 & 21 & A & 15 & 1668.9 & 1096.6 & 9 \\
\hline$*_{\mathrm{K}}$ & 4 & 499.3 & 2365.3 & 20 & $\mathrm{P}$ & 16 & 176.5 .9 & 1025.6 & 8 \\
\hline$Q$ & 5 & 627.3 & 2195.2 & 19 & $\mathrm{R}$ & 17 & 1922 & 928.5 & 7 \\
\hline $\mathrm{T}$ & 6 & 728.4 & 2067.1 & 18 & $\star \mathrm{K}$ & 18 & 2092.1 & 772.4 & 6 \\
\hline A & 7 & 799.4 & 1966.1 & 17 & Q & 19 & 2220.2 & 602.3 & 5 \\
\hline $\mathrm{R}$ & 8 & 955.5 & 1895 & 16 & $\mathrm{~L}$ & 20 & 2333.3 & 474.3 & 4 \\
\hline$*_{\mathrm{K}}$ & 9 & 1125.6 & 1738.9 & 15 & A & 21 & 2404.3 & 361.2 & 3 \\
\hline S & 10 & 1212.7 & 1568.8 & 14 & $\mathrm{~T}$ & 22 & 2505.4 & 290.2 & 2 \\
\hline $\mathrm{T}$ & 11 & 1313.7 & 1481.8 & 13 & $\star \mathrm{K}$ & 23 & 2675.5 & 189.1 & 1 \\
\hline G & 12 & 1370.7 & 1380.8 & 12 & & & & & \\
\hline
\end{tabular}

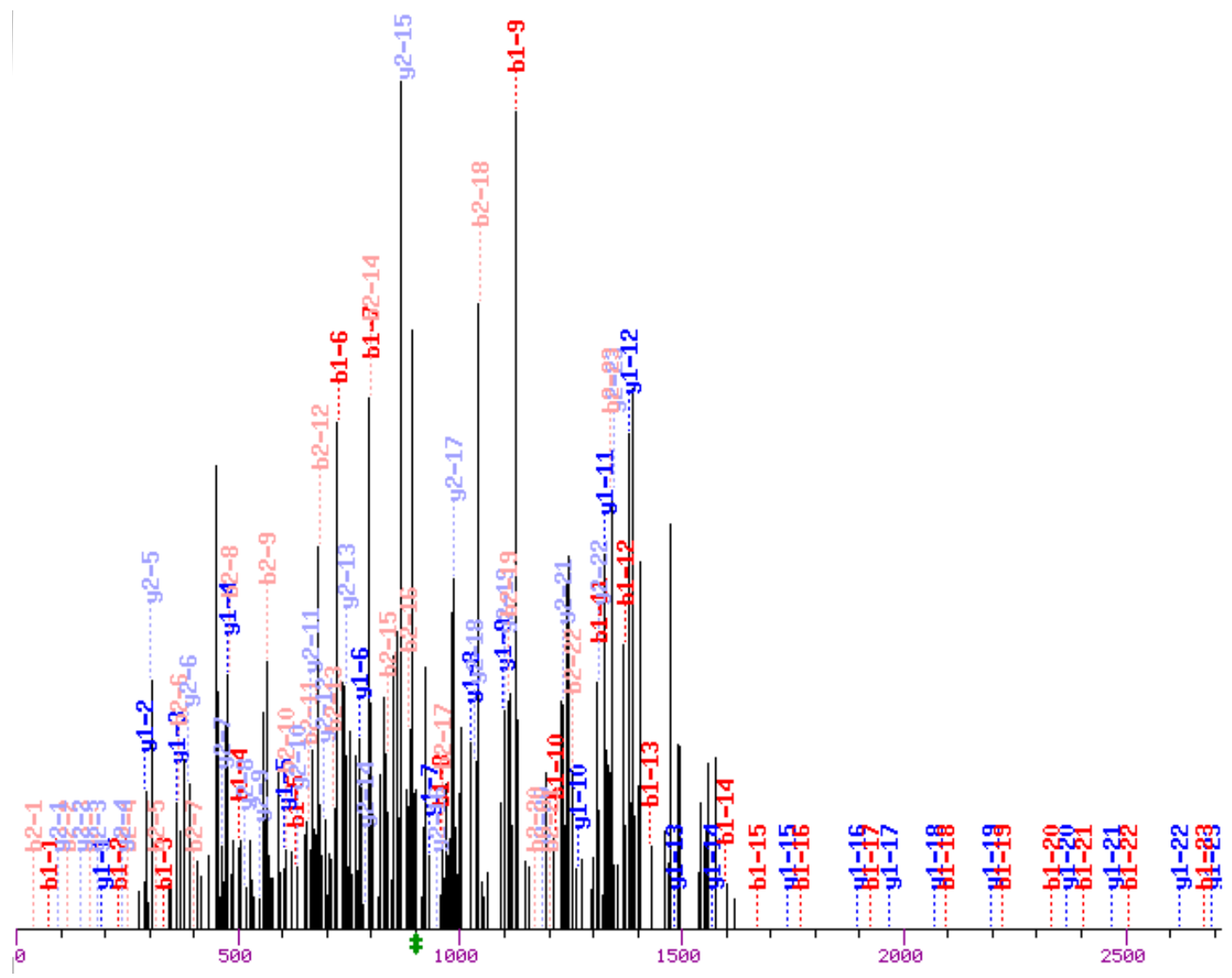

$\mathrm{m} / \mathbf{z}$ 
3.5 Identification of acetylated histone $\mathbf{H} 4$ by mass spectrometry. Histone $\mathrm{H} 4$ samples were also resolved by SDS-PAGE and visualized using Coomassie Blue staining. The histone $\mathrm{H} 4$ band was excised and digested with trypsin. The resulting tryptic peptides were analyzed by mass spectrometry to determine their individual mass values. Mass values for the specific peptide sequences of the N-terminal portion of histone $\mathrm{H} 4$ were attained by matching the measured masses with expected calculated mass values acquired from the International Protein Index (IPI) human database. Acetylation sites were identified using a differential modification of 42 Daltons added to Lysine residues. The acetylation sites for histone $\mathrm{H} 4$ were established showing 11 possible acetylation sites at Lys(K)-5, 8, 12, 16, 20, 31, 44, 59, 77, 79, and 91 (Figure 21A).

Control cells treated with solvent (DMSO), displayed acetylated Lysine residues at all possible sites except for K5, K8, and K12. Cells treated with hydroxychloroquine only showed acetylated Lysine residues at all possible sites except for K5 and K8. Interestingly, cells with only TSA treatment (positive control) and cells pretreated with $1 \mu \mathrm{M}$ ATRA before hydroxychloroquine addition displayed acetylated Lysine residues at all possible sites. These results were once again consistent with the hypothesis of a "zip" model, whereby acetylation of histone $\mathrm{H} 4$ proceeds in the direction from the nucleosome towards the N-terminal tail lysine residues, and deacetylation proceeds in the reverse direction (Zhang et al., 2002). In summary, hydroxychloroquine alone showed modification at K12 sites compared to control cells. The remaining acetylation sites, $\mathrm{K} 5$ and $\mathrm{K} 8$ were modified when cells were pretreated with $1 \mu \mathrm{M}$ ATRA.

The site of acetylation on the N-terminal tail of histone $\mathrm{H} 4$ was generated by fragmentation of a peptide sequence from each treatment group (Figure 21B-E). Although 
attempts at quantitation were unsuccessful using the in-gel tryptic digest to measure global acetylation levels in both histone $\mathrm{H} 3$ and histone $\mathrm{H} 4$, an in-solution protein purification using HPLC would be a more promising alternative for increasing the recovery of peptide sequences with lower charge ratios, and thus increasing the confidence of peptide identification. Nevertheless, the data from the peptide sequences provide a working-model, consistent with the Zhang's "zip" model for acetylation. Using this model, the overall data suggest that hydroxychloroquine may exert its effects by instead regulating acetylation via histone acetyltransferase (HAT) either directly or indirectly since both histone $\mathrm{H} 3$ and histone $\mathrm{H} 4$ lysine sites were modified in the direction of acetylation, but not all lysine sites were acetylated because histone deacetylase (HDAC) was not completely inhibited by hydroxychloroquine alone. On the other hand, since ATRA has been identified as a direct HDAC inhibitor, the model would explain why all the N-terminal lysine sites of histones $\mathrm{H} 3$ and H4 were acetylated upon combination treatment with ATRA and hydroxychloroquine. 
Figure 21. Histone $\mathbf{H 4}$ acetylation status in MCF-7 cells. A.) $1 \times 10^{7} \mathrm{MCF}-7$ cells were either pretreated with $1 \mu \mathrm{M}$ ATRA or not for 24 hours. Cells were then treated with solvent (DMSO; control), trichostatin A $(\mathrm{TSA}, 300 \mathrm{nM})$, or hydroxychloroquine $\left(\mathrm{HCQ}, \mathrm{IC}_{50}=57 \mu \mathrm{M}\right)$ for 8 hours. Total histone proteins were isolated using acid-extraction protocol from Upstate. $20 \mu \mathrm{g}$ of purified histone proteins were resolved on a $15 \%$ acrylamide gel and confirmed by Coomassie Blue staining. Histone H4 bands were excised, trypsin digested, and separated using reverse-phase HPLC with C18 column. Samples were analyzed on a ThermoFinnigan LCQ Deca XP Plus ion trap. MS/MS spectra were searched against International Protein Index (IPI) human database using Sequest Software. Acetylation sites were identified using a differential modification of 42 Daltons added to Lysine residues in two independent experiments. B-E.) MS/MS spectra of a histone H4 peptide sequence in MCF-7 cells for each treatment group. 
A.

\section{Acetylated Histone $\mathrm{H4}$}

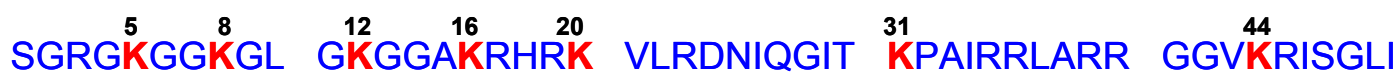

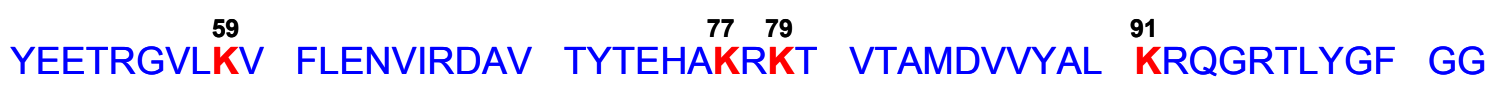

\section{Control (DMSO)}

SGRGKGGKGL GKGGAKRHRK VLRDNIQGIT $\stackrel{16}{20}$ KPAIRRLARR GGVKRISGLI

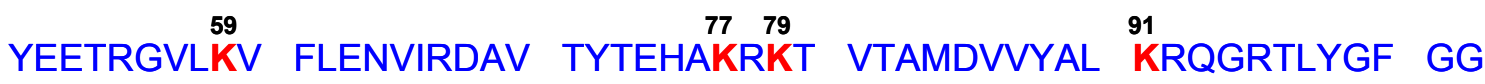

\section{Hydroxychloroquine}

SGRGKGGKGL GKGGAKRHRK VLRDNIQGIT $\stackrel{12}{12}{ }^{20}$ KAIRRLARR GGVKRISGLI

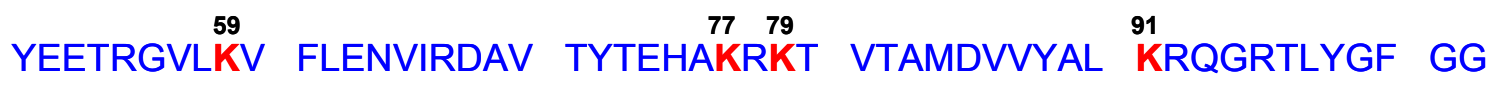

\section{ATRA + Hydroxychloroquine}

SGRGKGGKGL GKGGAKRHRK VLRDNIQGIT $\stackrel{31}{20}$ KPAIRRLARR GGVKRISGLI $\begin{array}{llll}59 & 77 & 79 & 91\end{array}$

YEETRGVLKV FLENVIRDAV TYTEHAKRKT VTAMDVVYAL KRQGRTLYGF GG

\section{TSA}

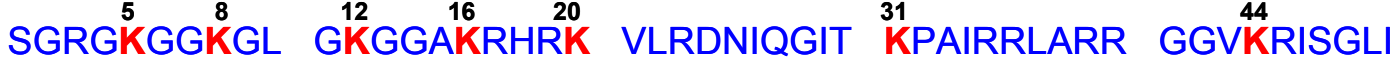

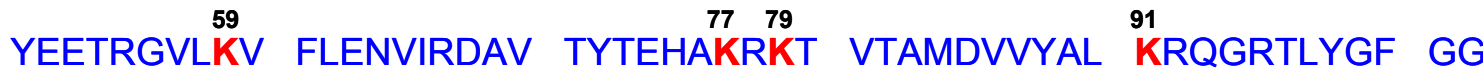




\section{B. Control (DMSO)}

\begin{tabular}{|c|c|c|c|c|c|c|c|c|c|}
\hline Seq & $\#$ & b & $y$ & $(+1)$ & Seq & $\#$ & b & $y$ & $(+1)$ \\
\hline S & 1 & 88.0 & 2444.4 & 23 & G & 13 & 1140.7 & 1361.8 & 11 \\
\hline G & 2 & 145.1 & 2357.4 & 22 & G & 14 & 1197.7 & 1304.8 & 10 \\
\hline $\mathrm{R}$ & 3 & 301.2 & 2300.4 & 21 & A & 15 & 1268.7 & 1247.8 & 9 \\
\hline G & 4 & 358.2 & 2144.3 & 20 & $\star \mathrm{K}$ & 16 & 1438.8 & 1176.7 & 8 \\
\hline K & 5 & 486.3 & 2087.3 & 19 & $\mathrm{R}$ & 17 & 1594.9 & 1006.6 & 7 \\
\hline G & 6 & 543.3 & 1959.2 & 18 & $\mathrm{H}$ & 18 & 1732.0 & 859.5 & 6 \\
\hline G & 7 & 600.3 & 1902.1 & 17 & $\mathrm{R}$ & 19 & 1888.1 & 713.5 & 5 \\
\hline K & 8 & 728.4 & 1845.1 & 16 & $\star \mathrm{K}$ & 20 & 2058.2 & 557.4 & 4 \\
\hline G & 9 & 785.4 & 1717.0 & 15 & V & 21 & 2157.2 & 387.3 & 3 \\
\hline L & 10 & 898.5 & 1660.0 & 14 & $\mathrm{~L}$ & 22 & 2270.3 & 266.2 & 2 \\
\hline G & 11 & 955.5 & 1546.9 & 13 & $\mathrm{R}$ & 23 & 2826.4 & 175.1 & 1 \\
\hline K & 12 & 1093.6 & 1489.9 & 12 & & & & & \\
\hline
\end{tabular}

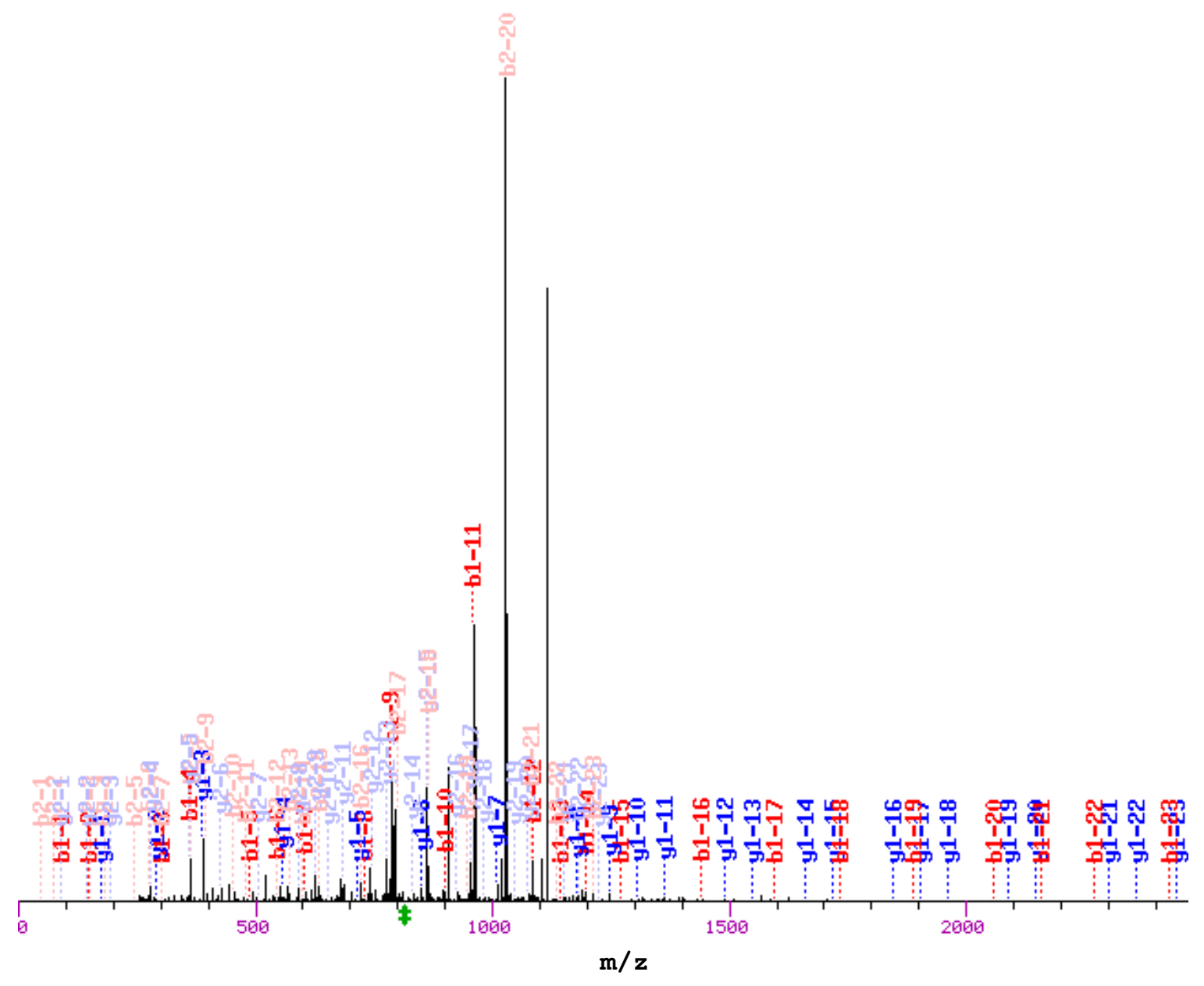




\section{Hydroxychloroquine}

\begin{tabular}{|c|c|c|c|c|c|c|c|c|c|c|}
\hline Seq & \# & $\mathbf{b}$ & $\mathbf{y}$ & $\mathbf{( + 1 )}$ & Seq & \# & $\mathbf{b}$ & $\mathbf{y}$ & $\mathbf{( + 1 )}$ \\
\hline S & 1 & 88.0 & 1948.1 & 19 & G & 11 & 955.5 & 1050.6 & 9 \\
G & 2 & 145.1 & 1861.1 & 18 & $* \mathrm{~K}$ & 12 & 1125.6 & 993.5 & 8 \\
R & 3 & 301.2 & 1804.0 & 17 & G & 13 & 1182.7 & $\mathbf{8 2 3 . 5}$ & 7 \\
G & 4 & 358.2 & 1647.9 & 16 & G & 14 & 1239.7 & 766.4 & 6 \\
K & 5 & 486.3 & 1590.9 & 15 & A & 15 & 1310.7 & 709.4 & 5 \\
G & 6 & 543.3 & 1462.8 & 14 & $\star K$ & 16 & 1480.8 & 638.4 & 4 \\
G & 7 & 600.3 & 1405.8 & 13 & R & 17 & 1636.9 & 468.3 & 3 \\
K & 8 & 728.4 & 1348.8 & 12 & H & 18 & 1774.0 & 312.2 & 2 \\
G & 9 & 785.4 & 1220.7 & 11 & R & 19 & 1930.1 & 175.1 & 1 \\
L & 10 & 898.5 & 1163.7 & 10 & & & & & \\
\hline
\end{tabular}

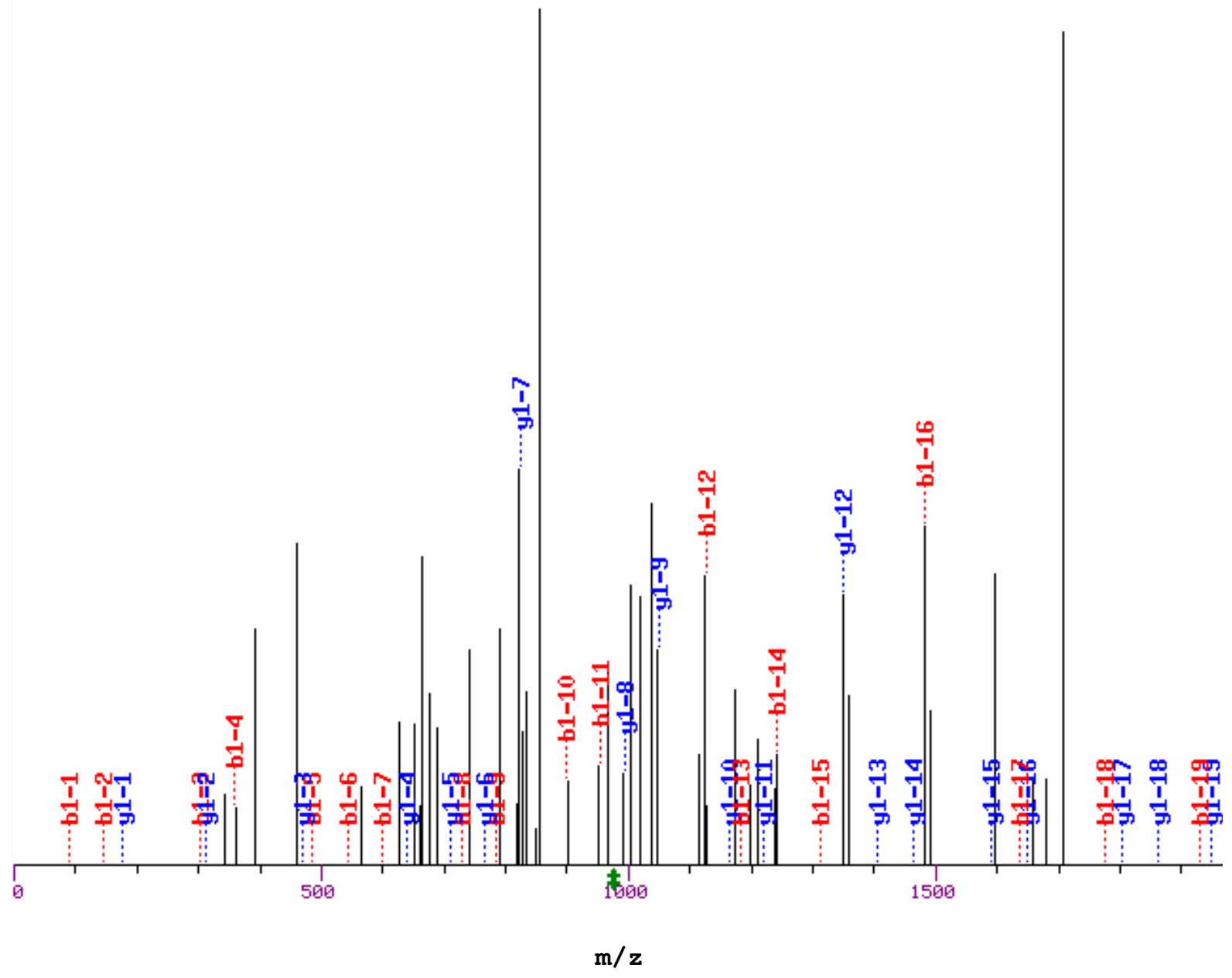




\section{ATRA + Hydroxychloroquine}

\begin{tabular}{|c|c|c|c|c|c|c|c|c|c|c|}
\hline Seq & \# & $\mathbf{b}$ & $\mathbf{y}$ & $\mathbf{( + 1 )}$ & Seq & \# & $\mathbf{b}$ & $\mathbf{y}$ & $\mathbf{( + 1 )}$ \\
\hline S & 1 & 88.0 & 2032.1 & 19 & G & 11 & 1039.5 & 1050.6 & 9 \\
G & 2 & 145.1 & 1945.1 & 18 & $* \mathrm{~K}$ & 12 & 1209.6 & 993.5 & 8 \\
R & 3 & 301.2 & 1888.0 & 17 & G & 13 & 1266.7 & 823.5 & 7 \\
G & 4 & 358.2 & 1731.9 & 16 & G & 14 & 1323.7 & 766.4 & 6 \\
* K & 5 & 528.3 & 1674.9 & 15 & A & 15 & 1394.7 & 709.4 & 5 \\
G & 6 & 585.3 & 1504.8 & 14 & $*$ K & 16 & 1564.8 & $\mathbf{6 3 8 . 4}$ & 4 \\
G & 7 & 642.3 & 1447.8 & 13 & R & 17 & 1720.9 & 468.3 & 3 \\
*K & 8 & 812.4 & 1390.8 & 12 & H & 18 & 1858.0 & 312.2 & 2 \\
G & 9 & 869.4 & 1220.7 & 11 & R & 19 & 2014.1 & 175.1 & 1 \\
L & 10 & 982.5 & 1163.7 & 10 & & & & & \\
\hline
\end{tabular}

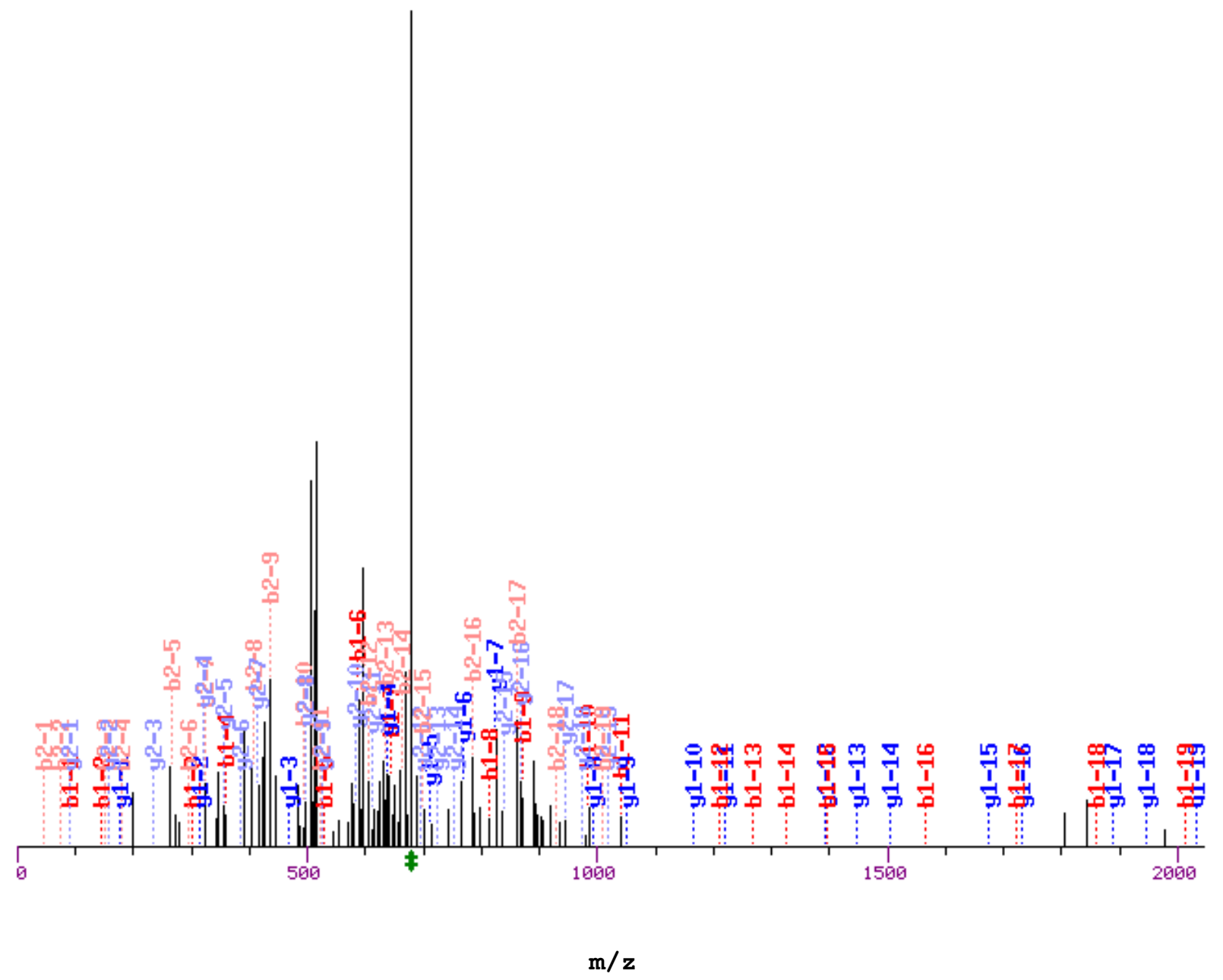




\section{E. Trichostatin A (TSA)}

\begin{tabular}{|c|c|c|c|c|c|c|c|c|c|}
\hline Seq & $\#$ & b & $y$ & $(+1)$ & Seq & $\#$ & b & y & $(+1)$ \\
\hline$S$ & 1 & 88.0 & 2570.4 & 23 & G & 13 & 1266.7 & 1361.8 & 11 \\
\hline G & 2 & 145.1 & 2463.4 & 22 & G & 14 & 1323.7 & 1304.8 & 10 \\
\hline $\mathrm{R}$ & 3 & 301.2 & 2426.4 & 21 & A & 15 & 1394.7 & 1247.8 & 9 \\
\hline G & 4 & 358.2 & 2270.3 & 20 & $\star_{\mathrm{K}}$ & 16 & 1564.8 & 1176.7 & 8 \\
\hline$\star \mathrm{K}$ & 5 & 528.3 & 2213.3 & 19 & $\mathrm{R}$ & 17 & 1720.9 & 1006.6 & 7 \\
\hline G & 6 & 585.3 & 2043.2 & 18 & $\mathrm{H}$ & 18 & 1858.0 & 850.5 & 6 \\
\hline G & 7 & 642.3 & 1986.1 & 17 & $\mathrm{R}$ & 19 & 2014.1 & 713.5 & 5 \\
\hline *K & 8 & 812.4 & 1929.1 & 16 & $\star_{\mathrm{K}}$ & 20 & 2184.2 & 557.4 & 4 \\
\hline G & 9 & 869.4 & 1759.0 & 15 & V & 21 & 2283.2 & 387.3 & 3 \\
\hline L & 10 & 982.5 & 1702.0 & 14 & $\mathrm{~L}$ & 22 & 2396.3 & 288.2 & 2 \\
\hline G & 11 & 1039.5 & 1588.9 & 13 & R & 23 & 2552.4 & 175.1 & 1 \\
\hline$\star \mathrm{K}$ & 12 & 1209.6 & 1531.9 & 12 & & & & & \\
\hline
\end{tabular}

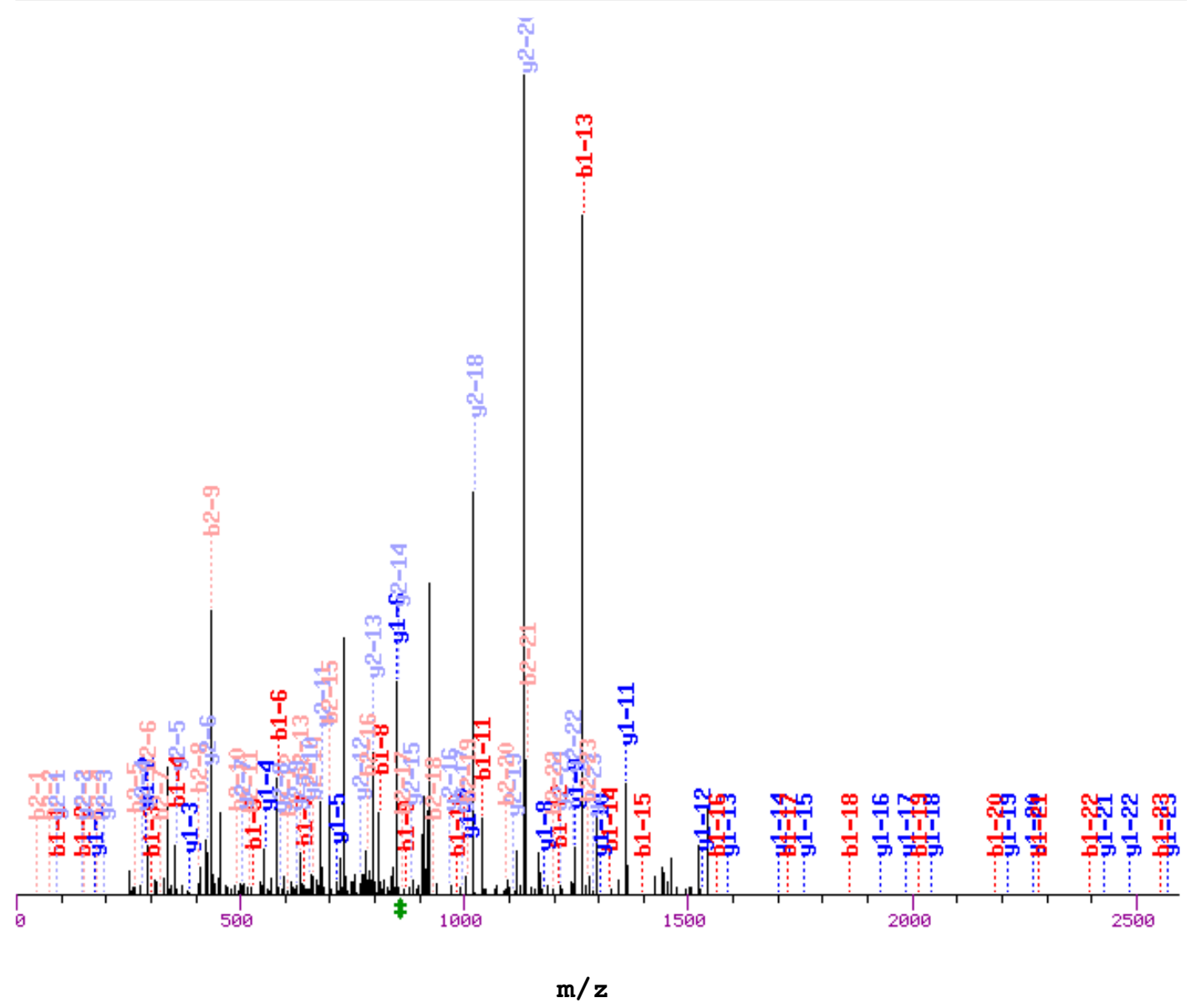




\subsection{Histone Acetylase (HAT) Activity of Hydroxychloroquine and ATRA. A non-}

radioactive ELISA assay containing PCAF as an active source of HAT enzyme was used to test whether the observed acetylation response is due to modulation of HAT activity (Figure 22). Interestingly, both ATRA and hydroxychloroquine caused direct HAT activation shown by increased acetylation of histone $\mathrm{H} 3$ and histone $\mathrm{H} 4$ substrate peptides. Hydroxychloroquine, augmented HAT activity more than ATRA alone; however, the combination of the drugs showed a more pronounced activation of HAT compared to basal levels. The hypothesis was that HCQ acts via HAT activation. The overall data suggest that direct HAT activation might contribute to both MCF-7 and MDA-MB-231 cell differentiation in response to the differentiation quinoline, hydroxychloroquine. On the other hand, ATRA seems to display dual roles by activating HAT as well as directly inhibiting HDAC (Figure 19). ATRA works thru the same mechanism of hydroxychloroquine by modulating HAT activity; therefore, an increase in HAT activity was seen upon combination treatment with both hydroxychloroquine and ATRA. However, ATRA acts via an independent mechanism by inhibiting HDAC enzymatic activity. Thereby, enhanced antiproliferative, differentiation, and histone acetylation responses are achieved during combination therapy with ATRA rather than the differentiating quinoline alone. 


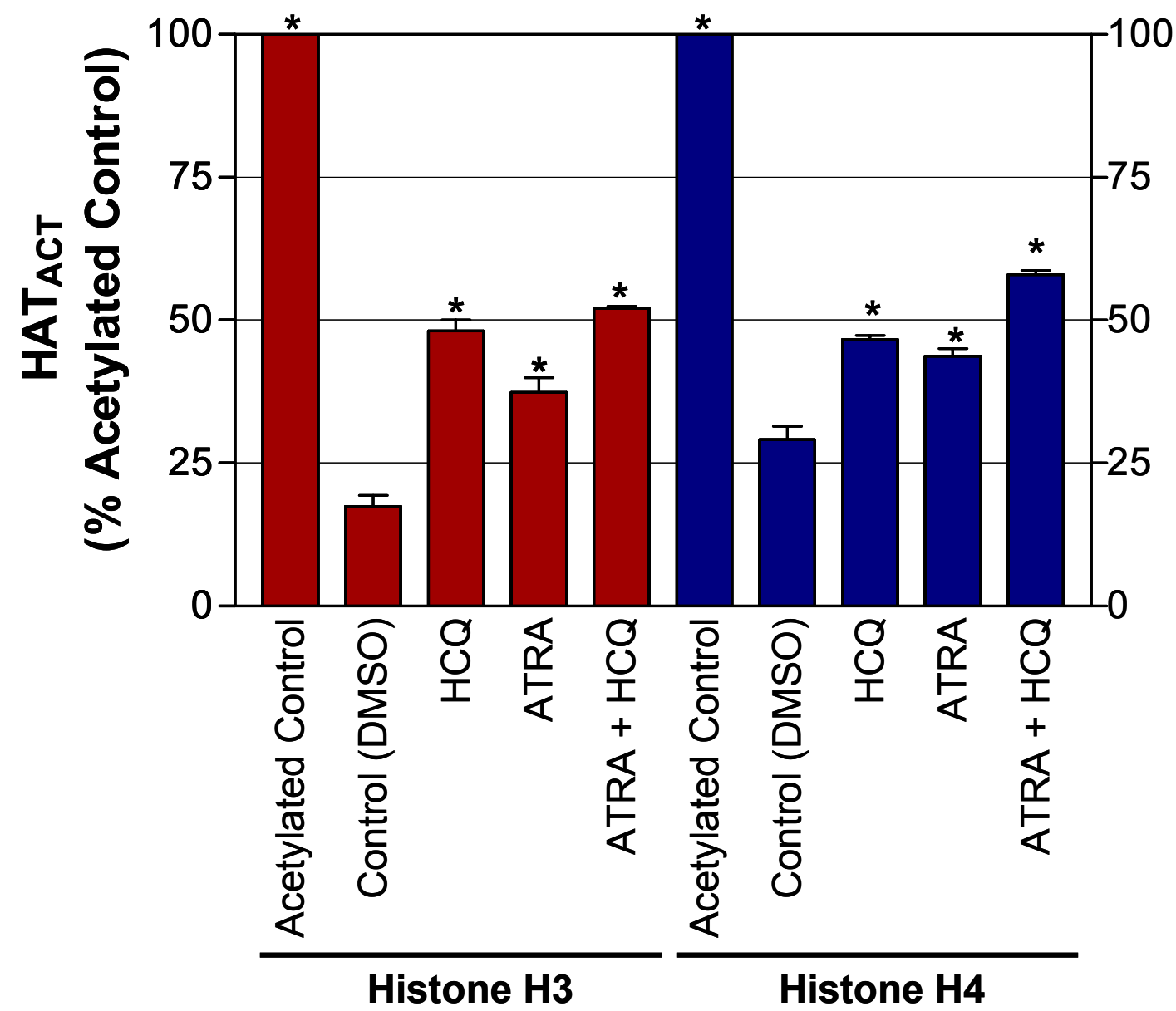

Figure 22. Histone Acetyltransferase (HAT) Activity of Hydroxychloroquine \pm ATRA. Drugs were screened using an indirect ELISA Assay for the detection of acetyl residues on biotinylated Histone $\mathrm{H} 3$ or Histone $\mathrm{H} 4$ peptides using $75 \mathrm{ng}$ of recombinant PCAF, an active histone acetyltransferase enzyme, in the presence of $100 \mu \mathrm{M}$ Acetyl-CoA and HAT assay buffer. Acetylated Histone $\mathrm{H} 3$ or Histone $\mathrm{H} 4$ peptides were used as positive controls. Hydroxychloroquine $\left(\mathrm{MCF}-7 \mathrm{IC}_{50}=57 \mu \mathrm{M}\right) \pm 1 \mu \mathrm{M}$ ATRA were tested for HAT activity. Data are the mean of $n=3$ experiments \pm SEM performed in triplicates per treatment. Statistically significant differences from control (DMSO) are indicated $\left({ }^{*} \mathrm{p}<0.05\right)$. 


\section{Chapter 4. Additional Studies.}

In addition to the studies delineated in the previous three chapters, several other experiments were conducted in conjunction with other projects. The results of these additional studies have been outlined and have either been published with the projects that they had supported or have aided in the understanding of future directions.

4.1 Martirosyan, A.R., Rahim-Bata, R., Freeman, A.B., Clarke, C.D., Strobl, J.S. (2004) Identification of differentiation-inducing quinolines as experimental breast cancer agents in the MCF-7 human breast cancer cell model. Biochemical Pharmacology (in press).

The rationale for these studies was to develop promising agents for cancer differentiation therapy by screening quinoline-ring containing compounds. The National Service Center (NSC) compound library maintained by the Developmental Therapeutics Program of the National Cancer Institute (NCI) allowed us to perform an anticancer screen data search by substructure using the known structure of differentiating antimalarial drugs (http://dtp.nci.nih.gov./). The NCI database screens compounds in a panel of cancer cells: breast, colon, lung, ovarian, renal, leukemia, melanoma, and CNS. It contains $>45,000$ compounds with antiproliferative activity in human breast tumor cells; however, the mechanism of these compounds is unknown. The most promising antiproliferative NSC anticancer agents with the structural match from the anticancer screen data search were provided by NCI and used in subsequent experiments as experimental agents in the MCF-7 and MDA-MB-231 human breast cancer cell lines (Figure 23). 


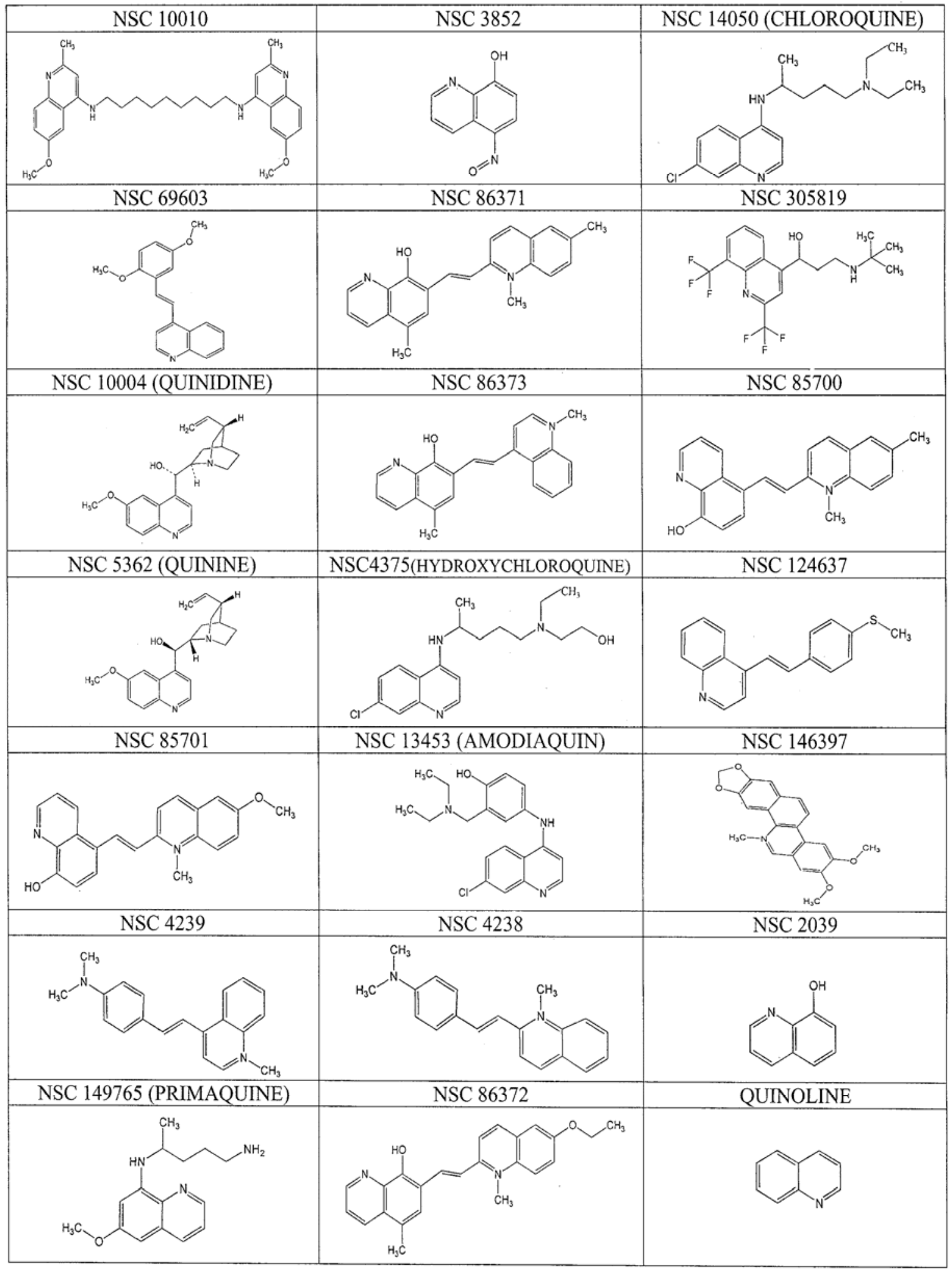

Figure 23. Chemical structures of quinoline-ring containing NSC compounds. 
4.1.1 Antiproliferative quinolines act as cell differentiation agents. The differentiation response of only compounds with known antiproliferative activity and unknown mechanism of action against breast cancer in vitro was measured. The antiproliferative activity of each compound in both the MCF-7 and MDA-MB-231 cell lines was reported using the MTS metabolism assay to attain $\mathrm{IC}_{50}$ values (Table 4). Growth curves using the $\mathrm{IC}_{50}$ values for the drugs were generated to explore the antiproliferative effects of the quinoline compounds (Figure 24). Functional screening assays were then performed to assess cell differentiation activity in the MCF-7 cell line using the MTS $\mathrm{IC}_{50}$ levels (Table 5) Primary markers for cellular differentiation include changes in cellular morphology as characterized by the accumulation of cytoplasmic lipid droplets, and exit from the cell cycle as measured by loss of Ki67 protein. Both of these endpoints were measured in all of the compounds as a screen for differentiation activity. Next, the drugs were screened for the ability to directly inhibit histone deacetylase (HDAC) activity in Hela cell nuclear extracts using the HDAC Fluorescent Activity Assay. Only NSC86371 and NSC3852 inhibited HDAC and caused cell differentiation. However, none of the other quinoline compounds inhibited HDAC activity even though some displayed an enhanced differentiation response. 


\begin{tabular}{|c|c|c|c|c|c|}
\hline \multicolumn{2}{|l|}{ Table 4} & \multicolumn{2}{|c|}{ MCF-7 } & \multicolumn{2}{|c|}{ MDA-MB-231 } \\
\hline NSC \# & Name & $\begin{array}{c}\text { MTS IC }_{50} \\
(\mu \mathrm{M})\end{array}$ & $\begin{array}{c}\text { SRB GI }_{50} \\
(\mu \mathrm{M})\end{array}$ & $\begin{array}{c}\text { MTS IC }_{50} \\
(\mu \mathrm{M})\end{array}$ & $\begin{array}{c}\operatorname{SRB~GI}_{50} \\
(\mu \mathrm{M})\end{array}$ \\
\hline 14050 & Chloroquine & 32.8 & 19 & 10.8 & 16 \\
\hline 4375 & Hydroxychloroquine & 56.6 & nd & 27.9 & nd \\
\hline 69603 & & 14.4 & 0.9 & 0.9 & 0.6 \\
\hline 305819 & & 7.9 & 13 & 3.9 & 9.4 \\
\hline 124637 & & 13 & 14 & 34.4 & 17 \\
\hline 86371 & & 5.7 & nd & 1.1 & nd \\
\hline 86373 & & 12.9 & nd & 12.9 & nd \\
\hline 85700 & & 6.5 & 7 & nd & 33.2 \\
\hline 85701 & & 4.4 & 4 & 0.6 & nd \\
\hline
\end{tabular}

Table 4. Antiproliferative activity of breast tumor differentiating NSC quinoline compounds in MCF-7 and MDA-MB-231 cells. MCF-7 and MDA-MB-231 breast cancer cells were plated at $4.0 \times 10^{3}$ and $5.0 \times 10^{2}$ cells per well in 96-well plates, respectively. MTS $\mathrm{IC}_{50}$ growth inhibitory concentrations represent the inhibition of mitochondrial metabolism of MTS following a 48 hour exposure to each compound. Data are the mean of $n=3$ independent experiments performed with 10 concentrations of each compound in triplicate. The $\mathrm{GI}_{50}$ for sulforhodamine blue (SRB) staining attained from the NCI website is presented for comparison. 


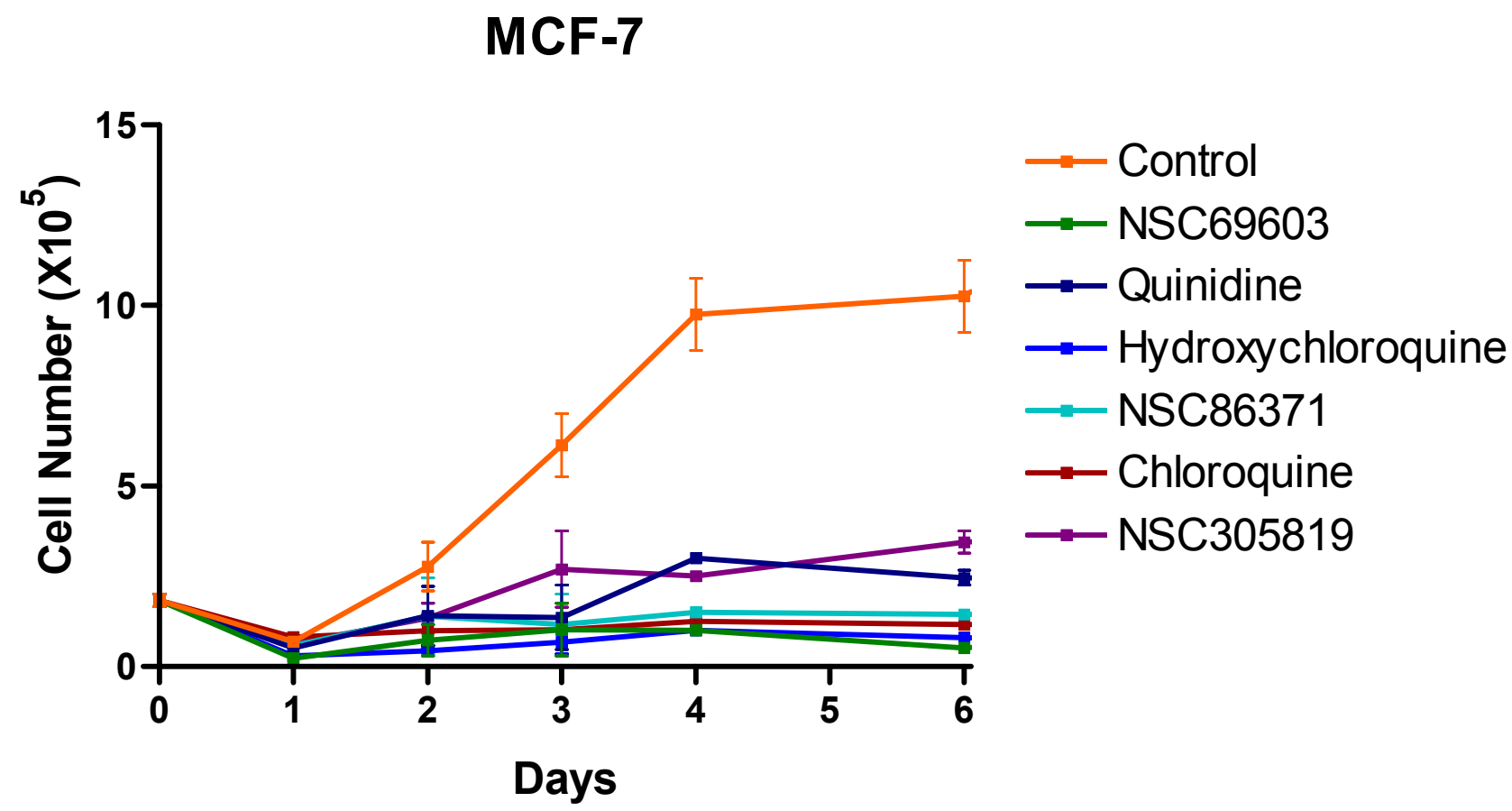

Figure 24. Inhibition of MCF-7 cell growth by quinoline compounds. MCF-7 cells $\left(2 \times 10^{5} / 35 \mathrm{~mm}^{2}\right.$ dish) were plated in $3 \mathrm{ml}$ of $5 \%$ FBS DMEM and allowed to attach for 3 hours before drug addition. Following drug treatments (MTS $\mathrm{IC}_{50}$ values), cell counting and viability were assessed on the indicated days to generate the growth curves. Data represents the mean of duplicate determinations in two independent experiments. 


\begin{tabular}{|r|c|l|c|c|c|}
\hline \# & NSC \# & \multicolumn{1}{|c|}{ Name } & $\begin{array}{c}\text { Oil Red-O } \\
(\mu \mathbf{M})\end{array}$ & Ki67 Index & $\begin{array}{c}\text { HDAC activity } \\
\text { (\% control) }\end{array}$ \\
\hline 1 & $\mathbf{1 4 0 5 0}$ & Chloroquine & 1 & $6.6^{*}$ & $91 \pm 6$ \\
\hline 2 & $\mathbf{4 3 7 5}$ & Hydroxychloroquine & 5 & 3.6 & $94 \pm 1$ \\
\hline 3 & 13453 & Amodiaquin & 10 & 2.4 & $86 \pm 4$ \\
\hline 4 & 10004 & Quinidine & 10 & 5 & $100 \pm 13$ \\
\hline 5 & 5362 & Quinine & 30 & 4.1 & $102 \pm 14$ \\
\hline 6 & 157387 & Mefloquine & Negative & 0.3 & $90 \pm 2$ \\
\hline 7 & 305789 & Halofantrine & 5 & 1.4 & $81 \pm 13$ \\
\hline 8 & 149765 & Primaquine & 2.5 & 1.1 & $95 \pm 14$ \\
\hline 9 & & Quinoline & Negative & 0.4 & $96 \pm 7$ \\
\hline 10 & 2039 & & 15 & 1.6 & $95 \pm 4$ \\
\hline 11 & 3852 & & 10 & $7.2^{*}$ & $69 \pm 6{ }^{*}$ \\
\hline 12 & & Quinolinic Acid & Negative & 0.4 & $99 \pm 6$ \\
\hline 13 & $\mathbf{6 9 6 0 3}$ & & 1 & $66^{*}$ & $111 \pm 7$ \\
\hline 14 & $\mathbf{3 0 5 8 1 9}$ & & 1 & $5.8^{*}$ & $90 \pm 17$ \\
\hline 15 & $\mathbf{1 2 4 6 3 7}$ & & 1 & 3.4 & $127 \pm 14$ \\
\hline 16 & 4239 & & 1.3 & 1.9 & $96 \pm 4$ \\
\hline 17 & 10010 & & 3.5 & $8.3^{*}$ & $94 \pm 8$ \\
\hline 18 & $\mathbf{8 6 3 7 1}$ & & 1 & $6{ }^{*}$ & $65 \pm 5^{*}$ \\
\hline 19 & $\mathbf{8 6 3 7 3}$ & & 1 & 4.7 & $97 \pm 2$ \\
\hline 20 & 86372 & & 2 & 0.8 & $91 \pm 7$ \\
\hline 21 & $\mathbf{8 5 7 0 0}$ & & 1 & 4.1 & $97 \pm 1$ \\
\hline 22 & $\mathbf{8 5 7 0 1}$ & & 0.5 & 2.7 & $90 \pm 7$ \\
\hline 23 & 4238 & & 1.9 & $109 \pm 13$ \\
\hline
\end{tabular}

Table 5. Summary of differentiation activity by NSC compounds in MCF-7 breast cancer cells. Functional screening assays for cell differentiation activity were performed using the compounds in bold. The lowest concentration of each compound that produced an Oil Red-O response is shown. Ki67 index, which is indicative of the fraction of G0 cells in a population, and inhibition of HDAC activity in vitro, which is expressed as a percent of HDAC activity in solvent control groups were determined after a 48 hour exposure to the IC50 levels of each compound. Data are the mean \pm SEM of atleast $n=3$ experiments performed in duplicates. Statistically significant differences from the control are indicated $(* \mathrm{p}<0.05)$ 
4.1.2 E2F-1 as a differentiation response marker. The antiproliferative activity of each compound in both the MCF-7 and MDA-MB-231 cell lines was reported using the MTS metabolism assay as shown in Table 4. Next, using the MTS $\mathrm{IC}_{50}$ values, expression of E2F-1 protein was assessed in MCF-7 breast cancer cells by Western blotting (Figure 25). The results showed that E2F-1 protein was downregulated by the quinoline compounds. Quinoline and primaquine served as negative controls since both failed to induce differentiation as measured by loss of Ki67 protein and lack of lipid droplet accumulation (quinoline only) (Table 5). E2F-1 protein was unchanged in MCF-7 cells treated with either quinoline or primaquine. Augmentation of the differentiation response was affirmed by downregulation of E2F-1 cell cycle regulatory protein. These data suggest that E2F-1 protein is an appropriate biochemical marker for in vitro activity in response to candidate quinoline differentiation agents.

Alterations in the level of E2F-1 and c-myc proteins were assessed in response to 24 and 48 hours of treatment with the candidate quinoline differentiation agents (Figure 26 and 27 , respectively). There was significant downregulation of both proteins by 48 hours of quinoline treatment. NSC69603, quinidine, and hydroxychloroquine showed the greatest downregulation. 
MCF-7

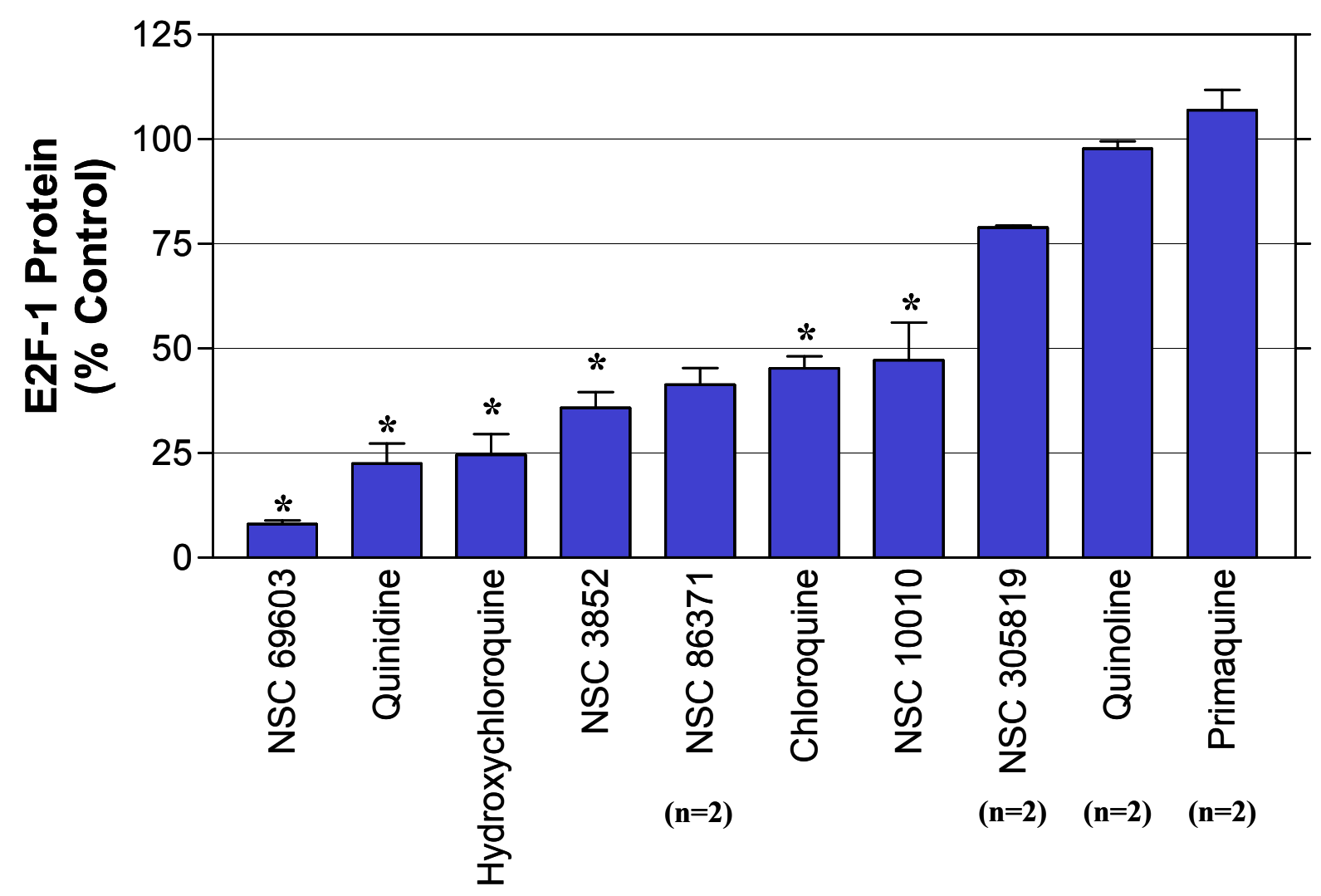

Figure 25. E2F-1 protein expression in MCF-7 cells following treatment with quinoline compounds. MCF-7 $\left(2 \times 10^{6}\right.$ cells $/ 60 \mathrm{~mm}^{2}$ dish $)$ were treated with quinidine $(90 \mu \mathrm{M})$ or NSC69603, hydroxychloroquine, NSC3852, NSC86371, chloroquine, NSC10010, NSC305819, quinoline, or primaquine at their respective $\mathrm{IC}_{50}$ concentrations for 48 hours. $80 \mu \mathrm{g}$ of whole cell extract proteins were resolved on a $10 \%$ acrylamide gel and analyzed by Western blot. Signals were quantitated by FluoroChem (Alpha Innotech, San Leandro, CA) spot densitometry using automatic background subtraction. Data shown represents the mean of three experiments \pm SEM or two experiments (denoted on the figure). Statistically significant differences from the control are indicated $(* \mathrm{p}<0.05)$. 

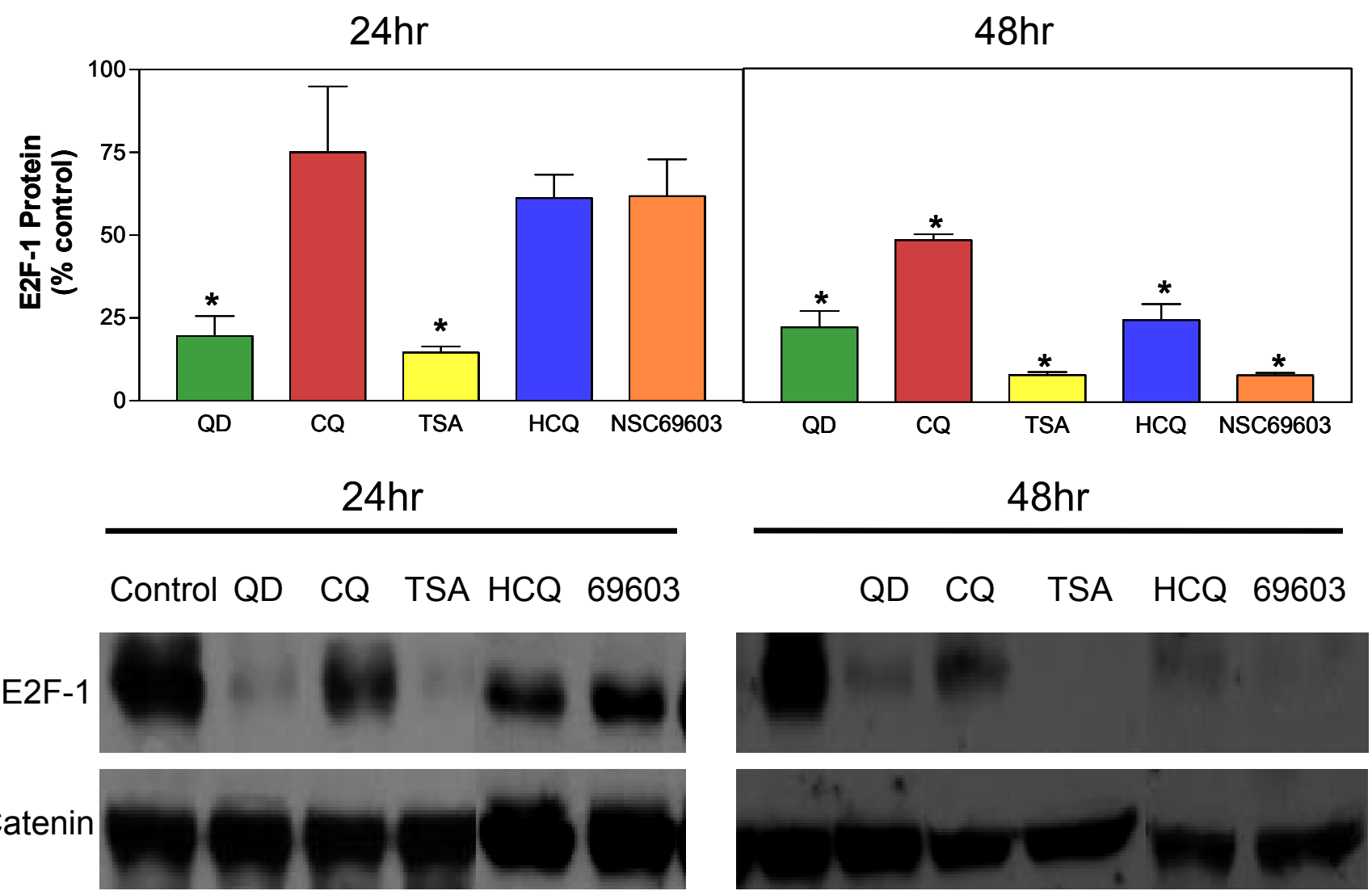

Figure 26. Downregulation of E2F-1 protein in MCF-7 cells treated with quinoline compounds. MCF-7 $\left(2 \times 10^{6}\right.$ cells $/ 60 \mathrm{~mm}^{2}$ dish $)$ were treated with quinidine (QD, $\left.90 \mu \mathrm{M}\right)$, chloroquine $\left(\mathrm{CQ}, \mathrm{IC}_{50}=33 \mu \mathrm{M}\right)$, trichostatin $\mathrm{A}(\mathrm{TSA}, 3 \mu \mathrm{M})$, hydroxychloroquine (HCQ, $\left.\mathrm{IC}_{50}=57 \mu \mathrm{M}\right)$, or NSC69603 $\left(\mathrm{IC}_{50}=15 \mu \mathrm{M}\right)$ for either 24 or 48 hours. Total cellular proteins were isolated using boiling lysis buffer (1\% SDS, $10 \mathrm{mM}$ Tris, $\mathrm{pH} 7.4)$. $80 \mu \mathrm{g}$ of whole cell extract proteins were resolved on a $10 \%$ acrylamide gel and analyzed by Western blot. Signals were quantitated by FluoroChem (Alpha Innotech, San Leandro, CA) spot densitometry using automatic background subtraction after normalization to $\beta$-catenin levels. Data shown represents the mean of three experiments \pm SEM. Statistically significant differences from the control are indicated $(* \mathrm{p}<0.05)$. 

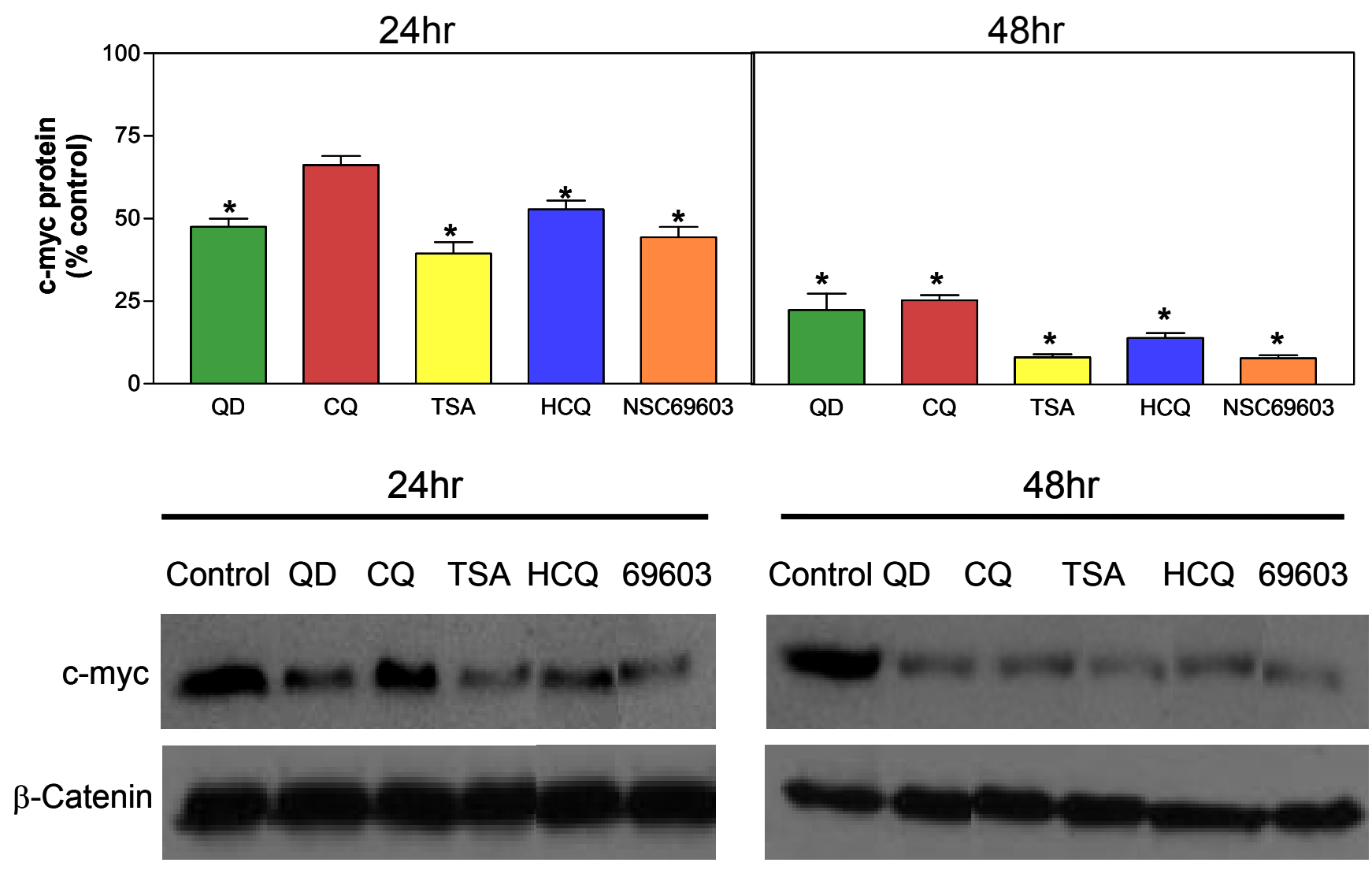

Figure 27. Downregulation of c-myc protein in MCF-7 cells treated with quinoline compounds. MCF-7 $\left(2 \times 10^{6}\right.$ cells $/ 60 \mathrm{~mm}^{2}$ dish) were treated with quinidine (QD, $\left.90 \mu \mathrm{M}\right)$, chloroquine $\left(\mathrm{CQ}, \mathrm{IC}_{50}=33 \mu \mathrm{M}\right)$, trichostatin A (TSA, $\left.3 \mu \mathrm{M}\right)$, hydroxychloroquine (HCQ, $\left.\mathrm{IC}_{50}=57 \mu \mathrm{M}\right)$, or NSC69603 $\left(\mathrm{IC}_{50}=15 \mu \mathrm{M}\right)$ for either 24 or 48 hours. Total cellular proteins were isolated using boiling lysis buffer (1\% SDS, 10mM Tris, $\mathrm{pH} 7.4) .80 \mu \mathrm{g}$ of whole cell extract proteins were resolved on a $10 \%$ acrylamide gel and analyzed by Western blot. Signals were quantitated by FluoroChem (Alpha Innotech, San Leandro, CA) spot densitometry using automatic background subtraction after normalization to $\beta$-catenin levels. Data shown represents the mean of three experiments \pm SEM. Statistically significant differences from the control are indicated $(* \mathrm{p}<0.05)$. 
4.2 Liu, C., Strobl, J.S., Bane, S., Schilling, J.K., McCracken, M., Chatterjee, S.K., RahimBata, R., Kingston, D.G.I. (2003) Design, synthesis, and bioactivities of steroid-linked taxol analogues as potential targeted drugs for prostate and breast cancer. Journal of Natural Products

The rationale for these studies was to target taxol to estrogen receptor positive (ER+) breast cancer by means of selected steroid hormone conjugates. Cytotoxicity of the synthesized estradiol-taxol conjugates was determined in MCF-7 (ER $\alpha+, \beta+)$ and MDA-MB-231 (ER $\alpha-$, $\beta+$ ) cells using the MTS metabolism assay to generate $\mathrm{IC}_{50}$ values. In Table 6 , the $\mathrm{IC}_{50}$ values attained for the estradiol-taxol conjugates $9,11,14,16$, and 21 compared with the $\mathrm{IC}_{50}$ value of taxol in both the MCF-7 and MDA-MB-231 cells are circled in red. The results suggest that the $\mathrm{IC}_{50}$ value for taxol is similar for both cell lines. Neither compound 9 nor 11 showed significant selectivity for the ER $\alpha+$ MCF-7 cell line, while compounds 14 and $\mathbf{1 6}$ showed modest selectivity towards it. More importantly, compound 21, which is a 10-substituted derivative, showed significant selectivity towards the ER $\alpha+$ MCF-7 compared with the ER $\alpha$ - MDA-MB-231 breast cancer cells. These results are directing future efforts to targeting taxol to ER $\alpha+$ breast cancer cells by synthesizing estradiol-taxol conjugates at the $\mathrm{C}-10$ position. 


\begin{tabular}{|c|c|c|c|c|c|c|}
\hline compound & $\begin{array}{c}\% \text { assembly, } \\
0.2 \mu \mathrm{M}^{a}\end{array}$ & $\begin{array}{c}\% \text { assembly } \\
1.0 \mu \mathrm{M}^{a}\end{array}$ & $\begin{array}{c}\mathrm{A} 2780 \\
\mathrm{IC}_{50}(\mathrm{nM})\end{array}$ & $\begin{array}{c}\mathrm{PC}-3 \\
\mathrm{IC}_{50}(\mathrm{nM})\end{array}$ & $\begin{array}{l}\text { MDA-MB-231 } \\
\mathrm{IC}_{50}(\mathrm{nM})\end{array}$ & $\begin{array}{c}\text { MCF-7 } \\
\mathrm{IC}_{50}(\mathrm{nM})\end{array}$ \\
\hline $\operatorname{taxol}(\mathbf{1})$ & 100 & 100 & 25 & $77 \pm 3$ & $4.5 \pm 1.2$ & $4.9 \pm 1.8$ \\
\hline 9 & 45 & 55 & 180 & $73 \pm 12$ & $22 \pm 4.5$ & $39 \pm 0.6$ \\
\hline 11 & 60 & 60 & 680 & $40 \pm 10$ & $51 \pm 4.6$ & $62 \pm 12$ \\
\hline 14 & 100 & 100 & 8300 & $120 \pm 20$ & $2200 \pm 800$ & $1600 \pm 90$ \\
\hline 16 & 100 & 100 & 2900 & $320 \pm 80$ & $780 \pm 100$ & $557 \pm 117$ \\
\hline 21 & 100 & 100 & 1900 & $68 \pm 7$ & $304 \pm 12^{b}$ & $103 \pm 3.4^{b}$ \\
\hline 25 & NT & NT & 15000 & NT & $1 \sqrt{1}$ & TVI \\
\hline 26 & NT & NT & 10000 & NT & NT & NT \\
\hline 27 & NT & NT & 13000 & NT & NT & NT \\
\hline 30 & NT & NT & 15000 & NT & NT & NT \\
\hline 31 & NT & NT & 12000 & NT & NT & NT \\
\hline 32 & NT & NT & 10000 & NT & NT & NT \\
\hline
\end{tabular}

Table 6. Cytotoxicity of steroid-linked taxol derivatives. MCF-7 and MDA-MB-231 breast cancer cells were plated at $4.0 \times 10^{3}$ and $5.0 \times 10^{2}$ cells per well in 96-well plates, respectively. MTS $\mathrm{IC}_{50}$ growth inhibitory concentrations represent the inhibition of mitochondrial metabolism of MTS following a 48 hour exposure to each compound. Data are the mean of $n=3$ independent experiments performed with 10 concentrations of each compound in triplicate. 


\section{DISCUSSION}

Despite improvements in therapeutic treatments for breast cancer within the last thirty years, both the absolute cause and the means for its cure still remain elusive. Although there have been advancements in the area of drug development, there is still a lack of effective chemotherapeutic agents that are active against breast cancer and that do not display harmful toxicity at higher doses or to neighboring normal breast cells and tissues. Novel strategies must be devised to administer potent therapy against cancer cells without the side effects of high-dose chemotherapy in breast cancer treatment. The aim of these studies was to develop new drugs which are active against breast cancer by restoring a less malignant (differentiated) phenotype, thereby reducing the tumors' aggressiveness and ultimately resulting in death of the human breast tumor cells. Preliminary studies indicate that two quinoline antimalarials, chloroquine and hydroxychloroquine, inhibit proliferation and induce differentiation in breast cancer cell lines without toxicity to normal MCF-10A breast cells. Since combination drug therapy is the key to success in the prevention and treatment of breast cancer, this proposal seeks to derive better chemotherapeutic agents by using these quinolines in combination with the most effective differentiating agents. Hence the goal of these studies was to explore whether a drug combination modulating epigenetic events would sensitize breast cancer cells to the antitumor activity of either chloroquine or hydroxychloroquine.

The advantage of using quinolines for breast cancer treatment is that they are already in wide use, as antimalarials and anti-inflammatory agents, and their human pharmacology is well known. At lower concentrations, these drugs are not only efficacious, but they are also 
orally active, inexpensive, and display very low and predictable toxicities in humans. Combining these quinolines with effective differentiating agents should ultimately help to lower the threshold for chemotherapy-induced cell death in breast cancer. Differentiationinducing agents, such as retinoids, have strong implications in the treatment of acute promyelocytic leukemia and have become promising agents for differentiation therapy of breast cancer (Baj et al., 2000; Singh et al., 2000). Retinoids have already been shown to play a myriad of potential roles in the prevention and treatment of breast cancer cells, including growth inhibition, cell differentiation, and induction of apoptosis. Several retinoids, including ATRA, have been shown to have potent activity in the treatment of breast cancer and are now in clinical trials in combination with other cytotoxic agents and anti-estrogens (Yang et al., 1999). Clinically, retinoids have been shown to reverse premalignant lesions and inhibit the generation of second primary tumors in some patients (Yang et al., 2002). Concurrently, my data showed that ATRA in combination with hydroxychloroquine had the most significant inhibitory effect on tumor cell clonogenic survival in both ER+ and ER- breast cancer cells compared to either of the drugs alone (Figure 9 and Table 2), showing a 92\% and $82 \%$ reduction compared to control cells in MDA-MB-231 and MCF-7 cells, respectively. Since clonogenic survival is the most sensitive test for predicting the responsiveness of a tumor to clinical treatment, this is a promising finding, suggesting a potential role for the combination of hydroxychloroquine and ATRA for breast cancer therapy.

Combination of ATRA with either chloroquine or hydroxychloroquine also enhanced the differentiation response. Lipid droplet accumulation and Ki67 index were elevated in both the MCF-7 and MDA-MB-231 breast cancer cell lines (Figures 10 and 11). Although 
the antitumor quinolines alone displayed an enhanced Ki67 index, pretreatment with ATRA lowered the concentration of chloroquine or hydroxychloroquine needed to achieve the same response. Cell cycle regulatory proteins, E2F-1 and c-myc were both downregulated, suggesting that cellular differentiation and cell cycle progression are interdependent.

Studies have shown that combinations of chemotherapy drugs are the most efficacious, by offering distinct ways of destroying the cancer cells; thereby, reducing the chance of the cancer becoming resistant to one drug. A better understanding of factors and mechanisms regulating differentiation would reveal new possibilities for successful chemotherapeutic approaches. Both chloroquine and hydroxychloroquine display anti-inflammatory properties in epithelial cell lines by regulating the NF- $\mathrm{kB}$ family of transcription factors, well-known for mediating immune and inflammatory responses. NF- $\mathrm{kB}$ has recently been identified as a molecular link between chronic inflammation and cancer. Recent studies conducted using distinct models of inflammation-associated cancer, now show the importance of NF-kB in promoting cancer progression during inflammation (Greten et al., 2004; Luo et al., 2004; Pikarsky et al., 2004). Results from these studies suggest that NF-kB exerts its oncogenic effects by promoting the survival of premalignant epithelial cells while also stimulating release of pro-inflammatory mediators from activated macrophages that promote tumor cell growth. The antirheumatic and antitumor properties of chloroquine and hydroxychloroquine may be interconnected by a distinct target. Significant observations link cancer prevention and treatment with a common drug target, an enzyme called histone deacetylase (HDAC). This HDAC enzyme modifies chromatin structure by removing acetyl groups from lysine residues in histones. The acetylation status of histones is critical for the modulation of chromatin structure and the regulation of gene transcription. When HDAC deacetylates 
histones at lysine sites, it generates a more condensed chromatin structure, which is characterized by transcriptional inactivity or tumor progression. On the other hand, when this HDAC enzyme is inhibited, it results in growth arrest, reverts cells to a differentiated phenotype, and leads to death of the human breast tumor cells.

Since previous work showed that another differentiation-inducing quinoline, quinidine, caused down-regulation of HDAC1 protein levels and hyperacetylation of histone $\mathrm{H} 4$ in a panel of human breast tumor cell lines (Zhou et al., 2000), we wanted to first see if any of these factors were responsible for the antiproliferative and differentiation responses displayed by the quinolines, chloroquine or hydroxychloroquine in combination with ATRA. In MCF-7 cells, HDAC protein levels had already declined as early as $0.5 \mathrm{~h}$ after quinoline addition and these levels were further decreased with pretreatment with ATRA (Figure 18). Although a transient response, hyperacetylated histone $\mathrm{H} 3$ and histone $\mathrm{H} 4$ protein levels were maximal by $8 \mathrm{~h}$. Cells pretreated with ATRA before quinoline addition, showed the greatest induction of RAR $\beta 2$ protein levels. Because these responses are typical of known HDAC inhibitory drugs, we tested HDAC enzymatic activity. To our surprise, $1 \mu \mathrm{M}$ ATRA alone was identified as a direct HDAC inhibitor (Figure 19). Direct inhibition of HDAC activity by ATRA was sustained, but not decreased further upon combination treatment with either chloroquine or hydroxychloroquine; therefore, HDAC inhibition might contribute to both MCF-7 and MDA-MB-231 cell differentiation in response to ATRA, but not to the differentiation quinolines.

MS peptide sequence data provide a working-model that supports a role for hydroxychloroquine in the regulation of acetylation since both histone $\mathrm{H} 3$ and histone $\mathrm{H} 4$ lysine sites were modified in the direction of acetylation, but not all lysine sites were 
acetylated because histone deacetylase (HDAC) was not completely inhibited by hydroxychloroquine alone (Figure 21). Consistent with the MS model, hydroxychloroquine did in fact activate histone acetyltransferase (HAT) enzyme (Figure 22). Interestingly, ATRA was also identified as a direct HAT activator, suggesting a possible interdependent role shared by the two agents. However, ATRA also acts via an independent mechanism by inhibiting HDAC enzymatic activity, thus enhancing sensitization of breast cancer cells to the antitumor activity of quinolines.

The goal of these studies was to explore whether a drug combination modulating epigenetic events would sensitize breast cancer cells to the antitumor activity of either chloroquine or hydroxychloroquine. The demethylating cytosine analog, 5-Aza-2'deoxycytidine (5-Aza-dC) was tested but was not as successful as ATRA in decreasing tumor cell clonogenic survival of ER-positive human breast carcinoma cells. Pretreatment of ER-negative breast cancer cells with 5-Aza-dC enhanced the antitumor activity of the quinolines similarly to the response from ATRA. In summary, combination drug therapy with differentiation-inducing agents enhance the antiproliferative, differentiation, and histone acetylation responses, and thereby, provide a more effective and less toxic therapeutic regimen for breast cancer prevention and treatment. 


\section{REFERENCES}

Adan Y., Goldman Y., Haimovitz R., Mammon K., Eilon T., Tal S., Tene A., Karmel Y., Shinitzky M. (2003) Phenotypic differentiation of human breast cancer cells by 1,3 cyclic propanediol phosphate. Cancer Letter 194(1):67-79.

Baj, G., Arnulfo, A., Deaglio, S., Mallone, R., Vigone, A., Rosa, M., Giana, M., Villa, L., Malavasi, F., Surico, N. (2000) Retinoids in breast cancer prevention and treatment: a review of the literature. European Journal of Gynaecologic Oncology 21(4): 411-415.

Berenbaum, M.C. (1978) A method for testing for synergy with any number of agents. Journal of Infectious Diseases 137(2):122-130.

Berenbaum, M.C. (1989) What is synergy? Pharmacological Reviews 1989(41):93-131.

Bonizzi, G., Piette, J., Merville, M.P., Bours, V. (1997) Distinict signal transduction pathways mediate nuclear factor-kappaB induction by IL-1beta in epithelial and lymphoid cells. Journal of Immunology 159(11):5264-5272.

Chambon, P. (1994) The retinoid signaling pathway: molecular and genetic analyses. Cell Biology 5:115-125.

Craig, C.R., Stitzel, R.E. (1997) Modern pharmacology with clinical applications (Fifth Edition), pp. 640-646 (chapter by Scheibel, L.K., Van Dyke, K).

Cruz, D.D. (2001) Antimalarial therapy: a panacea for mild lupus. Lupus 10:148-151.

De Bono, J.S., Tolcher, A.W., Rowinsky, E.K. (2003) The future of toxic therapy: selective cytotoxicity based on biology is the key. Breast Cancer Research 5(3):154-159. 
De Ruijter, A.J.M., Van Gennip, A.H., Carbon, H.N., Kemp, S., Van Kuilenburg, A.B.P. (2003) Histone deacetylases (HDACs): characterization of the classical HDAC family. Biochemistry Journal 370:737-749.

Decensi, A., Serrano, D., Bonanni, B., Cazzaniga, M., Guerrieri-Gonzaga, A. (2003) Breast cancer prevention trials using retinoids. Journal of Mammary Gland Biology and Neoplasia 8(1):19-30.

Demmer, L.A., Birkenmeier, E.H., Sweetser, D.A., Levin, M.S., Zollman, S., Sparkes, R.S., Mohandas, T., Lusis, A.J., Gordon, J.I. (1987) The cellular retinol binding protein II gene. The Journal of Biological Chemistry 262(6):2458-2467.

El-Osta, A., Kantharidis, P., Zalcberg, J., Wolffe, A. (2002) Precipitous release of methylCpG binding protein 2 and histone deacetylase 1 from the methylated human multidrug resistance gene (MDR1) on activation. Molecular and Cellular Biology 22(6): 1844-1857.

Fabian, C., Kimler, B. (2001) Beyond tamoxifen: new endpoints for breast cancer prevention, new drugs for breast cancer prevention. Annals New York Academy of Sciences 952:44-59.

Ferguson, A., Vertinos, P., Spitzner, J., Baylin, S., Muller, M., Davidson, N.(1997) Role of estrogen receptor gene demethylation and DNA methyltransferase-DNA adduct formation in 5-Aza-2'-deoxycytidine-induced cytotoxicity in human breast cancer cells. Journal of Biological Chemistry 272(51):32260-32266.

Foley, M., Tilley, L. (1998) Quinoline antimalarials: mechanisms of action and resistance and prospects for new agents. Pharmacol. Ther. 79:55-87.

Fu, S.W., Schwartz, A., Stevenson, H., Pinzone, J.J., Davenport, G.J., Orenstein, J.M., Gutierrez, P., Simmens, S.J., Abraham, J., Poola, I., Stephan, D.A., Berg, P.E. (2003) 
Correlation of expression of $\mathrm{BP} 1$, a homeobox gene, with estrogen receptor status in breast cancer. Breast Cancer Research 5(4):R82-97.

Furumai, R., Komatsu, Y., Nishino, N., Khochbin, S., Yoshida, M., Horinouchi, S. (2001) Potent histone deacetylase inhibitors built from trichostatin A and cyclic tetrapeptide antibiotics including trapoxin. Proc. Natl. Acad. Sci. U.S.A. 98:87-92.

Greten, F.R., Eckmann, L., Greten, T.F., Park, J.M., Li, Z.W., Egan, L.J., Kagnoff, M.F., Karin, M. (2004) IKKbeta links inflammation and tumorigenesis in a mouse model of colitis-associated cancer. Cell 118(3):285-96.

Hanahan, D., Weinberg, R.A. (2000) The hallmarks of cancer. Cell 100:57-70.

Hebbes, T., Thorne, A. (1988) A direct link between core histone acetylation and transcriptionally active chromatin. EMBO 7(5): 1395-1402

Hong, Z., Jiang, Z., Liangxi, W., Guofu, D., Ping, L., Yongling, L., Wendong, P., Minghai, W. (2004) Chloroquine protects mice from challenge with CpG ODN and LPS by decreasing proinflammatory cytokine release. Int Immunopharmacology 4(2):223-234.

Hu, J., Pham, J., Dey, I., Li, T., Vu, T.,Hoffman, A. (2000) Allele-specific histone acetylation accompanies genomic imprinting of the insulin-like growth factor 2 receptor gene. Endocrinology 141(12):4428-4435.

Jeong, J.Y., Jue, D.M. (1997) Chloroquine inhibits processing of tumor necrosis factor in lipopolysaccharide-stimulated RAW 264.7 macrophages. Journal of Immunology 158(10):4901-4907.

Jing, Y., Zhang, J., Bleiweiss, I.J., Waxman, S., Zelent, A., Mira-Lopez, R. (1996) Defective expression of cellular retinal binding protein type I and retinoic receptors $\alpha 2, \beta 2$, $\gamma 2$ in human breast cancer cells. FASEB Journal 10:1064-1070. 
Khorasanizadeh, S. (2004) The nucleosome: from genomic organization to genomic regulation. Cell 116:259-272.

Kopnin, B.P. (2000) Targets of oncogenes and tumor suppressors: key for understanding basic mechanisms of carcinogenesis. Biochemistry 65(1):5-33.

Kumala, S., Niemiec, P., Widel, M., Hancock, R., Rzeszowska-Wolny, J. (2003) Apoptosis and clonogenic survival in three tumour cell lines exposed to gamma rays or chemical genotoxic agents. Cellular and Molecular Biology Letters 8:655-665.

Kuppumbatti, Y.S., Bleiweiss, I.J., Mandel, J.P., Waxman, S., Mira-y-Lopez, R. (2000) Cellular retinol-binding protein expression and breast cancer. Journal of National Cancer Institute 92:475-480.

Lefebvre, P. (2001) Molecular basis for designing selective modulators of retinoic acid receptor transcriptional activities. Current Drug Targets 1:153-164.

Liu, C., Strobl, J.S., Bane, S., Schilling, J.K., McCracken, M., Chatterjee, S.K., Rahim-Bata, R., Kingston, D.G.I. (2003) Design, synthesis, and bioactivities of steroid-linked taxol analogues as potential targeted drugs for prostate and breast cancer. Journal of Natural Products

Lotan, R., Xu, X.C., Lippman, S.M., Ro, J.Y., Lee, J.S., Lee, J.J., Hong, W.K. (1995) Suppression of retinoic receptor $\beta$ in premalignant oral lesions and its upregulation by isotretinoin. New England Journal of Medicine 332:1405-1410.

Luo, J.L., Maeda, S., Hsu, L.C., Yagita, H., Karin, M. (2004) Inhibition of NF-kappaB in cancer cells converts inflammation-induced tumor growth mediated by TNFalpha to TRAIL-mediated tumor regression. Cancer Cell 6(3):297-305. 
Martinez-Balbas, M.A., Bauer, U.M., Nielsen, S.J., Brehm, A., Kouzarides, T. (2000) Regulation of E2F1 activity by acetylation. The EMBO Journal 19(4):662-671.

Martirosyan, A.R., Rahim-Bata, R., Freeman, A.B., Clarke, C.D., Strobl, J.S. (2004) Identification of differentiation-inducing quinolines as experimental breast cancer agents in the MCF-7 human breast cancer cell model. Biochemical Pharmacology (in press).

Mehta, R.G., Moon, R.C., Hawthorne, M., Formelli, F., Costa, A. (1991) Distribution of fenretinide in the mammary gland of breast cancer patients. Eur F Cancer 27:138-141.

Melkoumian, Z.K., Martirosyan, A.R., Strobl, J.S. (2002) Myc protein is differentially sensitive to quinidine in tumor versus immortalized breast epithelial cell lines. International Journal of Cancer 102(1):60-69.

Misra, U.K., Gawdi, G., Pizzo, S.V. (1997) Chloroquine, quinine and quinidine inhibit calcium release from macrophage intracellular stores by blocking inositol 1,4,5-triphosphate bining to its receptor. Journal of Cellular Biochemistry 64:225-232.

Morrow, M, Hager, C., Berger, D., Djordjevic, B. (1989) Chloroquine as a hyperthermia potentiator. Journal of Surgical Research 46(6):637-639.

Napoli, J.L. (1999) Interactions of retinoid binding proteins and enzymes in retinoid metabolism. Biochimica et Biophysica Acta 1440:139-162.

Osborne, C.K., Zhao, H., Fuqua, S.A.W. (2000) Selective estrogen receptor modulators: structure, function, and clinical use. Journal of Clinical Oncology 18(17):3172-3186.

Paik, J., Blaner, W.S., Sommer, K.M., Moe, R., Swisshlem, K. (2003) Retinoids, retinoic acid receptors, and breast cancer. Cancer Investigation 21(2):304-312. 
Parris, G. (2004) Hypotheses links emergence of chloroquine-resistant malaria and other intracellular pathogens and suggests a new strategy for treatment of diseases caused by intracellular parasites. Medical Hypotheses 62:354-357.

Petri, M. (1996) Hydroxychloroquine use in the Baltimore Lupus Cohort: effects on lipids, glucose and thrombosis. Lupus 5(supp 1):S16-S22.

Pikarsky, E., Porat, R.M., Stein, I., Abramovitch, R., Amit, S., Kasem, S., Gutkovich-Pyest, E., Urieli-Shoval, S., Galun, E., Ben-Neriah, Y. (2004) NF-kappaB functions as a tumour promoter in inflammation-associated cancer. Nature 431(7007):461-6.

Polyak, K. (2001) Review on the birth of breast cancer. Biochemica et Biophysical Acta 1552(2001):1-13.

Prichard, R.S., Hill, A.D.K., Dijkstra, B., McDermott, E.W., O’Higgins, N.J. (2003) The prevention of breast cancer. British Journal of Surgery 90:772-783.

Sakorafas, G., Tsiotou, A., Pavlakis, G. (2000) Follow-up after primary treatment for breast cancer. Acta Oncology 39(8):935-940.

Scholzen, T., and Gerdes, J. (2000) The Ki-67 protein: from the known and the unknown. Journal of Cellular Physiology 182:311-322.

Singh, H., Sekinger, E., Gross, D. (2000) Chromatin and cancer: causes and consequences. Journal of Cellular Biochemistry Supp. 35: 61-68.

Spaventi, R., Pavelic, K., Pavelicm Z.P., Gluckman, J.L. (1994) The concomitant expression of oncogenes and growth factors in human breast cancer. European Journal of Cancer 30A:723-724. 
Spencer, V., Davie, J. (2000) Signal transduction pathways and chromatin structure in cancer cells. Journal of Cellular Biochemistry Supp. 35:27-35.

Sporn, M.B., Dunlop, N.M., Newton, D.L., Smith, J.M. (1976) Prevention of chemical carcinogenesis by vitamin A and its synthetic analogs (retinoids). Fed. Proc. 35:1332-1338.

Suarez-Almazor, M.E., Belseck, E., Shea, B., Homik, J., Wells, G., Tugwell, P. (2000) Antimalarials for rheumatoid arthritis. Cochrane Database System Review 2:959-977.

Sullivan, J., Byron, K., Brewster, F., Purtilo, D. (1980) Deficient natural killer cell activity in x-linked lymphoprolifertive syndrome. Science 210:543-545.

Sundaram, M., Sivaprasadarao, A., Van Aalten, D.M.F., Findlay, J.B.C. (1998) Expression, characterization and engineered specificity of rat epididymal retinoic acid-binding protein. Biochemistry Journal 334:155-160.

Toma, S., Raffo, P., Nicolo, G., Canavese, G., Margallo, E., Vecchio, C., Dastoli Iacona, I., Regazzi-Bonora, M. (2000) Biological activity of all-trans-retinoic acid with and without tamoxifen and alpha-interferon $2 \mathrm{a}$ in breast cancer patients. International Journal of Oncology 17(5):991-1000.

Vigushin, D., Coombes, C. (2002) Histone deacetylase inhibitors in cancer treatment. AntiCancer Drugs 13:1-13.

Walia, H., Yu Chen, H., Sun, J., Holth, L., and Davie, J. (1998) Histone acetylation is required to maintain the unfolded nucleosome structure associated with transcribing DNA. Journal of Biological Chemistry 273(23): 14516-14522.

Wang, H., Huang, Z., Xia, L., Feng, Q., Erdjument-Bromage, H., Strahl, B., Briggs, S., Allis, C., Wong, J., Tempst, P., Zhang, Y. (2001) Methylation of histone H4 at arginine 3 facilitating transcriptional activation by nuclear hormone receptor. Science 293:853-857. 
Weinberg, R.A. (1996) How cancer arises. Scientific American 62-71.

West, C.M., Davidson, S.E., Roberts, S.A. and Hunter, R.D. (1997) The independence of intrinsic radiosensitivity as a prognostic factor for patient response to radiotherapy of carcinoma of the cervix. British Journal of Cancer 76:1184-1190.

Worm, J., Kirkin, A., Dzhandzhugazyan, D., Guldberg, P. (2001) Methylation-dependent silencing of the reduced folate carrier gene in inherently methotrexate-resistant human breast cancer cells. Journal of Biological Chemistry 276(43):39990-40000.

Wu, C.C., Howell, K.E., Neville, M.C., Yates, J.R., McManaman, J.L. (2000) Proteomics reveal contribution of endoplasmic reticulum membranes to the lipid secretion process in mammary epithelial cells. Electrophoresis 21:3470-3482.

Yamasaki, L., Jacks, T., Bronson, R., Goillot, E., Harlow, E., Dyson, N. (1996) Tumor induction and tissue atrophy in mice lacking E2F-1. Cell 85:537-548.

Yang, L., Tin-U, C., Wu, K., Brown, P. (1999) Role of retinoid receptors in the prevention and treatment of breast cancer. Journal of Mammary Gland Biol. Neoplasia 4(4): 377-388.

Yang, Q., Sakurai, T., Kakudo, K. (2002) Retinoid, retinoic acid receptor $\beta$ and breast cancer. Breast Cancer Research and Treatment 76:167-173.

Yang, X., Phillips, D., Ferguson, A., Herman, J., Davidson, N. (2001) Synergistic activation of functional estrogen receptor (ER)- $\alpha$ by DNA methyltransferase and histone deacetylase inhibition in human ER- $\alpha$-negative breast cancer cells. Cancer Research 61:7025-7029.

Yoshida, M., Horinouchi, S. (1999) Trichostatin and leptomycin: Inhibition of histone deacetylation and signal dependent nuclear export. Annals of New York Academy of Sciences 23-33. 
Zhou, Q., Melkoumian, Z., Lucktong, A., Moniwa, M., Davie, J., and Strobl, J. (2000) Rapid induction of histone hyperacetylation and cellular differentiation in human breast tumor cell lines following degradation of histone deacetylase-1. Journal of Biological Chemistry 275:35256-63.

Zhu, W., Lakshmanan, R., Beal, M., Otterson, G. (2001) DNA methyltransferase inhibition enhances apoptosis induced by histone deacetylase inhibitors. Cancer Research 61: 13271333. 


\author{
RAYHANA RAHIM-BATA \\ West Virginia University \\ School of Medicine \\ Robert C. Byrd Health Sciences Center \\ P.O. Box 9142 \\ Morgantown, WV 26506-9142 \\ (304) 599-9526 \\ rrahim@mix.wvu.edu
}

\title{
EDUCATION
}

Dec. 2004:

West Virginia University School of Medicine

Ph.D., Pharmacology

GPA 3.70

May 1999:

West Virginia University College of Arts and Sciences

B.A., Chemistry

GPA 3.78

May 1995:

\author{
Morgantown High School, West Virginia University Scholar Program \\ Valedictorian \\ GPA 4.00
}

\section{WORK EXPERIENCE}

Graduate Research and Teaching Assistant, West Virginia University (January 2000-Present)

Departments of Pharmacology and Toxicology, Biochemistry and Molecular Pharmacology, Morgantown, WV. Jeannine Strobl, Ph.D., Advisor.

Research:

* Dissertation Research Project: "Augmentation of the Differentiation Response to Antitumor Quinolines"

* Screened potential chemotherapeutic agents for antitumor activity by measuring cell survival, cellular differentiation, and histone acetylation status using an in vitro human breast cancer cell culture system

* Optimized conditions for a highly sensitive and qualitative assay using mass spectrometry to assess overall histone acetylation profile

* Developed a more effective and less toxic combination of therapeutic agents for breast cancer intervention

Teaching and Oral Communication:

* Lecturer for Nursing Pharmacology $(2002,2003)$

* Small Group Facilitator for Medical Pharmacology (2001)

* Speaker for Departmental literature-based and research seminars (2000-2004)

* Poster Presenter for American Society for Cell Biology (2001), American Association for Cancer Research (2003), and West Virginia University Research Day (2002, 2003) 
Written Communication:

* Prepared and edited manuscripts, abstracts, and posters

* Independently composed NIH Grant (written qualifying exam)

* Independently composed and was awarded the U.S. Army Medical Research and Material Command Predoctoral Training Grant (DAMD17-02-1-0622)

Chemist, Mylan Pharmaceuticals, Morgantown, WV (August 1999-August 2000)

* Engaged in extensive research entailing various experimentation on generic drugs. Research included identifying and testing for content uniformity, purity, and stability of the generic pharmaceuticals. Procedures included thin-layer chromatography, ultraviolet and infrared spectrophotometry, moisture analysis, and other methods of wet-chemistry.

Undergraduate Research Assistant, West Virginia University (Summer 1998)

Department of Anatomy, Morgantown, WV. Richard Dey, Ph.D., Supervisor.

* Mobilized laboratory research on distinct experiments conducted on rats in order to discern airway connections. Procedures included immunocytochemistry, sectioning of tissues using Cryostat machine, and cell counting to ascertain the differences of neuropeptide content in neurons innervating the nodos and jugular.

Work Study Student, West Virginia University (September 1997-May 1998)

Department of Anatomy, Morgantown, WV. Richard Dey, Ph.D., Supervisor.

* Conducted experiments entailing sectioning of tissues, immunocytochemistry, centrifugation, cultures, and cell counting in order to identify the neuropeptide content of trigeminal neurons innervating the rat nasal epithelium.

Undergraduate Research Assistant, West Virginia University (Summer 1997)

Department of Anatomy, Morgantown, WV. Richard Dey, Ph.D., Supervisor.

* Performed extensive laboratory experiments on ferret trachea in order to attain a clearer understanding of neural projections and pathways of the intrinsic airway neurons and their pertinent role on the regulation of smooth muscle tone and the pathogenesis of asthma. Procedures included whole mounts, sectioning tissues, immunocytochemistry, and tissue cultures.

High School Research Apprentice, West Virginia University (Summer 1995)

Department of Physiology, Morgantown, WV. Christine Baylis, Ph.D., Supervisor.

* Attained hands-on experience analyzing the role of nitric oxide on renal function and as a vasodilator in the body. Procedures entailed microscopy, perfusion, centrifugation, $\mathrm{pH}$ sampling, and formulation of buffers. Presented guided research to interested faculty and students.

High School Research Apprentice, West Virginia University (Summer 1994)

Department of Physiology, Morgantown, WV. Christine Baylis, Ph.D., Supervisor.

* Investigated the role of nitric oxide on renal function by conducting various experiments on rats. Procedures involved microscopy, calculation of osmolality, and glomerular filtration. Presented guided research to interested faculty and students. 
* U.S. Army Predoctoral Traineeship Award (2002-2005)

* NIH Predoctoral Trainee (2000-2001)

* Phi Beta Kappa (1999-Present)

* Golden Key National Honor Society (1997-Present)

* The Eberly College of Arts and Sciences Certificate of Achievement (1997, 1998, 1999)

* West Virginia University's Presidential Award for Excellence (1996, 1997, 1998)

* West Virginia University's Valedictorian Scholarship (1995-1999)

\section{PUBLICATIONS}

1. Liu, C., Strobl, J.S., Bane, S., Schilling, J.K., McCracken, M., Chatterjee, S.K., Rahim-Bata, R., Kingston, D.G.I. (2003) Design, synthesis, and bioactivities of steroid-linked taxol analogues as potential targeted drugs for prostate and breast cancer. Journal of Natural Products 67(2):152-159.

2. Martirosyan, A.R., Rahim-Bata, R., Freeman, A.B., Clarke, C.D., Strobl, J.S. (2004) Identification of differentiation-inducing quinolines as experimental breast cancer agents in the MCF-7 human breast cancer cell model. Biochemical Pharmacology 68(9):1729-1738.

3. Rahim-Bata, R., Strobl, J.S. (2005) Sensitization of human breast cancer cells to the antitumor activity of differentiation-inducing quinolines upon combination treatment with retinoic acid. (in preparation).

Abstracts:

1. Martirosyan, A., Zhou, Q., Bata, R.R., McCracken, M.A., Freeman, A.B., Morato-Lara, C., and Strobl, J. (2001) New pharmacologic agents promote cell differentiation in human breast tumor cells. (American Society for Cell Biology, Abstract \#762).

2. Bata, R.R., Zhou, Q., and Strobl, J.S. (2003) Combination drug therapy with antitumor antimalarials augment the differentiation response to breast cancer cells. (American Association for Cancer Research, Abstract \#3725).

3. Strobl, J., Martirosyan, A., Rahim-Bata, R., Freeman, A., Clarke, C. (2004) Experimental breast cancer differentiation agents NSC3852, NSC69603, NSC10010 and NSC305819. (ISC International Conference on Cancer Therapeutic, Molecular Targets, Pharmacology and Clinical Applications; Journal of Chemotherapy 16:128, Abstract \#23). 